UNIVERSIDADE DE BRASÍLIA

FACULDADE DE TECNOLOGIA

DEPARTAMENTO DE ENGENHARIA CIVIL E AMBIENTAL

\title{
METODOLOGIA MULTICRITÉRIO PARA CLASSIFICAR AS EMPRESAS DE TRANSPORTE RODOVIÁRIO INTERESTADUAL SEMIURBANO DE PASSAGEIROS POR NÍVEL DE SERVIÇO
}

PAULO HENRIQUE DA SILVA COSTA

ORIENTADOR: SÉRGIO RONALDO GRANEMANN

DISSERTAÇÃO DE MESTRADO EM TRANSPORTES

BRASÍLIA/DF: FEVEREIRO/2016 
UNIVERSIDADE DE BRASÍLIA

FACULDADE DE TECNOLOGIA

DEPARTAMENTO DE ENGENHARIA CIVIL E AMBIENTAL

\begin{abstract}
METODOLOGIA MULTICRITÉRIO PARA CLASSIFICAR AS EMPRESAS DE TRANSPORTE RODOVIÁRIO INTERESTADUAL SEMIURBANO DE PASSAGEIROS POR NÍVEL DE SERVIÇO
\end{abstract}

PAULO HENRIQUE DA SILVA COSTA

DISSERTAÇÃO SUBMETIDA AO DEPARTAMENTO DE ENGENHARIA CIVIL E AMBIENTAL DA FACULDADE DE TECNOLOGIA DA UNIVERSIDADE DE BRASÍLIA COMO PARTE DOS REQUISITOS NECESSÁRIOS PARA OBTENÇÃO DO GRAU DE MESTRE EM TRANSPORTES.

APROVADA POR:

Prof. Dr. Sérgio Ronaldo Granemann - PPGT/UnB (ORIENTADOR)

Prof. Dr. José Augusto Abreu Sá Fortes - PPGT/UnB (EXMINADOR)

Prof. Dra. Giovanna Megumi Ishida Tedesco - IFB (EXMINADOR EXTERNO)

BRASÍLIA/DF, 25 FEVEREIRO DE 2016. 


\section{FICHA CATALOGRÁFICA}

\section{COSTA, PAULO HENRIQUE DA SILVA}

Metodologia Multicritério para Classificar as Empresas de Transporte Rodoviário Interestadual Semiurbano de Passageiros por Nível de Serviço [Distrito Federal] 2016. xv, 133p., 210 x 297 mm (ENC/FT/UnB, Mestre, Transportes, 2016).

Dissertação de Mestrado - Universidade de Brasília. Faculdade de Tecnologia Departamento de Engenharia Civil e Ambiental.
1. Nível de Serviço
2. MCDA-C
3. Transporte Interestadual Semiurbano
4. Análise Multicritério
I. ENC/FT/UnB
II. Título (Série)

\section{REFERÊNCIA BIBLIOGRÁFICA}

COSTA, P.H.S. (2016). Metodologia Multicritério para Classificar as Empresas de Transporte Rodoviário Interestadual Semiurbano de Passageiros por Nível de Serviço. Dissertação de Mestrado em Transportes, Publicação T.DM-002/2016, Departamento de Engenharia Civil e Ambiental, Universidade de Brasília, Brasília, DF, 133p.

\section{CESSÃO DE DIREITOS}

AUTOR: Paulo Henrique da Silva Costa.

TÍTULO: Metodologia Multicritério para Classificar as Empresas de Transporte Rodoviário Interestadual Semiurbano de Passageiros por Nível de Serviço.

GRAU: Mestre ANO: 2016

É concedida à Universidade de Brasília permissão para reproduzir cópias desta dissertação de mestrado e para emprestar ou vender tais cópias somente para propósitos acadêmicos e científicos. O autor reserva outros direitos de publicação e nenhuma parte dessa dissertação de mestrado pode ser reproduzida sem autorização por escrito do autor.

Paulo Henrique da Silva Costa SQN 210, Bloco D, Apt. 310 - Asa Norte 70.862-040 Brasília - DF - Brasil. 


\section{DEDICATÓRIA}

Dedico essa obra a minha mãe, Salete, por ter me mostrado a importância da educação na vida, a minha esposa Patrícia pelo apoio e compreensão pelos momentos ausentes durante a elaboração desse trabalho, e a meus filhos Bruna e Eduardo para quem espero servir de inspiração. 


\section{AGRADECIMENTOS}

À Deus.

Ao meu orientador Prof. Dr. Sergio Ronaldo Granemann.

Aos professores do Programa de Pós-Graduação em Transportes da Universidade de Brasília: Adelaida Pallavicini Fonseca, Alan Ricardo da Silva, Ana Claudia Farranha Santana, Augusto Cesar de mendonça Brasil, Carlos Henrique Marques da Rocha, Fabiana Serra de Arruda, José Augusto Abreu Sá Fortes, José Matsuo Shimoishi, Maria Alice Prudêncio Jacques, Michelle Andrade, Pastor Willy Gonzales Taco, Paulo Cesar Marques da Silva, pelos ensinamentos passados durante o curso.

Aos professores Evaldo Cesar Cavalcante Rodrigues, Martha Maria Veras Oliveira Cavalcante Rodrigues, Marcelo Grangeiro Quirino pelo apoio, direcionamento e disponibilização de tempo para a conclusão desta dissertação.

Aos colegas de PPGT, turmas de 2013 e 2014 pelo companheirismo e lealdade demonstrados durante a árdua jornada que até aqui me trouxe.

Aos alunos do curso de engenharia da UNIPLAN: Érica Melo, Gabriel Masello, Rauenya Carvalho, Victor Vogado, Tafarel Gois, Ivo Almeida e Roberto Bernardo pela companhia e dedicação na aplicação dos formulários que permitiram concluir esta pesquisa.

Aos pesquisadores e amigos do Grupo de Pesquisa sobre Planejamento e Inovação em Transportes - GPIT.

À Lucinete, pela paciência e orientação acerca das questões burocráticas que facilitaram a jornada na vida acadêmica.

Aos amigos da ANTT, pelo apoio e incentivo que proporcionaram uma fonte menor de dificuldades para a transposição dessa etapa em minha vida.

Por fim, agradeço a todos que me ajudaram e torceram por mim. 


\section{RESUMO}

O serviço de transporte interestadual semiurbano de passageiros entre Distrito Federal e os Municípios de seu entorno transporta diariamente milhares de usuários. Esse transporte precisa ser prestado com qualidade, visto que deve considerar a de satisfação de todos os atores envolvidos. Assim, este trabalho teve como objetivo a construção de um modelo de avaliação da qualidade dos serviços prestados pelas empresas de transporte rodoviário interestadual semiurbano de passageiros para classificá-las por nível de serviço. Para alcançar o objetivo, o trabalho foi desenvolvido basicamente em duas etapas: na primeira etapa, foi construído o modelo de avaliação com a utilização da Metodologia Multicritério de Apoio à Decisão - Construtivista (MCDA-C); a segunda etapa consistiu na verificação da aplicabilidade do modelo, para tanto foi realizado um estudo de caso com a aplicação formulários junto aos usuários de uma empresa que presta o serviço semiurbano do DF e dos municípios de seu entorno. Os resultados se mostraram consistentes e indicaram que a metodologia pode ser utilizada para classificar as empresas que operam o serviço de transporte interestadual semiurbano de passageiros do Distrito Federal e dos Municípios de seu entorno. 


\begin{abstract}
The semi-urban interstate transport passenger service between the Federal District and the municipalities of their surroundings daily carries thousands of users. This transport must be provided with quality, as should consider the satisfaction of all stakeholders. This work aimed to build a model of evaluation of the quality of services provided by interstate bus companies semi-urban passenger to sort them by level of service. To achieve the goal, the work was done basically in two stages: the first stage, the evaluation model was constructed with the use of Multi-criteria Decision Aid - Constructivist (MCDA-C); the second step was to check the applicability of the model, therefore we conducted a case study with the application forms with the users of a company that provides the semi-urban service of the Federal District and the municipalities of its surroundings. The results were consistent and indicated that the methodology can be used to classify the companies operating the semi-urban interstate transportation of passenger service of the Federal District and its surrounding municipalities.
\end{abstract}


SUMÁRIO

RESUMO _................................................................................................................................

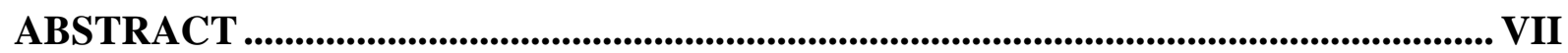

LISTA DE QUADROS ................................................................................................................ $\mathrm{X}$

LISTA DE GRÁFICOS ..............................................................................................

LISTA DE FIGURAS ….......................................................................................

LISTA DE SÍMBOLOS, NOMENCALTURA E ABREVIAÇÕES..................................XIV

1. INTRODUÇÃ

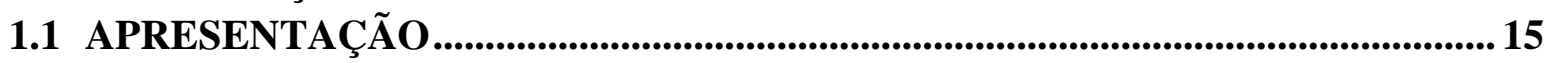

1.2 DELIMITAÇÃO DO PROBLEMA.................................................................16

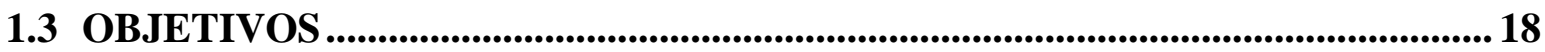

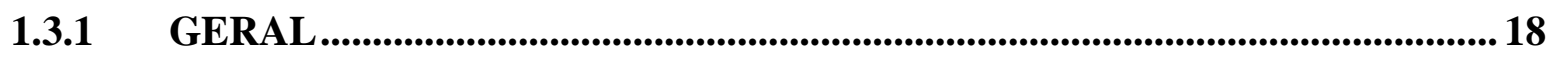

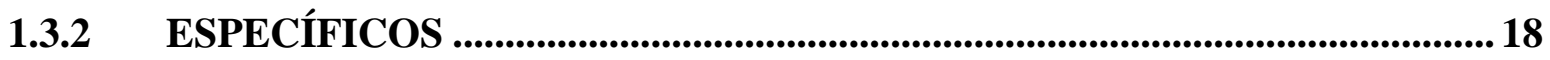

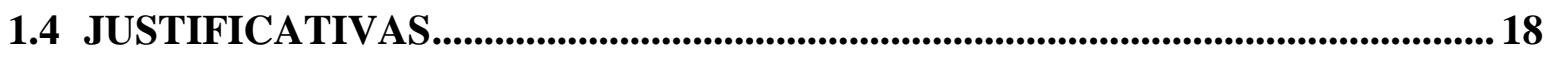

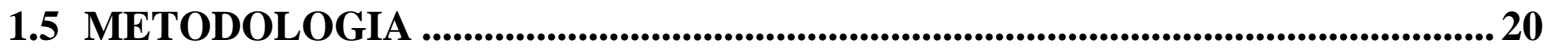

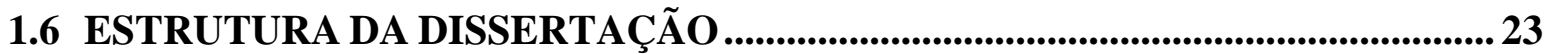

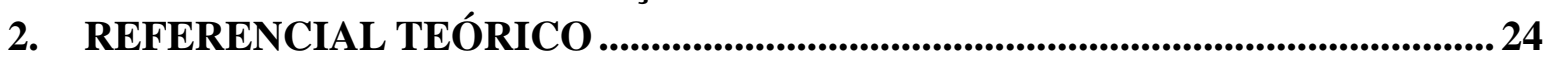

2.1 QUALIDADE EM SERVIÇOS .....................................................................................24

2.2 AVALIAÇÃO DA QUALIDADE EM SERVIÇOS REGULADOS.........................25

2.3 AVALIAÇÃO DA QUALIDADE NOS SERVIÇOS DE TRANSPORTE

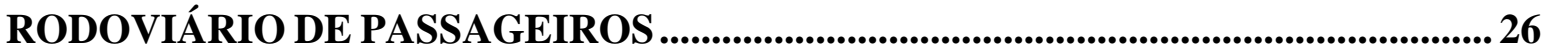

3. CONSTRUÇÃO DO MODELO MULTICRITÉRIO...............................................30

3.1 IDENTIFICAÇÃO DO CONTEXTO DECISÓRIO.....................................................30

3.1.1 IDENTIFICAÇÃO DOS ATORES............................................................30

3.1.2 IDENTIFICAÇÃO DO TIPO DE AÇÃ̃ A SER AVALIADA .........................33

3.1.3 ESCOLHA DA PROBLEMÁTICA DE REFERÊNCIA.....................................34

3.2 ESTRUTURAÇÃO DO PROBLEMA................................................................35

3.2.1 IDENTIFICAÇÃO DOS INDICADORES DE QUALIDADE DOS SERVIÇOS DE TRANSPORTE DE PASSAGEIROS.....................................................35

3.2.2 VALIDAÇÃO DOS INDICADORES DE QUALIDADE E

DETERMINAÇÃO DA FAMÍLIA DE PONTOS DE VISTA FUNDAMENTAIS ..... 38

3.3 ESTRUTURAÇÃO DO MODELO MULTICRITÉRIO...........................................39

3.3.1 ÁRVORE DE PONTOS DE VISTA FUNDAMENTAIS ..................................40

3.3.2 CONSTRUÇÃO DE CRITÉRIOS DE AVALIAÇÃO ....................................49

3.3.3 TAXAS DE SUBSTITUIÇÃO.............................................................53

3.4 MODELO MULTICRITÉRIO PARA AVALIAÇÃO DO NÍVEL DE SER VIÇO56

4. ANÁLISES E DISCUSSÕES......................................................................................58

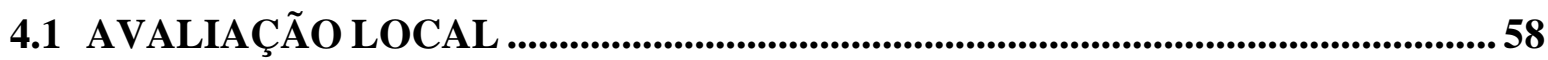


4.1.1 AVALIAÇÃO DOS COMPONENTES DO PVF 1 - SEGURANÇA ..............58

4.1.2 AVALIAÇÃO DOS COMPONENTES DO PVF 2 - CONFIABILIDADE ... 60

4.1.3 AVALIAÇÃO DOS COMPONENTES DO PVF 3 - ACESSIBILIDADE .... 61

4.1.4 AVALIAÇÃ̃ DOS COMPONENTES DO PVF 4 - COMUNICAÇÃO........ 64

4.1.5 AVALIAÇÃO DOS COMPONENTES DO PVF 5 - CONFORTO.................. 69

4.1.6 AVALIAÇÃO DOS COMPONENTES DO PVF 6 - CUSTO...........................70

4.1.7 AVALIAÇÃO DOS COMPONENTES DO PVF 7 - COMPORTAMENTO DOS OPERADORES ................................................................................................................. 71

4.2 PERFIL DE IMPACTO....................................................................................................... 74

4.3 AVALIAÇÃO PARCIAL ............................................................................................. 75

4.4 AVALIAÇÃO GLOBAL ........................................................................................... 76

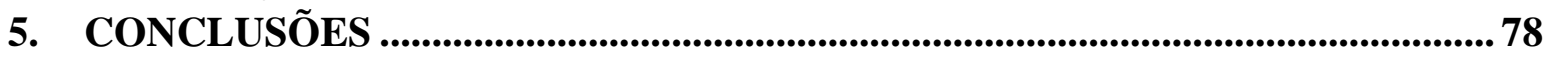

REFERÊNCIAS BIBLIOGRÁFICAS ......................................................................8

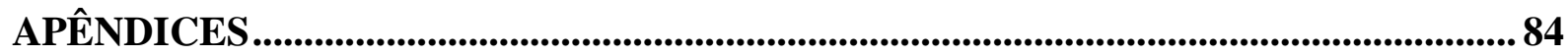

APÊNDICE A - MATRIZES DE JULGAMENTO SEMÂNTICO..................................................... 85

APÊNDICE B - DESCRITORES ............................................................................... 102

APÊNDICE C - FORMULÁRIO DE PESQUISA ......................................................................... 127

APÊNDICE D - CÁLCULO DAS PONTUAÇÕES dOS PVF NAS AVALIAÇõeS PARCIAIS..... 129

APÊNDICE E - DECOMPOSIÇÃO DOS PVF E PVE............................................................... 130 


\section{LISTA DE QUADROS}

Quadro 3-1 - Indicadores utilizados nos trabalhos sobre qualidade dos serviços de transporte

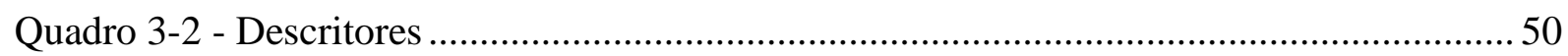

Quadro 3-3 - Taxas de Substituição do modelo ................................................................. 55

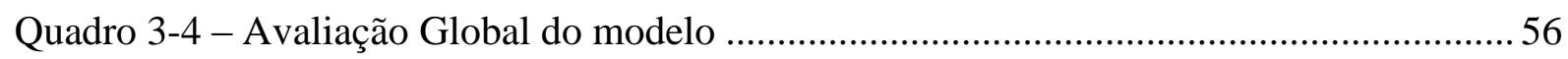




\section{LISTA DE GRÁFICOS}

Gráfico 4.1 - Perfil de impacto da empresa pesquisada ......................................................... 74

Gráfico 4.2 - Avaliação parcial da empresa pesquisada........................................................ 76 


\section{LISTA DE FIGURAS}

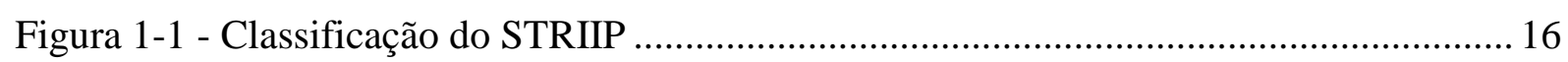

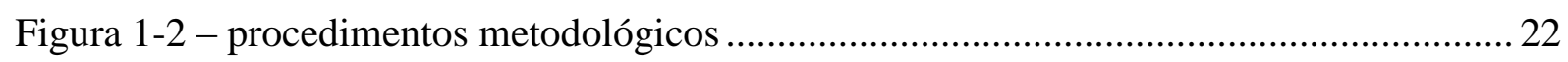

Figura 3-1 - Subsistema de atores do processo de avaliação da qualidade do serviço de

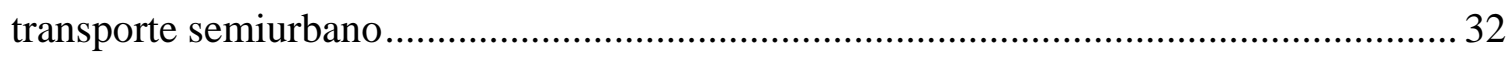

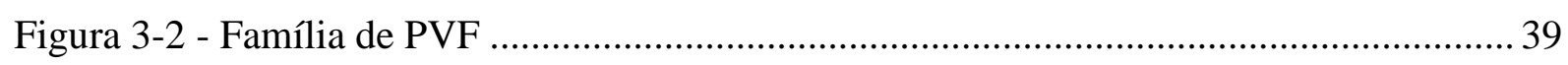

Figura 3-3 - Estrutura genérica de um Modelo Multicritério................................................. 41

Figura 3-4 - Árvore dos pontos de vista fundamentais ..................................................... 48

Figura 3-5 - Exemplo de um Descritor completo ............................................................... 50

Figura 3-6 - Descritor com níveis de referência................................................................. 51

Figura 3-7 - Matriz de Julgamento Semântico e Função de Valor do Descritor Custo........... 53

Figura 3-8 - Níveis de Serviço para classificar as empresas do Semiurbano do DF...............57

Figura 4-1 - Desempenho dos sub PVE componentes do PVE 1.1 - segurança física ........... 59

Figura 4-2 - Desempenho dos sub PVE componentes do PVE 1.2 - segurança não física ..... 60

Figura 4-3 - Desempenho dos PVE componentes do PVF 2 - confiabilidade ........................ 61

Figura 4-4 - Desempenho dos Sub PVE componentes do PVE 3.1 - acessibilidade no embarque.

Figura 4-5 - Desempenho dos sub PVE componentes do PVE 3.2 - acessibilidade no interior do ônibus.

Figura 4-6 - Desempenho dos sub PVE componentes do PVE 3.3 - acessibilidade no desembarque

Figura 4-7 - Desempenho dos sub PVE componentes do PVE 4.1 - informações nos terminais

Figura 4-8 - Desempenho dos sub PVE componentes do PVE 4.2 - informações nas paradas66 Figura 4-9 - Desempenho dos sub PVE componentes do PVE 4.3 - informações nos terminais

Figura 4-10 - Desempenho dos sub PVE componentes do PVE 4.4 - informações na internet .68

Figura 4-11 - Desempenho dos sub PVE componentes do PVE 4.5 - serviço de atendimento ao cliente.

Figura 4-12 - Desempenho dos PVE componentes do PVF 5 - conforto .70

Figura 4-13 - Desempenho do PVF 6 - custo

Figura 4-14 - Desempenho dos sub PVE componentes do PVE 7.1 - treinamento de pessoal72 
Figura 4-15 - Desempenho dos sub PVE componentes do PVE 7.2 - jornada de trabalho ..... 73

Figura 4-16 - Desempenho dos sub PVE componentes do PVE 7.3 - cortesia ....................... 74

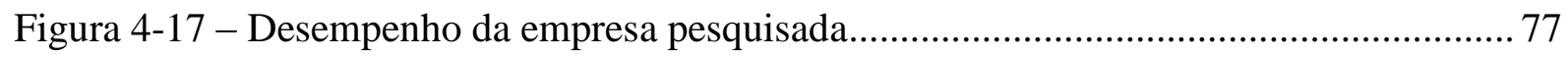




\section{LISTA DE SÍMBOLOS, NOMENCALTURA E ABREVIAÇÕES}

ADRM Airport Development Reference Manual

AHP

Analytic Hierarchy Process

ANATEL

Agência Nacional de Telecomunicações

ANEEL

Agência Nacional de Energia Elétrica

ANTT

Agência Nacional de Transportes Terrestres

DTH

Serviço de Distribuição de Sinais de Televisão e de Áudio por Assinatura via Satélite

EBTU

Empresa Brasileira dos Transportes Urbanos

$\mathrm{HCM}$

Highway Capacity Manual

IASC

Índice ANEEL de Satisfação do Consumidor

IATA

International Air Transport Association

ISA

Importance Satisfaction Analysis

MACBETH

Measuring Attractiveness by a Categorical Based Evaluation Technique

MCDA

Metodologia Multicritério de Apoio à Decisão

MMDS

Serviço de Distribuição de Sinais Multiponto Multicanal

PVE

Ponto de Vista Elementar

PVF

Ponto de Vista Fundamental

SCM

Serviço de Comunicação Multimídia

$\mathrm{SeAC}$

Serviço de Acesso Condicionado

SMP

Serviço Móvel Pessoal

STFC

Serviço Telefônico Fixo Comutado

STRIIP

Sistema de Transporte Rodoviário Interestadual e Internacional de Passageiros

TRB

Transportation Research Board

TVA

Serviço Especial de Televisão por Assinatura

TVC

Serviço de TV a Cabo 


\section{INTRODUÇÃO}

\subsection{APRESENTAÇÃO}

A qualidade na prestação dos serviços é julgada pelos clientes com base em suas percepções do resultado técnico gerado e da qualidade do ambiente físico em que os serviços são executados. Zeinthaml, Bitner e Gremler (2014) chamam a atenção para a existência de pesquisas sobre o assunto que sugerem que a qualidade é julgada pelos clientes com base em atributos diversos, relevantes ao contexto, e não de modo unidimensional.

Para Paladini e Bridi (2013), o desenvolvimento de modelos e métodos de avaliação da qualidade ao longo do século passado teve a ênfase fundamental no esforço de medi-la, sempre priorizando uma análise quantitativa de produtos e processos.

No Setor de Transportes, mais especificamente nos aeroportos e nas rodovias, tem-se utilizado critérios de avaliação da qualidade dos serviços a partir da classificação por níveis. Organismos internacionais como a International Air Transport Association (IATA, 2004) e o Transportation Research Board (TRB, 2000) definem em seus manuais métodos para determinar níveis de serviço. A IATA apresenta em seu manual, Airport Development Reference Manual - ADRM (2004), um método para determinar níveis de serviço dos terminais de passageiros dos aeroportos que ajusta níveis diferentes da provisão de espaço com respeito a seis níveis de serviço. Já o Highway Capacity Manual (HCM), do TRB, define nível de serviço como uma medida de qualidade que descreve as condições operacionais dentro de um fluxo de tráfego, geralmente em termos de medidas de serviços como a velocidade e o tempo de viagem, liberdade de manobra, interrupções de tráfego, conforto e conveniência.

Nos serviços de transporte rodoviário de passageiros, foram desenvolvidos trabalhos com o objetivo de mensurar a qualidade desses serviços. Alguns autores, dentre eles Lubeck et al. ( 2011); Ribeiro e Freitas (2012); Silva et al. (2014), identificaram os itens mais importantes para o aumento do índice de qualidade, a partir dos graus de satisfação dos usuários. Outros 
autores, como Bertozzi e Lima Júnior (1998) e Ferraz e Torres (2004), buscaram definir a qualidade além da ótica dos usuários, incluindo a visão dos operadores e dos órgãos gestores.

De acordo com Ferraz e Torrez (2004), atributos como confiabilidade, tempo de deslocamento, acessibilidade, conforto, conveniência, segurança e tarifas são avaliados pelos usuários, mesmo que subjetivamente, quando utilizam o transporte público. Nesse sentido, o grande número de atributos torna a aferição do nível de qualidade dos serviços prestados uma tarefa complexa para o órgão responsável pela regulação e fiscalização, o qual pode encontrar em uma metodologia multicritério a ferramenta apropriada para classificar as empresas prestadoras dos serviços em função da pontuação alcançada no processo de avaliação.

\subsection{DELIMITAÇÃO DO PROBLEMA}

O Sistema de Transporte Rodoviário Interestadual e Internacional de Passageiros no Brasil STRIIP pode ser classificado, de acordo com a forma como o serviço é prestado, em dois tipos: Transporte Regular e Transporte Fretado de Passageiros. A Figura 1-1 mostra a estrutura atual do STRIIP.

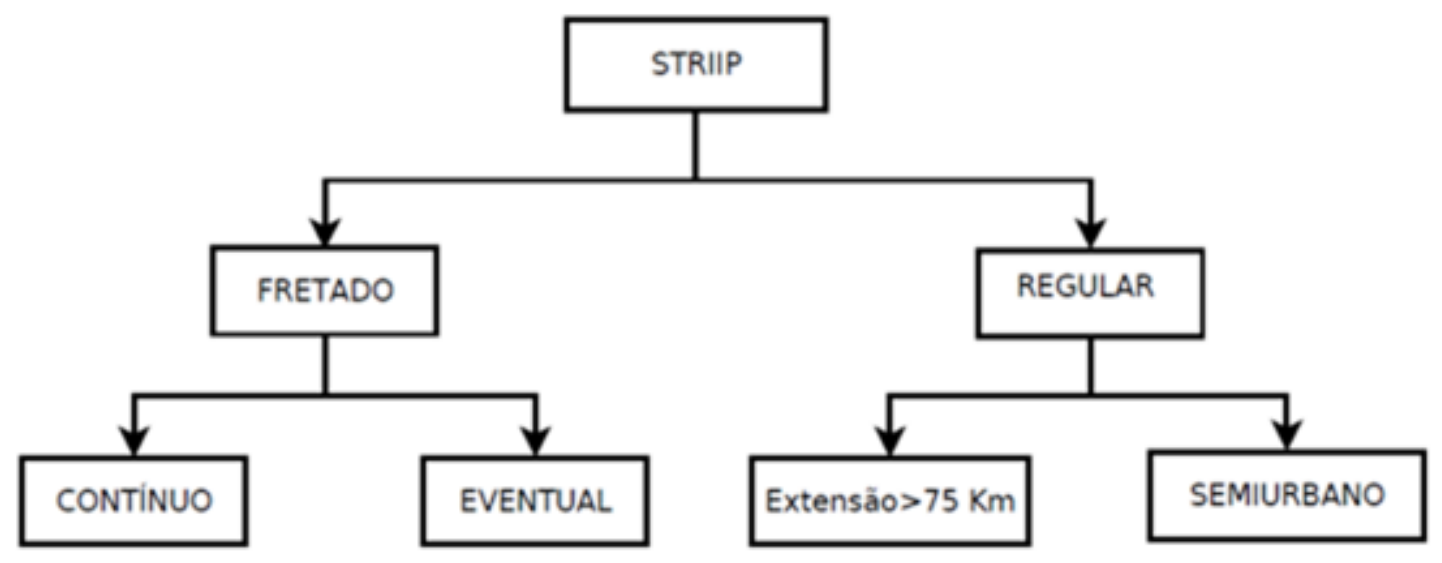

Figura 1-1 - Classificação do STRIIP

Fonte: ANTT (2013a)

O Serviço de Fretamento Contínuo é o serviço prestado a pessoas jurídicas para o transporte de seus empregados, bem como a instituições de ensino ou agremiações estudantis para o transporte de seus alunos, professores ou associados, estas últimas desde que legalmente constituídas, com prazo de duração máxima de doze meses e quantidade de viagens estabelecidas, com contrato escrito entre a transportadora e seu cliente. O contrato deve ser 
previamente analisado e autorizado pela Agência Nacional de Transportes Terrestres - ANTT (BRASIL, 1998).

Por outro lado, o Serviço de Fretamento Eventual ou Turístico é o serviço prestado à pessoa ou a um grupo de pessoas, em circuito fechado, que é a viagem de um grupo de passageiros com motivação comum que parte em um veículo de local de origem a um ou mais locais de destino e, após percorrer todo o itinerário, observado os tempos de permanência estabelecidos nesta Resolução, este grupo de passageiros retorna ao local de origem no mesmo veículo que efetuou o transporte na viagem de ida (ANTT, 2015), com emissão de nota fiscal e lista de pessoas transportadas, por viagem, com prévia autorização ou licença da Agência Nacional de Transportes Terrestres - ANTT (BRASIL, 1998).

O Serviço Regular com extensão superior a $75 \mathrm{~km}$, de acordo com o Plano de Outorga, representa 88\% das ligações do Sistema (ANTT, 2011). Em dezembro de 2013, existiam 2.744 serviços ativos operados por 266 empresas (ANTT, 2013b). Este serviço possui as seguintes características: ocorre principalmente em viagens de longa/média distâncias; demandam veículos de características diferentes (poltronas acolchoadas, reclináveis, bagageiros etc.) daqueles usualmente utilizados em ambiente urbano; possui venda antecipada de passagem e não permite transporte de passageiros em pé (ANTT, 2008).

Finalmente, o Serviço é definido como o serviço de transporte público coletivo entre municípios de diferentes Unidades Federativas, e possui características de transporte urbano (BRASIL, 1998). Ele é realizado em conurbações ou entre regiões metropolitanas, utilizado com frequência mínima semanal pelos usuários, ou aqueles cujos motivos de viagem de seus usuários são, predominantemente, trabalho e estudo (ANTT, 2013b). Por possuir características de transporte urbano, é permitido o transporte de passageiros em pé; não há compartimento específico para o transporte de bagagens; e o controle de acesso de passageiros se dá por meio de catraca ou equipamento similar (ANTT, 2008).

A partir da contextualização do sistema e da necessidade de desenvolvimento de metodologias e ferramentas para aferir a qualidade do serviço prestado pelos operadores de transporte, o problema da pesquisa resume-se no seguinte: Como criar níveis para classificar as empresas prestadoras de transporte rodoviário interestadual semiurbano de passageiros no Brasil a partir da qualidade dos serviços ofertados? 


\subsection{OBJETIVOS}

\subsubsection{GERAL}

O objetivo geral deste trabalho é construir, a partir da visão do órgão regulador e fiscalizador, um modelo de avaliação da qualidade dos serviços prestados pelas empresas de transporte rodoviário interestadual semiurbano de passageiros para classificá-las por nível de serviço.

\subsubsection{ESPECÍFICOS}

Os objetivos específicos são:

- Identificar e validar os atributos relevantes, sob a ótica do órgão regulador e fiscalizador, ao processo de avaliação da qualidade dos serviços de transporte rodoviário interestadual semiurbano de passageiros;

- estruturar hierarquicamente os atributos identificados pelo órgão regulador e fiscalizador;

- aplicar o modelo construído junto a uma empresa que opera o Serviço de transporte interestadual semiurbano de passageiros do Distrito Federal e dos Municípios de seu entorno, apresentando seu perfil de desempenho.

\subsection{JUSTIFICATIVAS}

O serviço de transporte rodoviário interestadual semiurbano de passageiros transporta anualmente cerca de 112 milhões de passageiros (ANTT, 2011b). A Agência Nacional de Transportes Terrestres - ANTT, que é o órgão de regulação e fiscalização deste serviço, considerado essencial e com caráter de dependência da sociedade, entende ser fundamental que ele seja prestado com um adequado patamar de qualidade (ANTT, 2014).

Em uma primeira tentativa de zelar e estimular a qualidade do serviço, a ANTT definiu cinco índices de produtividade e de qualidade a serem aplicados na avaliação dos serviços de transporte rodoviário de passageiros: regularidade na prestação do serviço; eficiência operacional do serviço; eficiência operacional da permissionária; qualidade operacional da operadora; e segurança operacional da permissionária. Porém, nesta definição, a Agência só 
estabeleceu critério para o índice de segurança operacional ao fixar um teto para o número de acidentes por empresa, deixando os outros índices sem a fixação de um nível de serviço mínimo a ser atendido pelas empresas (ANTT, 2005). Esta ausência de um nível de serviço mínimo não permite que sejam realizadas classificações das empresas a partir da qualidade dos serviços que prestam.

No ano de 2014, houve uma evolução a partir da publicação do Edital no 2/2014, que tinha como objetivo delegar as linhas do Transporte Rodoviário Interestadual Semiurbano de Passageiros entre o Distrito Federal e os Municípios de seu entorno. O Anexo V do contrato de permissão estabeleceu o Sistema de Avaliação de Desempenho para o serviço, que é definido como um conjunto de métodos de mensuração e avaliação de resultados com a utilização de índices e indicadores de desempenho para aferir a qualidade da operação dos serviços durante o período avaliativo. Os resultados desta avaliação servem de parâmetro para concessão de benefícios, aplicação de penalidades, elaboração de termo de ajuste de conduta e, em casos extremos, levar à caducidade da permissão (ANTT, 2014).

O Sistema de Avaliação de Desempenho proposto em 2014 é composto por dez índices específicos: 1) índice de Conforto; 2) Índice de Higiene; 3) Índice de Cortesia; 4) Índice de Confiabilidade na Conclusão de Viagens; 5) Índice de Pontualidade na Saída; 6) Índice de Regularidade; 7) Índice de Segurança; 8) Índice de Legalidade; 9) Índice de Modicidade Tarifária; e 10) Índice de Atualidade de Veículos (ANTT, 2014). Desses índices, somente três, conforto, higiene e cortesia são obtidos a partir da percepção que os usuários têm da prestação dos serviços. Sendo os demais calculados a partir de dados registrados na ANTT.

Ainda em 2014, a ANTT realizou, em todo território nacional, uma pesquisa com objetivo de avaliar a satisfação dos usuários com os serviços prestados pelas empresas que realizam os serviços de transporte regulados por ela. A expectativa com a pesquisa era de que seria possível, a partir do levantamento de dados, avaliar a percepção dos usuários em relação aos serviços prestados; obter índices parciais de satisfação dos usuários de acordo com cada atributo; obter um índice de satisfação global sobre os serviços prestados por cada empresa, de forma a permitir a comparação entre elas; obter um índice de satisfação global de satisfação, considerando todas as empresas que prestam determinado tipo de serviço (ANTT, 2014b). 
O problema é que esses dois modelos de avaliação não utilizam os mesmos critérios de cálculo para os índices e indicadores, além de não permitirem a classificação das empresas de acordo com o que a ANTT julga como um adequado patamar de qualidade. Desta forma, é justificável a criação de um modelo de avaliação da qualidade dos serviços prestados pelas empresas de transporte semiurbano de passageiros para classificá-las por nível de serviço.

\subsection{METODOLOGIA}

A metodologia utilizada na construção do modelo para classificar as empresas de transporte rodoviário interestadual semiurbano de passageiros por níveis de serviço foi desenvolvida em cinco etapas: identificação do contexto decisório; estruturação do problema; estruturação do modelo; estudo de caso; e análise e discussões.

\section{$1^{\text {a }}$ etapa - Identificação do contexto decisório}

Nesta etapa são identificados os atores envolvidos no processo de decisão, identificado o tipo de ação que será avaliada e escolhida a problemática de referência.

\section{$2^{\mathrm{a}}$ etapa - Estruturação do problema}

Nesta etapa foi realizada uma revisão bibliográfica em publicações que abordam o tema na literatura na literatura nacional e internacional para identificação dos atributos de qualidade utilizados para avaliar os serviços de transporte rodoviário de passageiros. Após a identificação, os atributos de qualidade identificados passaram por uma validação junto a especialistas da ANTT por meio de reuniões, para que estes especialistas ratificassem os atributos selecionados. Por fim, já com os atributos de qualidade identificados e selecionados, foi determinada a família dos pontos de vista fundamentais (PVF).

\section{$3^{\text {a }}$ etapa - Estruturação do modelo}

$\mathrm{Na}$ estruturação do modelo foi construída a árvore de pontos de vista fundamentais, construção dos critérios de avaliação, determinadas as taxas de substituição e, por fim, estabelecidos os níveis de serviço do modelo. 


\section{$4^{\text {a }}$ etapa - Estudo de caso}

Foi selecionada uma empresa que opera os serviços de transporte semiurbano de passageiros do Distrito Federal e dos municípios de seu entorno para realização de pesquisa de campo. A pesquisa foi feita por meio da aplicação de formulários junto aos usuários de uma empresa que opera as linhas do transporte rodoviário interestadual semiurbano de passageiros entre a cidade de Brasília/DF e os municípios de Águas Lindas de Goiás, Santo Antônio do Descoberto e Cidade Eclética, no Estado de Goiás, com objetivo de verificar o grau de satisfação em relação ao serviço prestado.

A população-alvo da pesquisa de campo é composta por todos os usuários da empresa, objeto do estudo de caso, que opera as linhas do transporte rodoviário interestadual semiurbano de passageiros entre a cidade de Brasília/DF e os municípios de Águas Lindas de Goiás, Santo Antônio do Descoberto e Cidade Eclética, no Estado de Goiás. Segundo dados disponíveis no sitio da Agência Nacional de Transportes Terrestres - ANTT, em 2014 as linhas selecionadas transportaram aproximadamente 7.000 .000 (sete milhões) de usuários, em viagens de ida e volta, que corresponde a aproximadamente 9.600 (nove mil e seiscentos) usuários por dia, por sentido (ANTT, 2015b). Dessa população, foi selecionada uma amostra do tipo probabilística aleatória simples, com intervalo de confiança de $95 \%$ e erro amostral de $7 \%$. Os cálculos da amostra indicaram que deveriam ser aplicados um número mínimo de 194 formulários, porém, foram aplicados 223 formulários, destes, 15 foram descartados por não terem sido preenchidos corretamente, ou por terem sido preenchidos parcialmente.

A coleta de dados foi realizada utilizando-se formulário com questões fechadas para obter as informações pessoais dos respondentes e com a aplicação de questionário baseado na escala Likert para avaliar as percepções dos usuários sobre os serviços prestados pela empresa com quarenta e nove questões. O formulário foi aplicado na segunda quinzena de novembro de 2015, no Terminal Rodoviário Metropolitano de Brasília/DF, ponto de partida das três linhas operadas pela empresa objeto do estudo de caso. Após a coleta, os dados foram tratados utilizando-se uma planilha eletrônica Microsoft Excel 2010 e o método MacBeth para avaliar a empresa e classifica-la pelo modelo multicritério construído.

\section{$5^{\mathrm{a}}$ etapa - Análise e discussões}


Nesta etapa foram analisados e discutidos os resultados encontrados no estudo de caso para avaliar a aplicabilidade do modelo multicritério construído.

A Figura 1-2 apresenta o esquema da metodologia utilizada na elaboração deste trabalho:
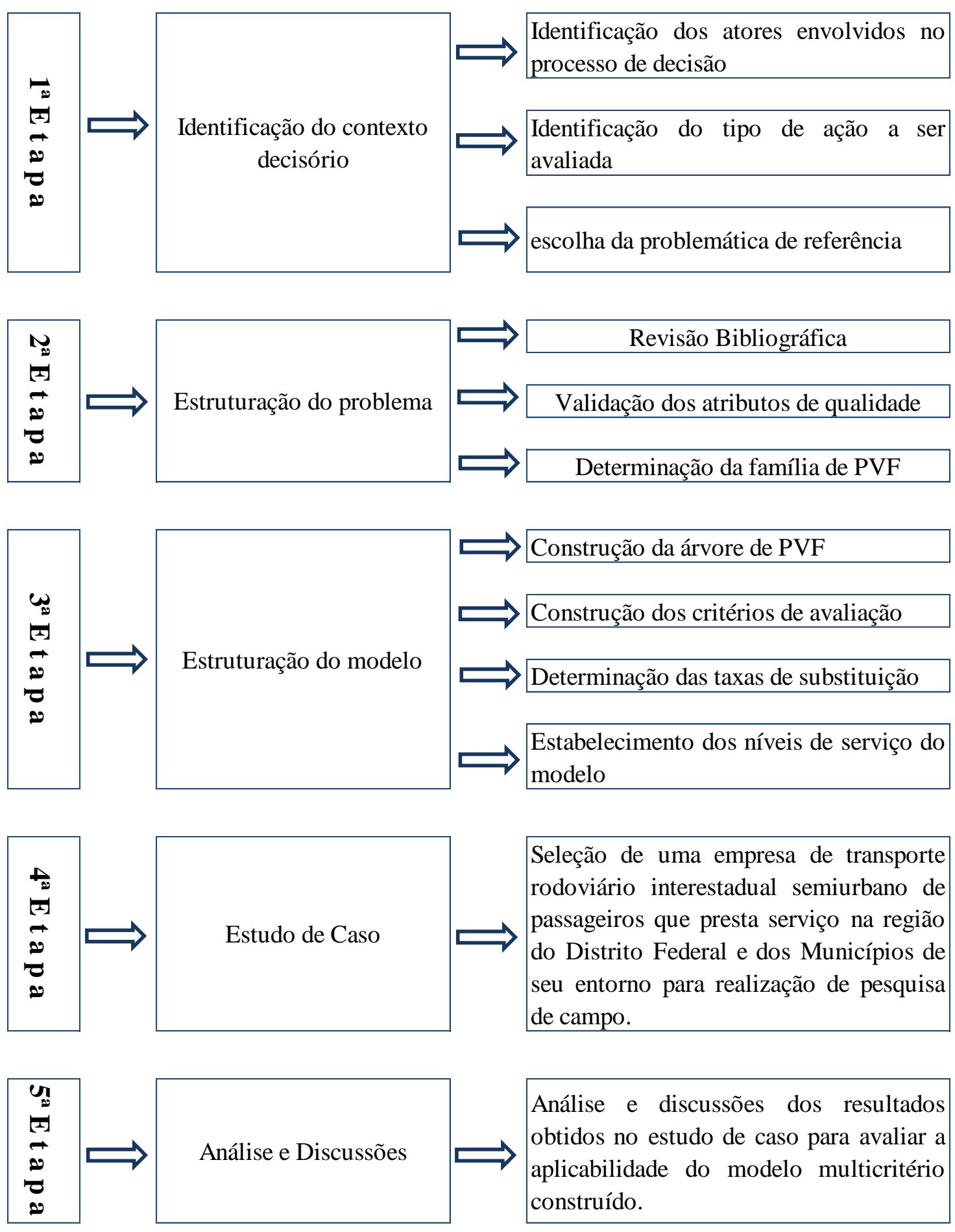

Figura 1-2 - procedimentos metodológicos 


\subsection{ESTRUTURA DA DISSERTAÇÃO}

A dissertação está organizada em cinco capítulos, além das referências bibliográficas e apêndices.

Capítulo 1 - Introdução. Neste capítulo será abordada a delimitação do problema, a hipótese, os objetivos: geral e específicos, a justificativa, a metodologia e a estrutura do trabalho.

Capítulo 2 - Referencial Teórico. Este capítulo tratará o estado da arte da Gestão da Qualidade, mostrando sua aplicação do setor de serviços e, mais especificamente, nos serviços de transportes de passageiros.

Capítulo 3 - Construção do Modelo para Classificar as Empresas de Transporte Rodoviário Interestadual Semiurbano de Passageiros por nível de serviço. Neste capítulo serão identificados os indicadores utilizados para aferir a qualidade dos transportes de passageiros a partir da bibliografia, para em seguida serem validados juntos ao órgão regulador e fiscalizador para, em seguida, construir o modelo para criar níveis de serviço objetivando a classificação das empresas prestadoras do serviço semiurbano a partir da qualidade esperada pelo órgão regulador e fiscalizador.

Capítulo 4 - Análise e Discussões. O objetivo deste capítulo é analisar e discutir os resultados encontrados a partir da aplicação da metodologia desenvolvida em um estudo de caso.

Por fim, as conclusões obtidas ao longo do desenvolvimento da dissertação, assim como sugestões propostas para futuros trabalhos sobre o tema da pesquisa serão apresentadas no Capítulo 5. 


\section{REFERENCIAL TEÓRICO}

Neste capítulo, busca-se fazer uma breve apresentação da qualidade em serviços, para, em seguida, discorrer sobre a avaliação da qualidade de serviços regulados no Brasil e sobre o estado da arte das metodologias utilizadas para avaliação da qualidade nos serviços de transporte rodoviário de passageiros.

\subsection{QUALIDADE EM SERVIÇOS}

Diversos autores apresentaram estudos em qualidade em serviços, dentre eles Garvin (1984), Gronroos (1984), Parasuraman et al. (1988), Teboul (1991), Ghobadian et al. (1994), Gomes (2004), Freitas (2005), Slack et al. (2009) e Paladini (2011).

Para Teboul (1991), a qualidade de um serviço é diferente da qualidade de um produto manufaturado na percepção de um cliente. $\mathrm{O}$ autor credita essa diferença na interação direta existente entre o cliente e o serviço, na prestação do mesmo.

Segundo Paladini (2011), a interação direta existente entre o cliente e o serviço, durante a sua prestação, faz com que não haja possibilidade de se separar o processo produtivo da prestação do serviço. Para ele, no ambiente de prestação de serviço, a Gestão da Qualidade centra-se fundamentalmente na interação com o usuário, que por estar fisicamente presente em sua geração, interfere na sua produção (prestação). O autor lista as principais características de serviços:

- São intangíveis;

- Não podem ser "possuídos";

- Não há estoques;

- Prevalece o ser humano como agente produtivo;

- Sua meta operacional é a flexibilidade;

- Enfatiza muito o valor percebido pelo usuário;

- Depende do efeito sistêmico de novos serviços; 
- Considera-se fundamental avaliar a complexidade, a oportunidade, a conveniência e a abrangência do serviço oferecido. Esses itens tendem a ter valor estratégico para as organizações.

\subsection{AVALIAÇÃO DA QUALIDADE EM SERVIÇOS REGULADOS}

No Brasil, a delegação da exploração de serviços públicos federais, ocorrida a partir da década de 1990, trouxe consigo a necessidade de criação de agências para regular e fiscalizar a prestação destes serviços. Nesse contexto, essas agências avaliam constantemente a qualidade dos serviços que cada prestador oferta aos usuários. Cada setor tem seus índices e metodologias para aferir o nível de serviço prestado. Para exemplificar, serão apresentadas as metodologias utilizadas para avaliar a qualidade dos serviços prestados na área de telefonia e de energia elétrica.

A Agência Nacional de Telecomunicações - ANATEL, órgão regulador das telecomunicações no Brasil, faz a aferição do grau de satisfação e de qualidade percebida junto aos usuários dos serviços de telecomunicações de interesse coletivo prestados pelas operadoras por meio de pesquisas que buscam retratar a visão que os usuários têm sobre a prestação dos serviços de telecomunicações. Os serviços incluem: o Serviço Móvel Pessoal (SMP); o Serviço de Comunicação Multimídia (SCM); o Serviço Telefônico Fixo Comutado (STFC); e os serviços de televisão por assinatura que compreendem o Serviço de Acesso Condicionado (SeAC), o Serviço de TV a Cabo (TVC), o Serviço de Distribuição de Sinais Multiponto Multicanal (MMDS), o Serviço de Distribuição de Sinais de Televisão e de Áudio por Assinatura via Satélite (DTH) e o Serviço Especial de Televisão por Assinatura (TVA) (ANATEL, 2015).

A Agência Nacional de Energia Elétrica - ANEEL acompanha a qualidade dos serviços prestados pelas distribuidoras por meio de quatro instrumentos: IASC - Índice de ANEEL de Satisfação do Consumidor; Qualidade do Atendimento Comercial; Qualidade do Atendimento Telefônico; e Reclamações. Destes instrumentos, destaca-se o Índice de ANEEL de Satisfação do Consumidor - IASC que representa o grau de satisfação do consumidor residencial quantos aos serviços prestados pela distribuidora de energia elétrica. O IASC é obtido a partir de pesquisa de satisfação realizada anualmente junto aos consumidores para avaliar as 
distribuidoras. As distribuidoras que são melhores avaliadas em suas categorias recebem o Prêmio IASC, que tem o objetivo de estimular a melhoria da prestação de serviço de energia elétrica, orientada para a satisfação dos consumidores (ANEEL, 2015).

\subsection{AVALIAÇÃO DA QUALIDADE NOS SERVIÇOS DE TRANSPORTE RODOVIÁRIO DE PASSAGEIROS}

Com o objetivo de avaliar a qualidade dos serviços de transporte rodoviário de passageiros, existem, tanto na literatura internacional como na nacional, diversas metodologias e técnicas que abordam a qualidade sob a ótica de cada um dos atores envolvidos na produção do serviço: empresas operadoras; órgãos gestores; e sociedade em geral. Existem inclusive metodologias e técnicas que combinam a visão de mais de um deles.

Esses trabalhos utilizam pesquisas de opinião com a aplicação de diversas metodologias para tratá-las. O método SERVQUAL foi utilizado por Silva et al. (2014), Lubeck et al. (2011), Jen Hu (1999), dentre outros. Outros autores, como Arruda et al. (2012) e Pereira Neto (2001) utilizaram análise multicritério para propor sistemas de avaliação de desempenho. Freitas et al. (2011) aplicaram uma metodologia para avaliar a qualidade baseada na escala de julgamento de valor Análise Importância-Satisfação (ISA - Importance Satisfaction Analysis).

Pereira Neto (2001) aplicou a Metodologia Multicritério de Apoio à Decisão - MCDA para estruturar um modelo de avaliação do desempenho operacional do transporte coletivo por ônibus no município de Fortaleza, para permitir que o órgão gestor acompanhasse, de forma clara, direta e continuada, o nível de serviço prestado aos usuários. O autor utilizou a Metodologia Multicritério de Apoio à Decisão - MCDA na construção do modelo de avaliação, onde foram identificados, priorizados, quantificados e ponderados os aspectos tidos como relevantes para a avaliação do desempenho operacional das empresas prestadoras do serviço.

Lubeck et al. (2011) usaram um modelo híbrido, adaptando o modelo qualidade de serviços SERVQUAL de Parasuraman et al. (1988) e o modelo da qualidade relativa ao transporte público de Ferraz e Torres (2004) para avaliar o nível de satisfação dos usuários em relação à 
qualidade do transporte público urbano da cidade de Santa Maria - RS. Os autores entendem que a avaliação do nível de satisfação permite que o Poder Concedente possa fazer um melhor acompanhamento do desempenho das empresas prestadoras, aumentando inclusive a demanda desses serviços em detrimento do transporte individual. Os dados coletados foram compilados e analisados com o software SPSS. Os resultados dos estudos mostraram que os usuários avaliaram bem os critérios relativos as dimensões empatia e segurança e, por outro lado, as dimensões que obtiveram as médias mais baixas na avaliação foram aspectos tangíveis e confiabilidade.

Ainda utilizando a escala SERVQUAL, desta vez combinando com a análise fatorial, Jen e Hu (1999) analisaram as dimensões de qualidade de serviço na percepção dos usuários nos serviços de ônibus da cidade de Taipei. Eles concluíram que a percepção dos passageiros para a qualidade dos serviços oferecidos está focada principalmente no serviço externo, especialmente na infraestrutura e tratamento dispensado a eles pelos funcionários das empresas de ônibus.

No mesmo sentido, Silva et al. (2014) avaliaram a qualidade dos serviços prestados pelas empresas de ônibus situados na cidade de Caruaru-PE. Para tal, utilizaram a escala SERVQUAL aplicada a uma pesquisa de satisfação junto aos usuários. A abordagem quantitativa de caráter descritivo, assumida pela investigação, procurou levantar e descrever indicadores numéricos referentes às avaliações dos usuários de ônibus. Os resultados mostraram que os usuários, de uma maneira geral, não percebem uma qualidade efetiva nos serviços prestados pelas empresas pesquisadas e se revelaram insatisfeitos em cada uma das cinco dimensões da qualidade, a exceção foi a dimensão segurança.

Já Freitas et al. (2011) apresentaram uma abordagem metodológica para avaliar a qualidade do transporte rodoviário intermunicipal de passageiros, segundo a percepção dos usuários, utilizando uma escala de julgamento de valor Análise Importância-Satisfação (ISA Importance Satisfaction Analysis). O trabalho explorou aspectos que, na visão dos autores, preenchem uma lacuna na questão da avaliação da qualidade do transporte público por ônibus. A metodologia utilizada procurou mensurar o grau de importância dos atributos/critérios relacionados ao transporte rodoviário de passageiros segundo a percepção destes; usar escalas ordinais para mensuração do grau de satisfação dos passageiros; e a não mensuração do grau de satisfação dos usuários. Os itens que foram considerados com prioridade crítica, que 
devem ser priorizados pela empresa, foram grau de cortesia dos funcionários, proporção custo-benefício, horário de saída do ônibus conforme previsto, respeito às leis de trânsito, veículos acessíveis a portadores de necessidades especiais e filas rápidas e organizadas. Para estes itens, foram sugeridas várias possíveis ações corretivas objetivando a melhoria da qualidade dos serviços prestados.

Arruda et al. (2012) desenvolveram uma proposta para avaliação de desempenho para o Transporte Rodoviário Interurbano de Passageiros focada nos resultados a serem esperados com a prestação do serviço. O sistema de Avaliação de Desempenho proposto baseia-se em parâmetros operacionais e resultados a serem buscados qualquer que seja a área de atuação do transporte rodoviário interurbano. Os autores acreditam que mantendo o foco na gestão dos serviços aos impactos mais perceptíveis pelos usuários e deixando parâmetros quanto à forma de exploração, soluções tecnológicas, técnicas e abordagens comerciais a serem escolhidas e evoluídas à cargo de cada empresa operadora, poderiam garantir uma maior flexibilidade e competitividade entre os operadores. Na proposta apresentada, foram considerados os requisitos de dez subindices e dois índices gerais que foram definidos considerando a literatura citada e a legislação sobre o tema quanto aos aspectos do serviço adequado. Os índices definidos para a observação do desempenho foram compostos pela soma linear compensatória de indicadores ou por um só indicador. Foram adotados pesos diferenciados para a qualidade do serviço prestado utilizando o método de Análise Hierárquica (Analytic Hierarchy Process - AHP).

Rodrigues e Sorratini (2008) analisaram o transporte coletivo urbano realizado por ônibus baseados no resultado de uma pesquisa de opinião aplicada a uma amostra de usuários e em indicadores de qualidade do serviço ofertado pelas empresas operadoras encontrados na literatura. Os autores buscaram fazer um diagnóstico da qualidade em transporte coletivo urbano comparando o grau de importância dos indicadores para os usuários e o grau de importância destes indicadores. A partir desta comparação, foram obtidos subsídios para formulação de propostas para melhoria do atendimento aos usuários e do nível de serviço para o poder público e as empresas prestadoras. Foram utilizados doze indicadores de qualidade existentes na literatura, destes, quatro foram avaliados como satisfazendo plenamente aos anseios de qualidade dos usuários, dois satisfazendo na média e seis indicadores foram considerados insatisfatórios pelos entrevistados. 
Embora existam muitos trabalhos que buscam mensurar a qualidade dos serviços de transporte rodoviário de passageiros, nenhum deles buscou a criação de um modelo capaz de classificar as empresas que prestam este serviço por níveis. Assim, o presente trabalho traz como contribuição a criação de um modelo de avaliação da qualidade dos serviços prestados pelas empresas prestadoras de serviços de transporte rodoviário interestadual semiurbano de passageiros, para classificá-las por nível de serviço atribuído pelo órgão regulador e fiscalizador, segundo sua expectativa de qualidade para o serviço. 


\section{CONSTRUÇÃO DO MODELO MULTICRITÉRIO}

Neste capítulo será construído o modelo multicritério para classificar as empresas que prestam o serviço de transporte interestadual semiurbano de passageiros por nível de serviço a partir da visão do órgão regulador e fiscalizador.

O processo de apoio à decisão é dividido em quatro passos (ENSSLIN et al.,2001). Nesta etapa do trabalho serão abordados três deles: Identificação do Contexto Decisório, Estruturação do Problema e Estruturação do Modelo Multicritério. O quarto passo, Avaliação das Ações Potenciais, será tratado no capítulo destinado a analisar os resultados encontrados no Estudo de Caso.

\subsection{IDENTIFICAÇÃO DO CONTEXTO DECISÓRIO}

Na identificação do contexto decisório, devem ser definidos aspectos necessários ao início do processo de apoio à decisão. Basicamente, são três aspectos: identificar os atores envolvidos na tomada de decisão e escolher os decisores que participarão ativamente na construção do modelo; identificar o tipo de ação que será avaliada pelo modelo multicritério; e decidir o tipo de avaliação a ser feita através do modelo, ou seja, escolher a problemática de referência (ENSSLIN et al., 2001).

\subsubsection{IDENTIFICAÇÃO DOS ATORES}

A identificação dos atores envolvidos no processo decisório constitui-se num importante passo na construção de um modelo multicritério, pois será deles o sistema de valores que norteará a sua construção. Ensslin et al. (2001) distinguem os atores em dois grupos, conforme a participação no processo decisório: os intervenientes e os agidos.

Os atores intervenientes, segundo Ensslin et al. (2001), participam diretamente do processo decisório com o objetivo de fazer prevalecer nele seus sistemas de valores. Já os atores classificados como agidos, são os que sofrem de forma passiva as consequências da implementação da decisão tomada. 
Ensslin et al. (2001) ensinam ainda que no grupo de atores intervenientes é possível distinguir três tipos: os decisores, o representante do decisor e o facilitador. Os decisores são os atores a quem foi formalmente delegado o poder de decisão. O representante do decisor é o ator incumbido pelo decisor para representá-lo no processo de apoio à decisão. E, por fim, o facilitador que, segundo Schwarz, apud Ensslin et al., (2001), nunca será neutro no processo de apoio à decisão. Ele tem como função facilitar e apoiar o processo de tomada de decisão através de ferramentas (modelos) construídos com tal finalidade (ENSSLIN et al., 2001).

No processo de apoio à decisão de construção de um modelo para classificar as empresas de transporte semiurbano de passageiros por nível de serviço, foram identificados seguintes atores intervenientes:

Decisor: o Artigo 52 da Lei $n^{\circ} 10.233 / 2001$, dispõe que a Diretoria da Agência Nacional de Transportes Terrestres atuará em regime de colegiado como órgão máximo de sua estrutura organizacional. No Artigo 53, a referida norma estabelece a composição da Diretoria da ANTT: um Diretor-Geral e quatro Diretores. No Artigo 67 está definido que as decisões das Diretorias serão tomadas pelo voto da maioria absoluta de seus membros, cabendo ao DiretorGeral o voto de qualidade, e serão registradas em atas. Desta forma, a Diretoria da ANTT exercerá o papel de decisor no processo decisório objeto deste trabalho.

Representante do decisor: como representantes dos decisores foram escolhidos quatro especialistas em transportes terrestres lotados na Superintendência de Serviços de Transporte de Passageiros - SUPAS, da ANTT, com experiência em regulação e fiscalização de transporte rodoviário interestadual de passageiros.

Facilitador: neste trabalho, o pesquisador será o facilitador e será o responsável por conduzir o processo de apoio à tomada de decisão.

Agido: as consequências da implementação da decisão tomada afetarão as empresas de transporte rodoviário semiurbano de passageiros e os usuários (passageiros) desses serviços. Assim, as empresas e os usuários serão os atores agidos no processo de apoio à decisão objeto deste trabalho. 
A Figura 3.1 apresenta o subsistema de atores para classificar as empresas de transporte interestadual semiurbano de passageiros por nível de serviço.

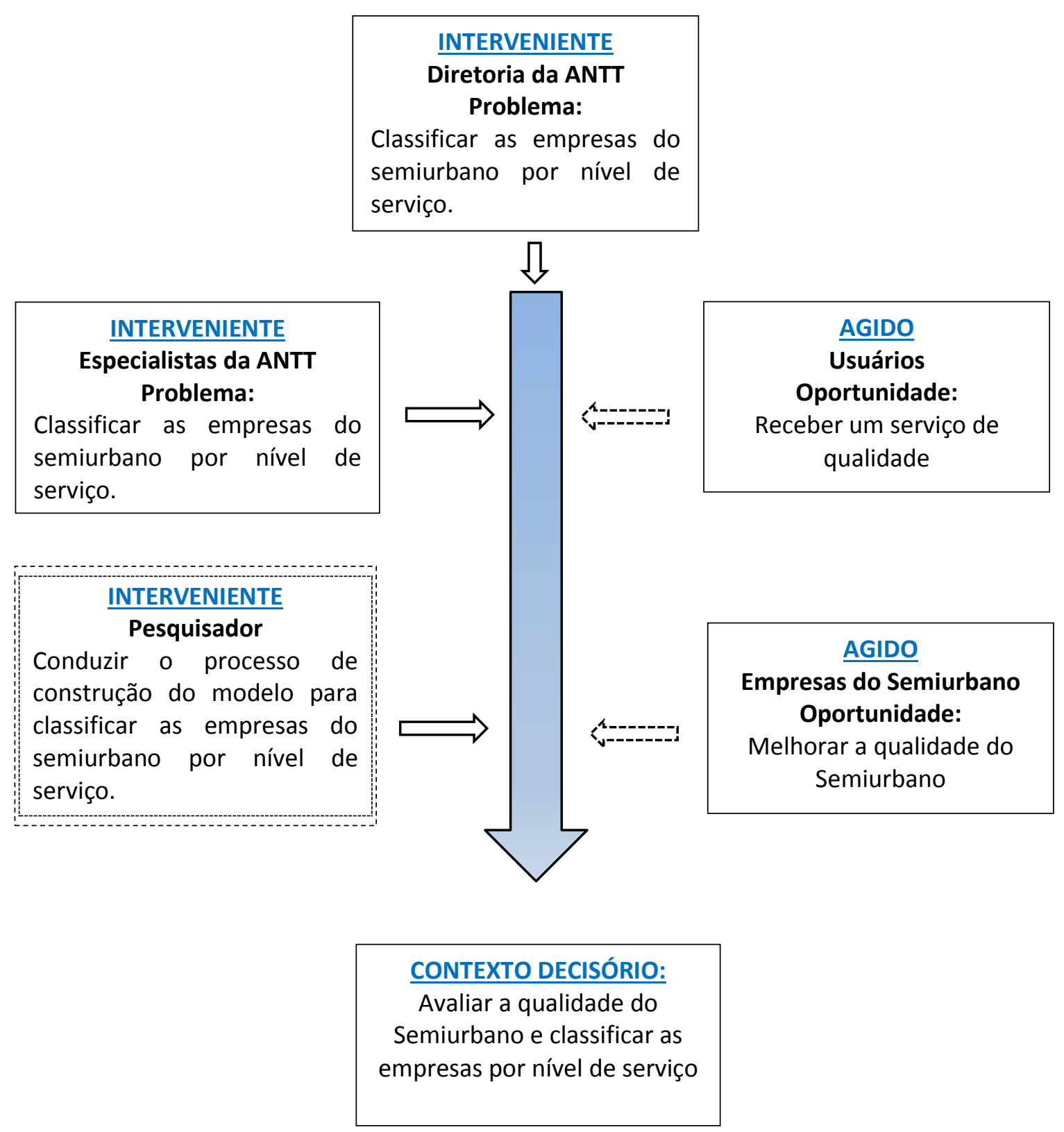

Figura 3-1 - Subsistema de atores do processo de avaliação da qualidade do serviço de transporte semiurbano 


\subsubsection{IDENTIFICAÇÃO DO TIPO DE AÇÃO A SER AVALIADA}

As ações referem-se aos objetos, decisões, candidatos, alternativas etc. que serão explorados durante o processo decisório (VINCKE, 1992), ou seja, serão analisados pelo modelo multicritério construído (ENSSLIN et al., 2001).

Segundo Roy, apud Ensslin et al., 2001, ação é uma representação de uma possível contribuição à decisão, representação esta que pode ser considerada autônoma com relação ao processo de decisão.

As ações podem ser classificadas de diversas formas. Ensslin et al. (2001) apresentam como importantes as seguintes ações:

- Ações Reais - são as ações originadas de um projeto completamente desenvolvido, que pode ser executado;

- Ações Fictícias - são as ações que correspondem a um projeto idealizado, ou não completamente desenvolvido, ou ainda um projeto hipotético;

- Ação Global - é a ação que, quando avaliada, é exclusiva de todas as outras ações introduzidas no modelo multicritério; e

- Ação Fragmentada - corresponde a ação que não é exclusiva de todas as outras ações, ou seja, é apenas uma parte de uma ação global que não foi especificada completamente.

Existe ainda o conceito de ação potencial, que é uma ação real ou fictícia, julgada por pelo menos um decisor como um projeto cuja implementação pode ser razoavelmente prevista.

No processo de construção do modelo multicritério para classificar as empresas de transporte interestadual semiurbano de passageiros por nível de serviço, a ação potencial será o nível do serviço prestado pelas empresas. 


\subsubsection{ESCOLHA DA PROBLEMÁTICA DE REFERÊNCIA}

Quando se considera o conjunto de ações potenciais, tanto reais como fictícias, o facilitador e os atores intervenientes podem se deparar com uma série de dúvidas. Dessa forma, cabe ao decisor definir dentre o conjunto de problemática de referência que será utilizada. A escolha da problemática irá influenciar o processo de estruturação do modelo multicritério, inclusive, eventualmente, na definição de quais critérios serão utilizados (ENSSLIN et al., 2001).

A problemática de referência que será utilizada para alcançar o resultado pretendido em determinado problema pode ser:

- Problemática da Descrição: descreve as ações e suas características de maneira formalizada. Ela é utilizada quando os decisores desejam apenas que o facilitador os ajude a realizar uma descrição completa e formalizada das ações, em termos qualitativos e quantitativos (ROY, apud ENSSLIN et al., 2001).

- Problemática da Alocação em Categorias: classifica as ações em categorias definidas através de normas previamente estabelecidas. Cada ação deve ser alocada a uma e apenas uma categoria (ROY, apud ENSSLIN et al., 2001).

De acordo com Ensslin et al. (2001), existe um caso particular da problemática da alocação em categorias que é a problemática da rejeição absoluta. Nela, se as ações não cumprirem as regras definidas pelo decisor, são eliminadas do conjunto de ações viáveis.

- Problemática da Escolha: escolhe uma ação ou um conjunto de ações. Segundo Ensslin et al. (2001), a problemática da escolha é considerada a mais clássicas das problemáticas na medida em que a pesquisa operacional tradicional quase sempre encarou a tomada de decisão meramente como uma escolha ótima.

- Problemática da Ordenação: ordena as ações em termos de preferência. Esta problemática consiste em arranjar as ações a partir de uma ordem de preferência (total ou parcial) ou através de um método de ranking (ENSSLIN et al., 2001). 
No processo de construção do modelo multicritério para classificar as empresas de transporte interestadual semiurbano de passageiros por nível de serviço, a problemática de referência escolhida foi a da alocação em categorias, uma vez que o objetivo do modelo é classificar as empresas em função do nível de serviço que elas prestam.

Com a identificação dos atores do processo decisório, a identificação do tipo de ação a ser avaliada e a escolha da problemática de referência, concluiu-se o primeiro passo na construção do modelo multicritério, ou seja, definiu-se o contexto decisório. Desta forma, é possível avançar para a estruturação do problema.

\subsection{ESTRUTURAÇÃO DO PROBLEMA}

Com base na literatura existente, foram identificados e selecionados os indicadores de qualidade dos serviços de transporte de passageiros os quais foram submetidos aos representantes dos decisores para validação. Assim, a partir da validação, os indicadores passaram a ser considerados como sendo a Família dos Pontos de Vista Fundamentais (PVF).

\subsubsection{IDENTIFICAÇÃO DOS INDICADORES DE QUALIDADE DOS SERVIÇOS DE TRANSPORTE DE PASSAGEIROS}

$\mathrm{Na}$ análise da literatura, foi possível observar que diversos autores utilizam denominações diversas para esses indicadores, dependendo inclusive da metodologia utilizada, que para alguns são chamados de fatores caracterizadores de qualidade, para outros são atributos de qualidade, outros chamam de dimensões da qualidade etc.

Paladini e Bridi (2013) definem indicadores de qualidade como mecanismos de avaliação formulados em bases quantitativas e com foco no usuário final. As bases quantitativas, como explicam os autores, estão no fato de que os indicadores caracterizam uma avaliação expressa em termos mensuráveis e, o foco no usuário final, decorre da medição que os indicadores fazem para verificar se o processo de prestação do serviço atingiu seu objetivo final.

Ainda de acordo com Paladini e Bridi (2013), a aplicação de indicadores de qualidade em serviços deve ser feita com bastante cuidado. Desta forma, eles formularam os princípios da 
utilização de indicadores para avaliar a qualidade em serviços, dentre os quais destacam dois como sendo relevantes:

“(1) O processo de disponibilização dessas informações deve atender a um conjunto de requisitos bem definidos.

(2) Cada informação será composta de um conjunto de componentes específicos".

Nos serviços de transporte de passageiros, esses indicadores de qualidade são também chamados de atributos. A Empresa Brasileira dos Transportes Urbanos - EBTU (1988) elencou e caracterizou sete atributos, que considerou como os principais atributos relacionados ao transporte público e ponderados pelos usuários: confiabilidade, tempo de deslocamento, acessibilidade, conforto, conveniência, segurança e custo (tarifa).

Por sua vez, Jen e Hu (1999), denominaram de dimensões de qualidade os indicadores de qualidade dos serviços de ônibus. Eles apresentaram dez dimensões de qualidade: tangibilidade, confiabilidade, capacidade de resposta, competência, cortesia, credibilidade, segurança, acesso, comunicação e compreendendo o Cliente.

Com a denominação de fatores de qualidade, Torres e Ferraz (2004) alertaram para importância de que sejam atendidos certos requisitos quanto à comodidade e à segurança durante todas as etapas da viagem, ou seja, o percurso a pé da origem até o local de embarque no sistema, a espera pelo coletivo, a locomoção dentro do coletivo e a caminhada do ponto de desembarque até o destino final. Para estes autores, são doze os principais fatores que influenciam a qualidade do transporte público urbano: acessibilidade, frequência de atendimento, tempo de viagem, lotação, confiabilidade, segurança, características dos veículos, características dos locais de parada, sistema de informações, conectividade, comportamento dos operadores e estado das vias.

Muralha (1990) utilizou os atributos custo, conforto, acessibilidade, confiabilidade, conveniência, segurança e tempo de viagem, e chamou a atenção para o fato de que esta escolha varia de acordo com o autor. O Quadro 3.1 apresenta a relação de atributos dos autores pesquisados, comprovando assim a observação feita por Muralha (1990). 


\begin{tabular}{|c|c|c|c|c|c|c|c|c|c|c|c|c|c|}
\hline & 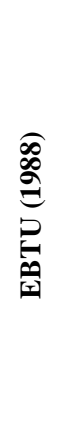 & 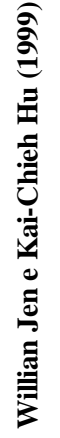 & 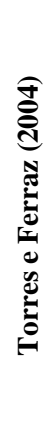 & 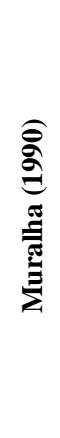 & 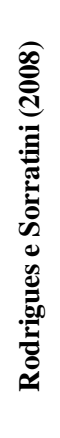 & 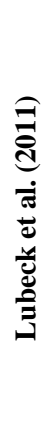 & 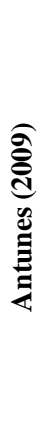 & 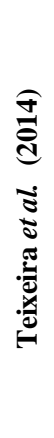 & 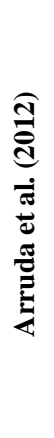 & 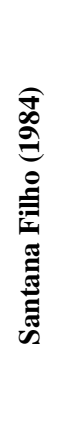 & 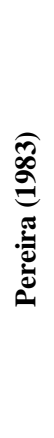 & 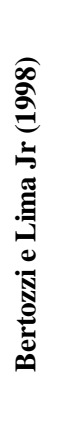 & 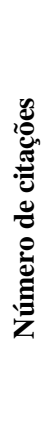 \\
\hline Segurança & $x$ & $x$ & $x$ & $x$ & $x$ & $x$ & $x$ & $x$ & $x$ & $x$ & & $x$ & 11 \\
\hline Confiabilidade & $x$ & $x$ & $x$ & $x$ & $x$ & $x$ & & & $x$ & $x$ & $x$ & $x$ & 10 \\
\hline Acessibilidade & $x$ & $x$ & $x$ & $x$ & $x$ & $x$ & $x$ & & & $x$ & & $x$ & 9 \\
\hline Comunicação/Sistema de Informações & & $\mathrm{x}$ & $\mathrm{x}$ & & $\mathrm{x}$ & $\mathrm{x}$ & $\mathrm{x}$ & $\mathrm{x}$ & & 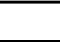 & & $\mathrm{x}$ & 7 \\
\hline Conforto & $x$ & & & $x$ & & & & $x$ & $x$ & $x$ & $x$ & $\rtimes$ & 7 \\
\hline Modicidade Tarifária (Custo) & $x$ & & & $x$ & 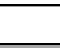 & & 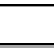 & $x$ & $x$ & $x$ & & $x$ & 6 \\
\hline Tempo de deslocamento & $x$ & & $x$ & $x$ & $x$ & & $x$ & & & & & & 5 \\
\hline Características dos Locais de Parada & & & $\mathrm{x}$ & & $\mathrm{x}$ & $\mathrm{x}$ & $\mathrm{x}$ & & & & & & 4 \\
\hline Características dos Veículos & & & $\mathrm{x}$ & & $\mathrm{x}$ & $\mathrm{x}$ & $\mathrm{x}$ & & & & & & 4 \\
\hline Comportamento dos Operadores & & & $\mathrm{x}$ & & $\mathrm{x}$ & $\mathrm{x}$ & $\mathrm{x}$ & & & & & & 4 \\
\hline Lotação & & & $\mathrm{x}$ & & $\mathrm{x}$ & $\mathrm{x}$ & $\mathrm{x}$ & & & & & & 4 \\
\hline Frequencia de Atendimento & & & $\mathrm{x}$ & & $\mathrm{x}$ & $\mathrm{x}$ & & & & & & & 3 \\
\hline Conveniência & $x$ & & & & & & & & & $x$ & & & 2 \\
\hline Cortesia & & $x$ & & & & & & & $x$ & & & & 2 \\
\hline Credibilidade & & $\mathrm{x}$ & & & & & $\mathrm{x}$ & & & & & & 2 \\
\hline Estado das vias & & & $\mathrm{x}$ & & $\mathrm{x}$ & & & & & & & & 2 \\
\hline Higiene & & & & & & & & $x$ & $x$ & & & & 2 \\
\hline Pontualidade & & & & & & & $x$ & & $x$ & & & & 2 \\
\hline Rapidez & & & & & & & & & & $x$ & $x$ & & 2 \\
\hline Responsividade & & & & & & $\mathrm{x}$ & & & & & & $\mathrm{x}$ & 2 \\
\hline Tangibilidade & & $\mathrm{x}$ & & & & & & & & & & $\mathrm{x}$ & 2 \\
\hline Atualidade dos Veículos & & & & & & & & & $x$ & & & & 1 \\
\hline Capacidade de Resposta & & $\mathrm{x}$ & & & & & & & & & & & 1 \\
\hline Competência & & $\mathrm{x}$ & & & & & & & & & & & 1 \\
\hline Compreendendo o Cliente & & $\mathrm{x}$ & & & & & & & & & & & 1 \\
\hline Conectiviadde & & & $\mathrm{x}$ & & & & & & & & & & 1 \\
\hline Exatidão do Itinerário & & & & & & & & $\mathrm{x}$ & & & & & 1 \\
\hline Legalidade & & & & & & & & & $x$ & & & & 1 \\
\hline Localização & & & & & & & & $\mathrm{x}$ & & & & & 1 \\
\hline Regularidade & & & & & & & & & $x$ & & & & 1 \\
\hline Satisfação geral e nos horários de pico & & & & & & & $\mathrm{x}$ & & & & & & 1 \\
\hline Serviços & & & & & & & & $\mathrm{x}$ & & & & & 1 \\
\hline Transbordo & & & & & $\mathrm{x}$ & & & & & & & & 1 \\
\hline Empatia & & & & & & & & & & & & $x$ & 1 \\
\hline Ambiente & & & & & & & & & & & & $x$ & 1 \\
\hline Imagem & & & & & & & & & & & & $x$ & 1 \\
\hline Momentos de interação & & & & & & & & & & & & $x$ & 1 \\
\hline
\end{tabular}

Quadro 3-1 - Indicadores utilizados nos trabalhos sobre qualidade dos serviços de transporte

Os indicadores mais citados foram selecionados e apresentados aos representantes dos decisores para que fossem validados e, em seguida, se determinasse a Família de Pontos de Vista Fundamentais. 


\subsubsection{VALIDAÇÃO DOS INDICADORES DE QUALIDADE E DETERMINAÇÃO DA FAMÍLIA DE PONTOS DE VISTA FUNDAMENTAIS}

Sete indicadores de qualidade foram selecionados: segurança, confiabilidade, acessibilidade, comunicação, conforto, custo (tarifa) e comportamento dos operadores. Eles foram selecionados para serem validados pelos representantes do decisor, uma vez que convergem com os mais utilizados na literatura que trata do assunto. Desta forma, os indicadores passaram a ser considerados candidatos a Pontos de Vista Fundamentais (PVF), apresentados na Figura 3.2.

Pontos de Vista Fundamentais são aqueles aspectos considerados, por pelo menos um dos decisores, como fundamentais para avaliar as ações potenciais. Eles explicitam os valores que os decisores consideram importantes naquele contexto e, ao mesmo tempo, definem as características (propriedades) das ações que são de interesse dos decisores. Os PVF constituem-se os eixos de avaliação do problema (ENSSLIN et al., 2001).

Segundo Ensslin et al. (2001), existem propriedades que devem ser obedecidas, todas elas, para que um conjunto de PVF seja considerado uma família de PVF:

- Essencial - O PVF deve levar em conta os aspectos que sejam de fundamental importância aos decisores, segundo seus sistemas de valores;

- Controlável - O PVF deve apresentar um aspecto que seja influenciado apenas pelas ações potenciais em questão;

- Completo - O conjunto de PVF deve incluir todos os aspectos considerados como fundamentais pelos decisores;

- Mensurável - O PVF permite especificar, com a menor ambiguidade possível, a performance das ações potenciais, segundo os aspectos considerados fundamentais pelos decisores;

- Operacional - O PVF possibilita coletar as informações requeridas sobre a performance das ações potenciais, dentro do tempo disponível e com um esforço viável;

- Isolável - O PVF permite a análise de um aspecto fundamental de forma independente com relação aos demais aspectos do conjunto; 
- Não-redundante - O conjunto de PVF não deve levar em conta o mesmo aspecto mais de uma vez;

- Conciso - O número de aspectos considerados pelo conjunto de PVF deve ser o mínimo necessário para modelar de forma adequada, segundo a visão dos decisores, o problema;

- Compreensível - O PVF deve ter seu significado claro para os decisores, permitindo a geração e comunicação de ideias.

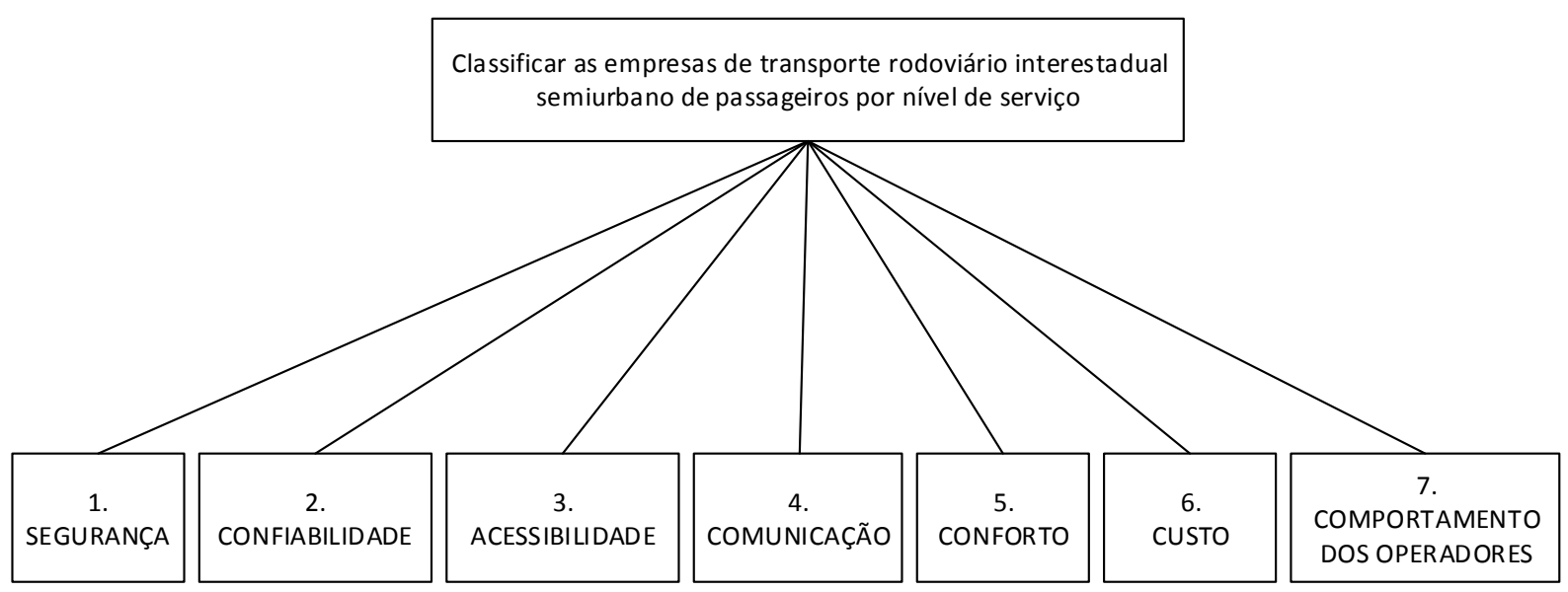

Figura 3-2 - Família de PVF

Com a determinação dos Pontos de Vistas Fundamentais, conclui-se a fase de estruturação do problema. O próximo passo será a estruturação do modelo.

\subsection{ESTRUTURAÇÃO DO MODELO MULTICRITÉRIO}

$\mathrm{Na}$ estruturação de um modelo multicritério, inicialmente deve-se definir quais os aspectos, dentro do contexto decisório, que os decisores consideram essenciais e desejáveis no processo de avaliação das ações potenciais (ENSSLIN et al., 2001). Estes aspectos constituem os eixos de avaliação, que Bana e Costa et al. (1999) definem como uma dimensão considerada como relevante, segundo os valores dos decisores, para avaliar as ações potenciais.

Segundo Ensslin et al. (2001), a identificação dos eixos de avaliação do problema é chamada de transição de um mapa cognitivo para um modelo multicritério. Porém, neste estudo, como a determinação dos PVF foi realizada a partir da identificação na literatura existente dos 
principais indicadores de qualidade e da validação desses indicadores junto aos decisores, não foi construído um mapa cognitivo.

Assim, a estruturação do modelo multicritério será realizada a partir da construção de uma Árvore de Pontos de Vista Fundamentais ou, como também é conhecida, construção da Arborescência da Família de Pontos de Vista Fundamentais; criação de critérios de avaliação para cada PVF com a definição de um Descritor para mensurar cada critério de avaliação e a obtenção de uma Função de Valor Associada ao Descritor; e definição das Taxas de substituição entre os PVF.

\subsection{1 ÁRVORE DE PONTOS DE VISTA FUNDAMENTAIS}

A estruturação em árvore (ou "árvore de valores") permite visualizar de forma organizada a totalidade dos aspectos importantes do problema (BANA E COSTA, 2005). De acordo com Ensslin et al. (2001), a estrutura arborescente utiliza a lógica da decomposição, em que um critério mais complexo de ser mensurado é decomposto em subcritérios de mais fácil mensuração. Em regra, o critério de nível hierárquico superior é definido pelo conjunto de critérios de nível hierárquico inferior que estão ligados a ele na árvore.

A Árvore de Pontos de Vista Fundamentais é estruturada em níveis, cada nível utiliza um elemento. O primeiro nível é composto pelo Rótulo do Problema, que descreve o problema a ser solucionado e representa o objetivo a ser alcançado. O nível seguinte é composto pela Família de Pontos de Vista Fundamentais que podem ou não serem decompostos em Pontos de Vista Elementares (PVE). Os PVE são utilizados sempre que existe a necessidade de decomposição do eixo de avaliação e permitem que seja realizada uma melhor avaliação da performance das ações potenciais no ponto de vista considerado. Os PVE podem ser decompostos em sub-PVE, desde que os decisores sintam necessidade, para uma melhor explicação de um ponto de vista. Desta forma, a estrutura genérica de um modelo multicritério que adota uma estrutura de arborescente é apresentada na figura 3.3. 


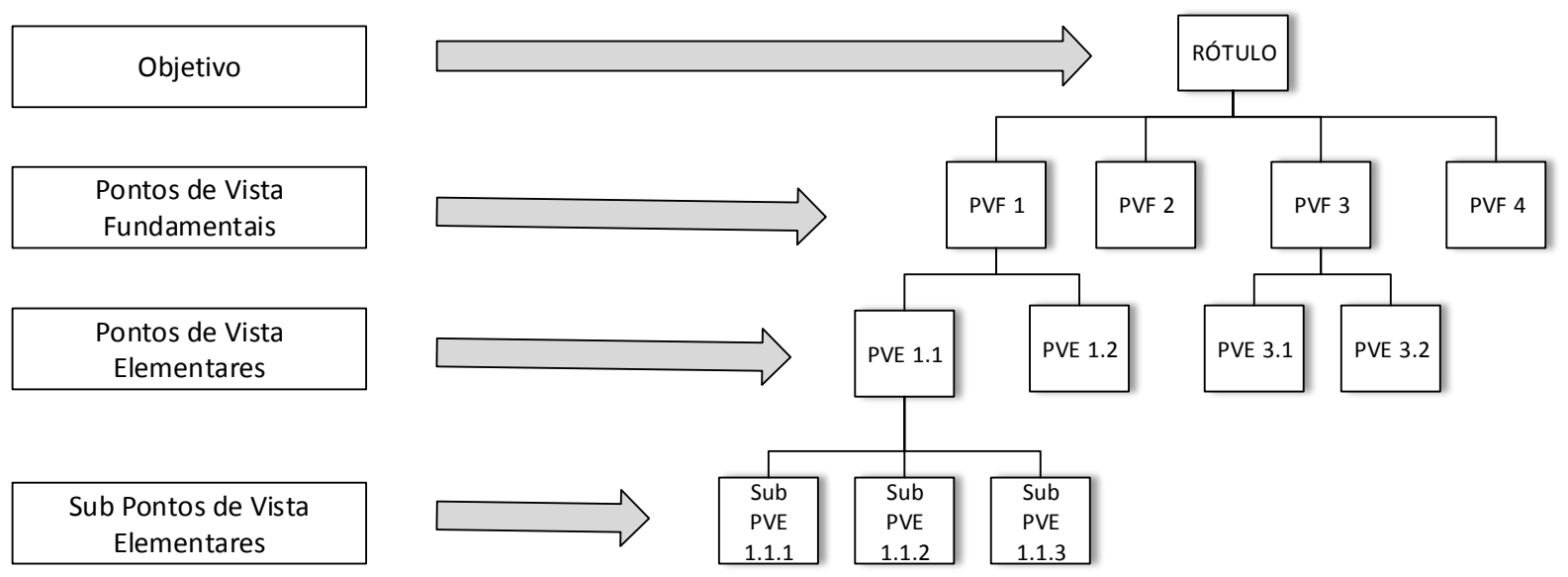

Figura 3-3 - Estrutura genérica de um Modelo Multicritério

Fonte: Quirino, 2002.

A árvore de valor do modelo multicritério para classificar as empresas de transportes de serviço semiurbano de passageiros por nível de serviço foi construída pelos representantes do decisor junto com o pesquisador que sentiram necessidade de decompor os PVF em PVE e sub PVE para que fosse possível uma melhor avaliação da performance das ações potenciais e uma melhor explicação dos pontos de vista. As figuras das decomposições realizadas constam do Apêndice E.

\section{PVF 1 - SEGURANÇA}

O PVF 1 - Segurança é decomposto em dois Pontos de Vista Elementares: 1.1 - Segurança física e 1.2 - Segurança não física. O objetivo deste PVF é verificar a percepção que o usuário tem sobre a segurança oferecida pela empresa durante a viagem.

\section{Ponto de Vista Elementar 1.1 - Segurança Física}

O PVE 1.1 - Segurança física é decomposto em três Subpontos de Vista Elementares: 1.1.1 Câmera de monitoramento; 1.1.2 - Iluminação no interior do ônibus; e 1.1.3 - Forma de condução do ônibus. Esse PVE tem por objetivo avaliar a qualidade do serviço sob o aspecto da segurança física oferecida ao usuário, desde a inibição a assaltos devido a presença de um maior monitoramento com o uso de câmeras e ambientes mais iluminados até a redução de acidentes devido a uma forma mais prudente de conduzir o veículo por parte do motorista. 


\section{Ponto de Vista Elementar 1.2 - Segurança não física}

O PVE 1.2 - Segurança não física é decomposto em dois Subpontos de Vista Elementares: 1.2.1 - Agressão moral no interior do ônibus; 1.2.2 - Discussão com a tripulação. Esse PVE tem por objetivo avaliar a qualidade do serviço sob o aspecto da segurança não física oferecida ao usuário, ou seja, aspectos capazes de assegurar aos usuários, durante a prestação do serviço, que eles não serão vítimas de agressões morais por parte de outros usuários e tripulantes bem como de ter a garantia que a tripulação saberá contornar os conflitos que aparecerem sem se envolverem em discussões com os usuários.

\section{PVF 2 - CONFIABILIDADE}

O PVF 2 - Confiabilidade é decomposto em cinco PVE: 2.1 - Continuidade do serviço; 2.2 Cumprimento da programação; 2.3 - Cumprimento de itinerários; 2.4 - Intervalo entre ônibus; e 2.5 - Interrupção de viagem por quebra. O PVF tem objetivo de verificar a confiabilidade que os usuários têm sobre o serviço.

\section{PVF 3 - ACESSIBILIDADE}

O PVF 3 - Acessibilidade é composto dos PVE: 3.1 - Acessibilidade no embarque; 3.2 Acessibilidade no interior do ônibus; e 3.3 - Acessibilidade no desembarque. O objetivo deste item é verificar a percepção que os usuários têm do acesso ao serviço quando embarcam e desembarcam dos ônibus, bem como da acessibilidade no interior do veículo.

\section{Ponto de Vista Elementar 3.1 - Acessibilidade no embarque}

O PVE 3.1 - Acessibilidade no embarque é decomposto em dois Subpontos de Vista Elementares: 3.1.1 - Tempo na fila dos terminais; e 3.1.2 - Tempo de embarque. Nesse PVE o objetivo principal é a percepção do usuário sobre o tempo dispendido entre a chegada ao terminal e o acesso ao serviço (embarque no ônibus), incluindo o tempo gasto na fila e o tempo necessário para entrar no ônibus depois que o embarque é autorizado. 


\section{Ponto de Vista Elementar 3.2 - Acessibilidade no interior do ônibus}

O PVE 3.2 - Acessibilidade no interior do ônibus é decomposto em três Subpontos de Vista Elementares: 3.2.1 - Acesso a assentos especiais; 3.2.2 - Facilidade para pagamento das passagens; e 3.2.3 - Controle de acesso pela catraca. Nesse PVE o objetivo principal é a avaliação da acessibilidade no interior do ônibus, principalmente nos aspectos relacionados ao pagamento da passagem (se existe dificuldade para troco, quando é utilizado dinheiro), se os tripulantes observam o uso dos assentos especiais para permitir que os passageiros a quem se destinam não tenham seus direitos suprimidos e, por fim, saber se existem dificuldades para passar pela catraca devido a defeitos nestes equipamentos.

\section{Ponto de Vista Elementar 3.3 - Acessibilidade no desembarque}

O PVE 3.3 - Acessibilidade no desembarque é decomposto em dois Subpontos de Vista Elementares: 3.3.1 - Parada correta no ponto de desembarque; e 3.3.2 - Tempo de parada adequado para o desembarque. Nesse PVE o objetivo principal é avaliar a acessibilidade para desembarque do ônibus relacionados a posição do veículo em relação a parada, não ficando muito a frente ou muito atrás do local de desembarque, e o tempo de permanência para desembarque, ou seja, se o tempo era suficiente, curto ou longo.

\section{PVF 4 - COMUNICAÇÃO}

O PVF 4 - Comunicação é composto dos PVE: 4.1 - Informações nos terminais; 4.2 Informações nas paradas; 4.3 - Informações nos ônibus; 4.4 - Informações na internet; e 4.5 Serviço de atendimento ao cliente. O objetivo da avaliação deste item é verificar o impacto que a comunicação da empresa com os usuários tem na qualidade do serviço prestado sob a ótica do tomador. 


\section{Ponto de Vista Elementar 4.1 - Informações nos terminais}

O PVE 4.1 - Informações nos terminais é decomposto em quatro Subpontos de Vista Elementares: 4.1.1 - Sinalização horizontal para filas; 4.1.2 - Identificação do local de saída dos ônibus; 4.1.3 - Sinalização vertical das linhas; e 4.1.4 - Panfletos informativos. Nesse PVE o objetivo principal é avaliar a comunicação que a empresa prestadora do serviço semiurbano mantém nos terminais de embarque e desembarque, analisando itens como a sinalização para formação das filas de espera, indicação do local correto dos ônibus, indicação por meio de totens das linhas que partem de determinada baia nos terminais, além da distribuição de panfletos com informações diversas sobre a empresa e as linhas por ela operadas.

\section{Ponto de Vista Elementar 4.2 - Informações nas paradas}

O PVE 4.2 - Informações nas paradas é decomposto em três Subpontos de Vista Elementares: 4.2.1 - Informações das linhas que passam na parada; 4.2.2 - Informações dos intervalos médios entre os ônibus; e 4.2.3 - Informações sobre os canais de acesso à informações. Nesse PVE o objetivo principal foi obter do usuário a avaliação da comunicação que a empresa pesquisada mantém nos pontos de parada ao longo dos itinerários das linhas que estas operam, tais como quais as linhas que passam pelas paradas e os intervalos médios dos ônibus além de disponibilizar os canais de informações que os usuários podem utilizar para dirimir duvidam e obter informações.

\section{Ponto de Vista Elementar 4.3 - Informações nos ônibus}

O PVE 4.3 - Informações nos ônibus é decomposto em três Subpontos de Vista Elementares: 4.3.1 - Letreiros com informações claras da linha; 4.3.2 - Avisos sonoros; e 4.3.3 - Avisos de solicitação de parada. Nesse PVE o objetivo principal é avaliar a comunicação que a empresa mantém com os usuários durante a prestação do serviço a bordo dos ônibus, assim, o usuário avaliou as informações dos letreiros dos ônibus, os avisos sonoros dados no interior do ônibus e os avisos de solicitação de parada. 


\section{Ponto de Vista Elementar 4.4 - Informações na internet}

O PVE 4.4 - Informações na internet é decomposto em cinco Subpontos de Vista Elementares: 4.4.1 - Mapas de horários; 4.4.2 - Valor das tarifas; 4.4.3 - Divulgação dos itinerários das linhas; 4.4.4 - Formas de pagamento das tarifas; e 4.4.5 - Informações sobre os canais de acesso à informações. Nesse PVE o objetivo principal é avaliar a comunicação que a empresa pesquisada mantém por meio de seu sitio eletrônico, analisando itens como a disponibilização de mapas de horários, valor das tarifas, itinerários das linhas, formas de pagamento das tarifas e os canais de informações à disposição para que os usuários entrem em contato com a empresa.

\section{Ponto de Vista Elementar 4.5 - Serviço de atendimento ao cliente}

O PVE 4.5 - Serviço de atendimento ao cliente é decomposto em quatro Subpontos de Vista Elementares: 4.5.1 - Informações sobre tarifas; 4.5.2 - Informações de horários; 4.5.3 Registro de reclamações; e 4.5.4 - Informações sobre os canais de acesso à informações. Nesse PVE o objetivo principal é avaliar o sistema de atendimento ao Cliente - SAC, analisando os registros de reclamações, informações sobre tarifas e horários, além de informar quais os canais onde podem ser obtidas outras informações.

\section{PVF 5 - CONFORTO}

O PVF 5 - Conforto é decomposto em cinco PVE: 5.1 - Atualidade da frota (idade da frota); 5.2 - Espaço entre os bancos (espaço entre os bancos dos ônibus que operam as linhas da empresa); 5.3 - Espaço no corredor; 5.4 - Lotação (lotação dos ônibus durante as viagens, desconforto causado pela superlotação); 5.5 - Ventilação (ventilação no interior dos ônibus durante as viagens); e 5.6 - Temperatura no interior do ônibus (temperatura no interior dos ônibus durante a prestação do serviço). O objetivo da avaliação deste item é verificar a percepção de conforto dos usuários no serviço prestado. 


\section{PVF 6 - CUSTO}

O PVF 6 - Custo não foi decomposto, dessa forma, sua avaliação será dada diretamente pelo Nível de impacto onde se encontra a mediana. O objetivo deste PVF é verificar se o preço cobrado pelo serviço estava de acordo com a qualidade da contraprestação.

\section{PVF 7 - COMPORTAMENTO DOS OPERADORES}

O PVF 7 - Comportamento dos operadores é composto dos PVE: 7.1 - Treinamento de pessoal; 7.2 - Jornada de trabalho; e 7.3 - Cortesia. O objetivo da avaliação deste item é verificar a percepção que os usuários têm do fator humano na prestação do serviço, desde a operação dos ônibus durante as viagens e a rotatividade da tripulação, passando pela jornada de trabalho, culminando na cortesia ao atender solicitações dos usuários.

\section{Ponto de Vista Elementar 7.1 - Treinamento de pessoal}

O PVE 7.1 - Treinamento de pessoal é decomposto em dois Subpontos de Vista Elementares: 7.1.1 - Parada fora de pontos de parada/terminais; e 7.1.2 - Troca constante de tripulação. Nesse PVE o objetivo principal é colher a opinião do usuário sobre a habilidade dos motoristas na condução dos ônibus, bem como a percepção que tem com a troca da tripulação de tempos em tempos ("rodizio" de tripulação).

\section{Ponto de Vista Elementar 7.2 - Jornada de trabalho}

O PVE 7.2 - Jornada de trabalho é decomposto em dois Subpontos de Vista Elementares: 7.2.1 - Tripulação com aparência de cansada; e 7.2.2 - Tripulação com alteração de comportamento. Nesse PVE o objetivo principal é colher a opinião do usuário sobre o impacto da jornada de trabalho na tripulação durante a prestação do serviço através do ânimo e variação de humos da tripulação durante as viagens. 


\section{Ponto de Vista Elementar 7.3 - Cortesia}

O PVE 7.3 - Cortesia é decomposto em dois Subpontos de Vista Elementares: 7.3.1 Tripulação Atende Pedidos de Informações; e 7.3.2 - Despachantes Orientam Formação de Filas. Nesse PVE o objetivo principal é colher a opinião do usuário sobre a cortesia dos funcionários durante a prestação do serviço, principalmente dos tripulantes durante a viagem e dos despachantes nos terminais.

Desta forma, foi possível construir a árvore de pontos de vista fundamentais apresentada na Figura 3.15 e avançar para a próxima etapa na estruturação do modelo multicritério, que é a criação dos critérios de avaliação. 


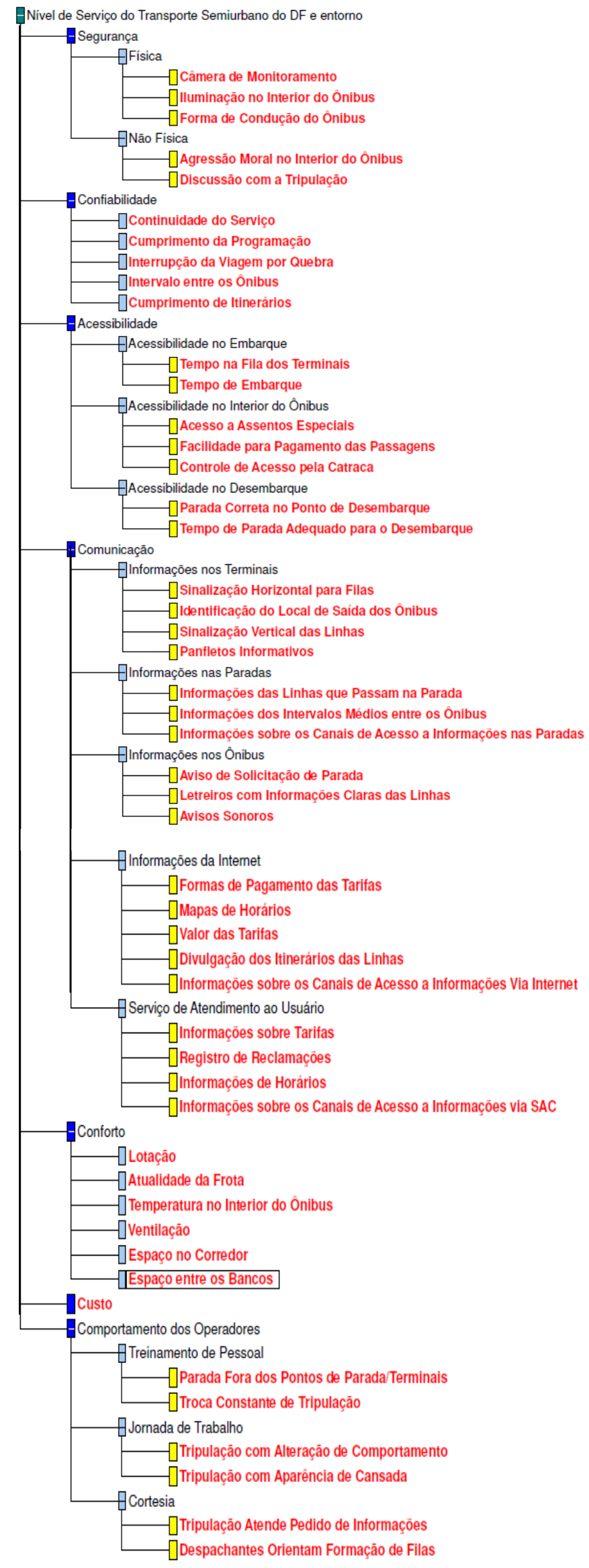

Figura 3-4 - Árvore dos pontos de vista fundamentais 


\subsubsection{CONSTRUÇÃO DE CRITÉRIOS DE AVALIAÇÃO}

Os critérios de avaliação permitem mensurar a performance de cada ação avaliada em cada ponto de vista. Para sua construção, utilizam-se duas ferramentas: um descritor e uma função de valor associada ao respectivo descritor (ENSSLIN et al., 2001).

\section{a) Descritores}

Bana e Costa (1992) definem descritor como um conjunto ordenado de níveis de impacto destinados a servir de base para descrever as performances plausíveis das ações potenciais em relação a cada PVF. O nível de impacto representa o desempenho que pode ser alcançado pela ação potencial e seu conjunto deve ter um significado claro para os atores e ser definido de forma clara, menos ambígua possível (ENSSLIN et al., 2001).

A construção de um descritor adequado deve ser feita com cuidado, além de exigir uma grande interação entre o facilitador e os decisores. Kenney (1992) classificou os descritores em três tipos: direto, indireto e construído. Os descritores podem ainda ser classificados em quantitativo ou qualitativo, e contínuo ou discreto (ENSSLIN et al., 2001).

Para que um descritor operacionalize um PVF de forma adequada é necessário que seja atendida uma exigência básica: que ele seja o mínimo possível ambíguo. Um descritor é considerado não ambíguo quando seus níveis de impacto têm um significado claro aos atores do processo decisório.

Kenney (1992) descreveu três propriedades desejáveis para os descritores, todas elas podem ser afetadas pelo problema da ambiguidade: mensurabilidade, operacionalidade e compreensibilidade.

$\mathrm{Na}$ construção do modelo multicritério para classificação das empresas de serviços de transporte semiurbano de passageiros foram construídos quarenta e nove descritores qualitativos apresentados no Quadro 3.2. Este número de descritores foi obtido utilizando a lógica da decomposição dos PVF em PVE e sub PVE para melhorar a mensuração desses PVF. 


\begin{tabular}{|c|c|}
\hline \multicolumn{2}{|c|}{ DESCRITORES } \\
\hline 1.1.1 Câmera de Monitoramento & 4.3.2 Avisos Sonoros \\
\hline 1.1.2 Ihuminação no Interior do Ônibus & 4.3.3 Avisos de Solicitação de Parada \\
\hline 1.1.3 Forma de Condução do Ônibus & 4.4.1 Mapas de Horários \\
\hline 1.2.1 Agressão Moral no Interior do Ônibus & 4.4.2 Valor das Tarifas \\
\hline 1.2.2 Discussão com a Tripulação & 4.4.3 Divulgação dos Itinerários das Limhas \\
\hline 2.1 Continuidade do Serviço & 4.4.4 Forma de Pagamento das Tarifas \\
\hline 2.2. Cumprimento da Programação & $\begin{array}{l}\text { 4.4.5 Informações dos Canais de Acesso a Informações } \\
\text { na Internet }\end{array}$ \\
\hline 2.3 Cumprimento de Itinerários & 4.5.1 Informações sobre Tarifas \\
\hline 2.4 Intervalo entre Ônibus & 4.5.2 Informações de Horários \\
\hline 2.5 Interrupção de Viagem por Quebra & $\begin{array}{l}\text { 4nformações dos Canais de Acesso a Informações } \\
\text { Via SAC }\end{array}$ \\
\hline 3.1.1 Tempo nas Filas dos Terminais & 4.5.4 Registro de Reclamações \\
\hline 3.1.2 Tempo de Embarque & 5.1 Atualidade da Frota \\
\hline 3.2.1 Acesso a Assentos Especiais & 5.2 Espaço entre os Bancos \\
\hline 3.2.2 Facilidade para o Pagamento das Passagens & 5.3 Espaço no Corredor \\
\hline 3.2.3 Controle de Acesso pela Catraca & 5.4 Lotação \\
\hline 3.3.1 Parada Correta no Ponto de Desembarque & 5.5 Ventilação \\
\hline 3.3.2 Tempo de Parada Adequado para o Desembarque & 5.6 Temperatura no Interior do Ônibus \\
\hline 4.1.1 Indicação do Local de Saída do Ônibus & 6 Custo \\
\hline 4.1.2 Sinalização Horizontal para F ilas & 7.1.1 Parada fora dos Pontos de Parada/Terminais \\
\hline 4.1.3 Sinalização Vertical das Linhas & 7.1.2 Troca Constante de Tripulação \\
\hline 4.1.4 Panfletos Informativos & 7.2.1 Tripulação com Aparência de Cansada \\
\hline 4.2.1 Informações das Linhas que Passam na Parada & 7.2.2 Tripulação com Alteração de Comportamento \\
\hline 4.2.2 Informações dos Intervalos Médios entre os Ônibus & 7.3.1 Trípulação Atende Pedidos de Informações \\
\hline 4.2.3 Divulgação dos Canais de Acesso a Informações & 7.3.2 Despachantes Orientam Formação de Filas \\
\hline 4.3.1 Letreiros com Informações Claras das Linhas & 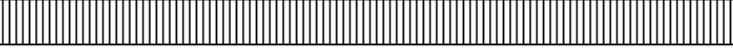 \\
\hline
\end{tabular}

Quadro 3-2 - Descritores

A Figura 3.16 apresenta, a título de exemplo, o Descritor do PVE 1.1.1 - câmera de monitoramento, com seus níveis de impacto e suas descrições. Os demais descritores possuem os mesmos níveis de impacto e descrições.

\section{Descritor do PVE 1.1.1 Câmera de Monitoramento}

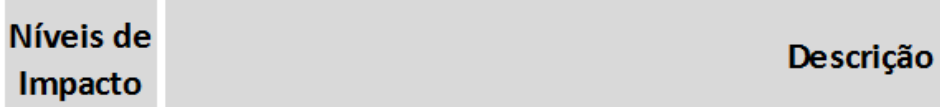

A O usuário está plenamente satisfeito com a qualidade do serviço prestado pela empresa

B O usuário está satisfeito com a qualidade do serviço prestado pela empresa

C O usuário está indiferente a qualidade do serviço prestado pela empresa

D O usuário está insatisfeito com a qualidade do serviço prestado pela empre sa

E O usuário está Plenamente Insatisfeito com a qualidade do serviço prestado pela empresa

Figura 3-5 - Exemplo de um Descritor completo 
Após a construção dos descritores, foram definidos, para cada um deles, dois níveis de impacto de referência, o Nível de Impacto Bom e o Nível de Impacto Neutro. Esses níveis são importantes para os procedimentos de verificação da independência preferencial e, principalmente, para a determinação das taxas de substituição (ENSSLIN et al., 2001).

A definição dos níveis "bom" e "neutro" contribui para um melhor entendimento do ponto de vista que está sendo avaliado na medida em que torna mais claro, no processo decisório, identificar quais ações são atrativas e quais não são. Consideram-se ações atrativas aquelas com desempenho acima do nível neutro e ações não atrativas aquelas com desempenho abaixo deste nível. As ações que se encontram no nível bom, são aquelas que têm uma performance acima das expectativas dos decisores.

Esses níveis de impacto podem ser utilizados para que se reconheçam as ações com performance à nível de excelência, ou seja, aquelas que apresentam um desempenho acima do nível bom, já as ações com desempenho no intervalo entre o nível neutro e o nível bom, são consideradas ações de performance competitiva. Porém, se o desempenho da ação está abaixo do nível neutro, ela é considerada uma ação com performance comprometedora (ENSSLIN et al., 2001).

A importância da definição dos níveis de impacto "bom" e "neutro" é que a partir deles será possível para os decisores criar incentivos para as empresas que tenham desempenho acima do nível bom e aplicar medidas corretivas para aquelas empresas que apresentarem desempenho abaixo do nível neutro. Os decisores escolheram como níveis de referência o nível B, como nível bom, e o nível D, como nível neutro, conforme mostra a Figura 3.17.

\begin{tabular}{|c|c|c|}
\hline \multicolumn{3}{|r|}{ Descritor do PVE 1.1.1 Câmera de Monitoramento } \\
\hline $\begin{array}{l}\text { Níveis de } \\
\text { Impacto }\end{array}$ & $\begin{array}{l}\text { Níveis de } \\
\text { Referência }\end{array}$ & Descrição \\
\hline A & & O usuário está plenamente satisfeito com a qualidade do serviço prestado pela empresa \\
\hline B & Bom & O usuário está satisfeito com a qualidade do serviço prestado pela empresa \\
\hline C & & O usuário está indiferente a qualidade do serviço prestado pela empresa \\
\hline D & Neutro & O usuário está insatisfeito com a qualidade do serviço prestado pela empresa \\
\hline $\mathrm{E}$ & & O usuário está Plenamente Insatisfeito com a qualidade do serviço prestado pela empresa \\
\hline
\end{tabular}

Figura 3-6 - Descritor com níveis de referência 
Após a construção dos descritores, que definiram como serão julgadas as ações potenciais em cada Ponto de Vista, o próximo passo para a estruturação do modelo multicritério foi quantificar as performances das ações de acordo com os valores dos decisores. Para esta quantificação é necessária a construção das funções de valor que são um instrumento para auxiliar os decisores a expressar, de forma numérica, suas preferências (ENSSLIN et al., 2001).

b) Funções de Valor

As funções de valor auxiliam os decisores a expressarem numericamente suas preferências, devendo, desta forma, ser construídas para um decisor, ou grupo de decisores, com objetivo de avaliar as ações segundo um determinado ponto de vista (ENSSLIN et al.,2001).

Neste trabalho a função de valor foi obtida utilizando o Método do Julgamento Semântico MACBETH (Measuring Attractiveness by a Categorical Based Evaluation Technique), que consiste em comparar par a par a diferença de atratividade entre as ações potenciais (Beinat, 1995). O MACBETH utiliza os julgamentos semânticos dos decisores para, através de Programação Linear (Wagner, 1986) determinar a função de valor que melhor represente tais julgamentos.

Ao utilizar o MACBETH, o decisor expressa verbalmente a diferença de atratividade entre duas ações potenciais a e b. Considerando a mais atrativa que $b$, escolhe uma das seguintes categorias semânticas:

$\mathrm{C} 0$ - nenhuma diferença de atratividade (indiferença)

$\mathrm{C} 1$ - diferença de atratividade muito fraca

$\mathrm{C} 2$ - diferença de atratividade fraca

C3 - diferença de atratividade moderada

$\mathrm{C} 4$ - diferença de atratividade forte

C5 - diferença de atratividade muito forte

C6 - diferença de atratividade extrema

Neste trabalho, a cada um dos descritores foi associada uma função de valor. Assim, considera-se construído um critério de avaliação para cada eixo de avaliação. A Figura 3.18 
apresenta a matriz de julgamento semântico do descritor custo e sua respectiva função de valor geradas no Software M-MACBETH.

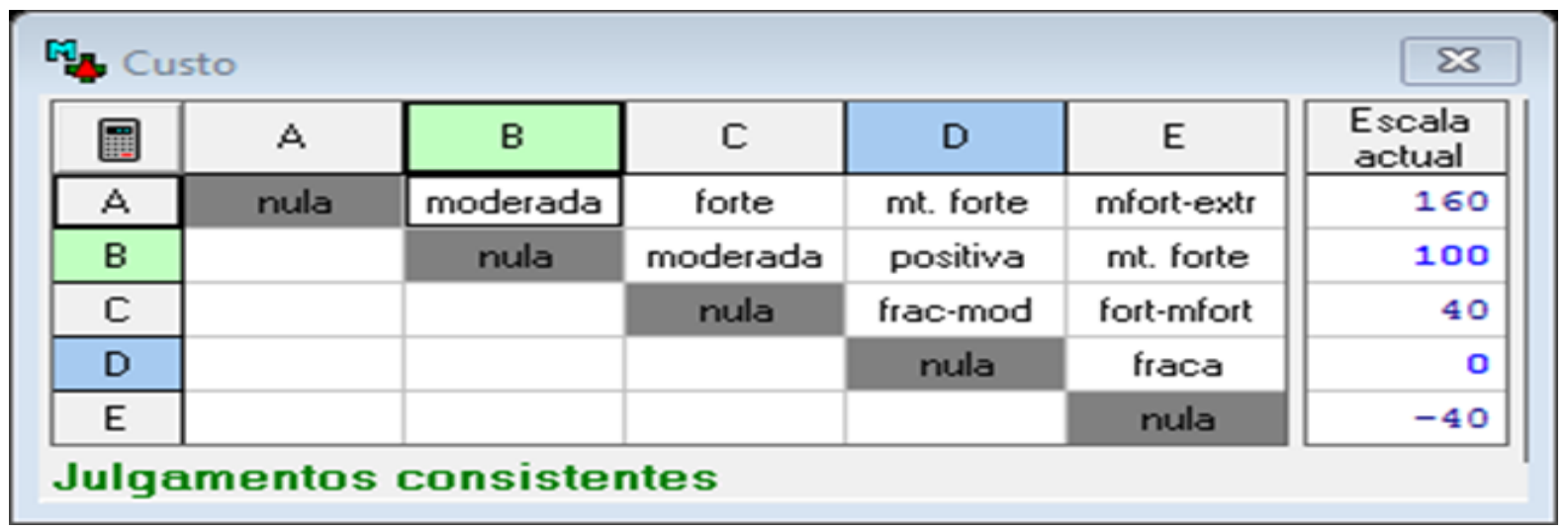

Figura 3-7 - Matriz de Julgamento Semântico e Função de Valor do Descritor Custo

Após a definição dos critérios de avaliação, é possível realizar a avaliação local das ações potenciais, porém, será necessária a agregação destas informações locais para obtenção da avaliação global. Para realizar esta agregação, é necessário um conjunto de parâmetros associados aos critérios: suas taxas de substituição.

\subsubsection{TAXAS DE SUBSTITUIÇÃO}

Segundo Ensslin et al. (2001), as taxas de substituição, também conhecidas como pesos, são parâmetros que os decisores julgam adequados para agregar, de forma compensatória, desempenhos locais (nos critérios) em uma performance global.

As Taxas de substituição de um modelo multicritério expressam, à luz da preferência do decisor, a perda de performance que uma ação potencial deve sofrer em um critério para compensar o ganho de desempenho em outro (BOUYSSOU, 1986; KEENEY, 1992; KEENEY e RAIFFA, 1993; ROY, 1996). Elas são também chamadas de trade-offs, taxas de compensação e constantes de escala. Vulgarmente, e na literatura inglesa, são também conhecidas como "pesos” (weights) (ENSSLIN et al., 2001).

Ao utilizar uma abordagem construtivista, não se considera a existência de taxas de substituição "verdadeiras", ou seja, que represente uma realidade existente na cabeça do 
decisor. Na verdade, as taxas de substituição expressam o julgamento do decisor em um determinado momento sobre as importâncias dos pontos de vista (ENSSLIN et al., 2001; QUIRINO, 2002).

Existem na literatura diversos métodos para determinar as taxas de substituição. Por exemplo, Ensslin et al. (2001) citam três deles: Trade-Off, Swing Weights e Comparação par a par. Neste trabalho foi utilizado o método Swing Weights (Pesos Balanceados). A escolha deste método foi uma opção dos decisores, depois de terem sido apresentados os demais métodos citados, por entenderem ser mais prático para determinação das taxas de substituição do modelo.

Para isso, os seguintes passos devem ser seguidos:

$1^{\circ}$ ) ordenar os PVF por níveis;

$2^{\circ}$ ) atribuir pontos para cada PVF; e

$\left.3^{\circ}\right)$ normalizar os valores atribuídos.

Para ordenação dos PVF pode ser utilizada a Matriz de Ordenação - Roberts, segundo o juízo de valor dos decisores ou os próprios decisores podem ordenar arbitrariamente os critérios (QUIRINO, 2002).

Na construção do modelo multicritério, os decisores primeiro ordenaram os PVF em ordem decrescente segundo o que julgam mais relevante. Em seguida, foram atribuídos pontos para cada PVF, partindo do mais importante, que recebeu 100 pontos. Após a atribuição dos pontos, foi realizada a normalização dos valores, que consistiu em relativizar a participação de cada PVF em relação ao somatório de pontos dos PVF.

Para cada desmembramento dos PVF e PVE este procedimento foi repetido. O Quadro 3-3 apresenta as taxas de substituição encontradas. 


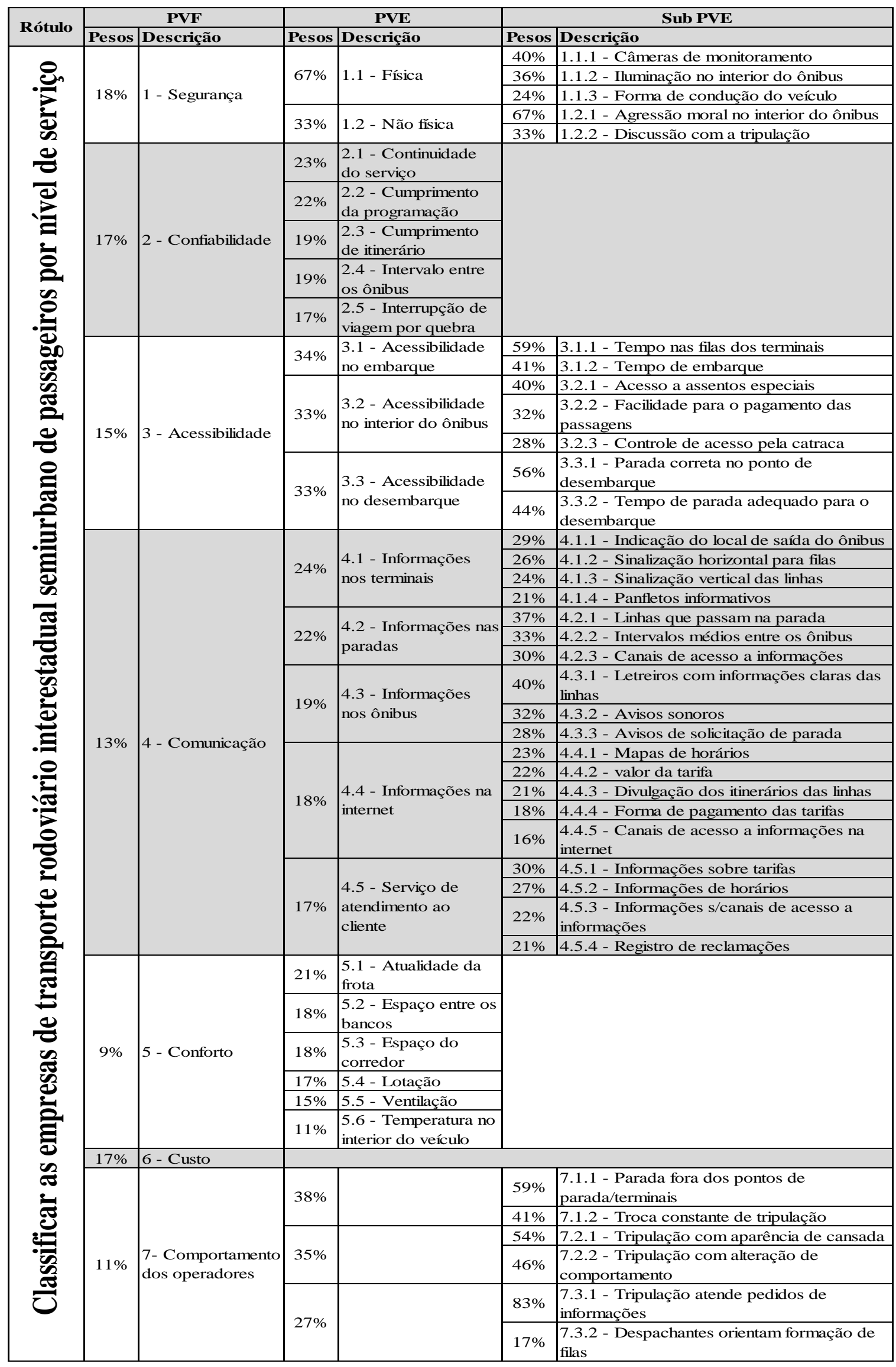

Quadro 3-3 - Taxas de Substituição do modelo 


\subsection{MODELO MULTICRITÉRIO PARA AVALIAÇÃO DO NÍVEL DE SERVIÇO}

A partir da avaliação global do modelo, Figura 3-4, criado pelos atores intervenientes, foram estabelecidos quatro níveis de serviço para classificar as empresas de transporte semiurbano de passageiros do DF e dos municípios de seu entorno:

\begin{tabular}{|c|c|c|}
\hline \multicolumn{3}{|c|}{ Avaliação Global } \\
\hline $\begin{array}{c}\text { Níveis de } \\
\text { Impacto }\end{array}$ & $\begin{array}{c}\text { Níveis de } \\
\text { Referência }\end{array}$ & $\begin{array}{c}\text { Função de } \\
\text { Valor }\end{array}$ \\
\hline N5 & & 147,16 \\
\hline N4 & Bom & 100 \\
\hline N3 & & 48,55 \\
\hline N2 & Neutro & 0 \\
\hline N1 & & $-40,57$ \\
\hline
\end{tabular}

Quadro 3-4 - Avaliação Global do modelo

- Nível A - este é o nível de excelência de prestação do serviço. Para as empresas serem classificadas neste nível precisam obter entre 100 e 147,16 pontos na avaliação global;

- Nível B - este é o nível competitivo superior de prestação do serviço. Para as empresas serem classificadas precisam obter entre 48,55 e 100,00 pontos na avaliação global;

- Nível C - este é o nível competitivo inferior de prestação do serviço. Para as empresas serem classificadas precisam obter entre 0 (zero) e 48,55 pontos na avaliação global;

- Nível D - este é o nível comprometedor de prestação do serviço. Para as empresas serem classificadas precisam obter entre - 40,57 e 0,00 pontos na avaliação global; e

Para calcular a pontuação da empresa avaliada, utiliza-se a fórmula de agregação aditiva que é formada pela soma dos modelos de cada PVF. Assim, a fórmula será (ENSSLIN et al., 2001): 
Onde:

$\mathrm{V}(\mathrm{a}) \rightarrow$ Valor da pontuação obtida pela empresa $\mathbf{a}$.

$\mathrm{v}_{1}(\mathrm{a}), \mathrm{v}_{2}(\mathrm{a}), \ldots \mathrm{v}_{\mathrm{n}}$ (a) $\rightarrow$ Valor parcial da empresa a nos critérios $1,2, \ldots, \mathrm{n}$.

$\mathrm{w}_{1}(\mathrm{a}), \mathrm{w}_{2}(\mathrm{a}), \ldots \mathrm{w}_{\mathrm{n}}(\mathrm{a}) \rightarrow$ Taxas de substituição dos critérios $1,2, \ldots, \mathrm{n}$.

$\mathrm{n} \rightarrow$ número de critérios do modelo.

Na Figura 3.20, onde são representados os níveis de serviço e suas respectivas pontuações, é possível verificar que o nível A representa a prestação de serviço de excelência porque apresenta desempenho acima do nível de referência "Bom", os níveis B e C representam serviços competitivos, pois estão localizados entre os níveis de referência "Bom" e "Neutro", e o nível D representa a prestação de serviço comprometedora, porque apresenta desempenho abaixo do nível de referência "Neutro" (ENSSLIN, 2001).

\begin{tabular}{|c|c|c|}
\hline Nível A & $147,16<x>100,00$ & Excelência \\
\hline Nível B & $48,55<x>100,00$ & \multirow{2}{*}{ Competitivo } \\
\cline { 1 - 2 } Nível C & $0,00<x>48,55$ & \\
\hline Nível D & $-40,57<x>0,00$ & Comprometedor \\
\hline
\end{tabular}

Figura 3-8 - Níveis de Serviço para classificar as empresas do Semiurbano do DF

No próximo capítulo serão analisados os resultados do estudo de caso realizado para testar a aplicabilidade do modelo multicritério em uma empresa prestadora de serviço de transporte rodoviário semiurbano de passageiros do Distrito Federal (DF). 


\section{ANÁLISES E DISCUSSÕES}

A partir deste ponto serão apresentados os resultados encontrados na aplicação da metodologia desenvolvida e dos dados obtidos na pesquisa de campo. Nele será realizada a avaliação da empresa, que se constitui no quarto passo da Metodologia Multicritério de Apoio à Decisão - Construtivista (MCDA-C). Desta forma, foram realizadas a avaliação local da empresa, traçado o perfil de impacto, realizada a avaliação parcial e por fim, a avaliação global da empresa.

\subsection{AVALIAÇÃO LOCAL}

A avaliação local identifica qual o desempenho da empresa em cada um dos critérios e subcritérios do modelo, ou seja, nos PVF, PVE e Sub PVE. O processo consiste em identificar, na tabela que representa o descritor e sua função de valor, o nível que melhor representa o desempenho da empresa avaliada. Como os critérios do modelo foram mensurados por descritores quantitativos, a avaliação é realizada a partir do nível que melhor represente o desempenho da ação potencial que está sendo avaliada (ENSSLIN et al., 2001). O Apêndice B contém os descritores e as respectivas funções de valor utilizadas para determinar os níveis de impacto de cada critério de avaliação.

\subsubsection{AVALIAÇÃO DOS COMPONENTES DO PVF 1 - SEGURANÇA}

a) Ponto de vista elementar 1.1 - segurança física

A partir das medianas foi possível determinar os níveis de impacto desses sub PVE. Dessa forma, no sub PVE 1.1.1 - câmera de monitoramento a posição da mediana correspondia ao nível de impacto N2, cujo valor na função de valor é 0 (zero), indicando que o usuário está insatisfeito com este item. No sub PVE 1.1.2 - iluminação no interior do veículo, a posição da mediana correspondia ao nível de impacto N4, cujo valor na função de valor é 100 (cem), mostrando que o usuário está satisfeito com a iluminação no interior dos ônibus da empresa avaliada. Finalmente, no sub PVE 1.1.3 - forma de condução do ônibus, a posição da mediana correspondia ao nível de impacto N3, cujo valor na função de valor é 50 (cinquenta), 
indicando que os usuários se mostram indiferentes a forma como os motoristas conduzem os ônibus durante a prestação do serviço. A representação gráfica da avaliação deste PVE é apresentada na Figura 4.1. Assim, aplicando a fórmula de agregação aditiva, foi possível calcular a pontuação do PVE 1.1 - segurança física, que totalizou 56 pontos.

$$
\begin{aligned}
& \mathrm{V}(1.1)=\mathrm{w}(1.1 .1) \times \mathrm{v}(1.1 .1)+\mathrm{w}(1.1 .2) \times \mathrm{v}(1.1 .2)+\mathrm{w}(1.1 .3) \times \mathrm{v}(1.1 .3) \\
& \mathrm{V}(1.1)=(0,24 \times 0)+(0,36 \times 100)+(0,40 \times 50) \\
& \mathbf{V}(\mathbf{1 . 1})=\mathbf{5 6}
\end{aligned}
$$

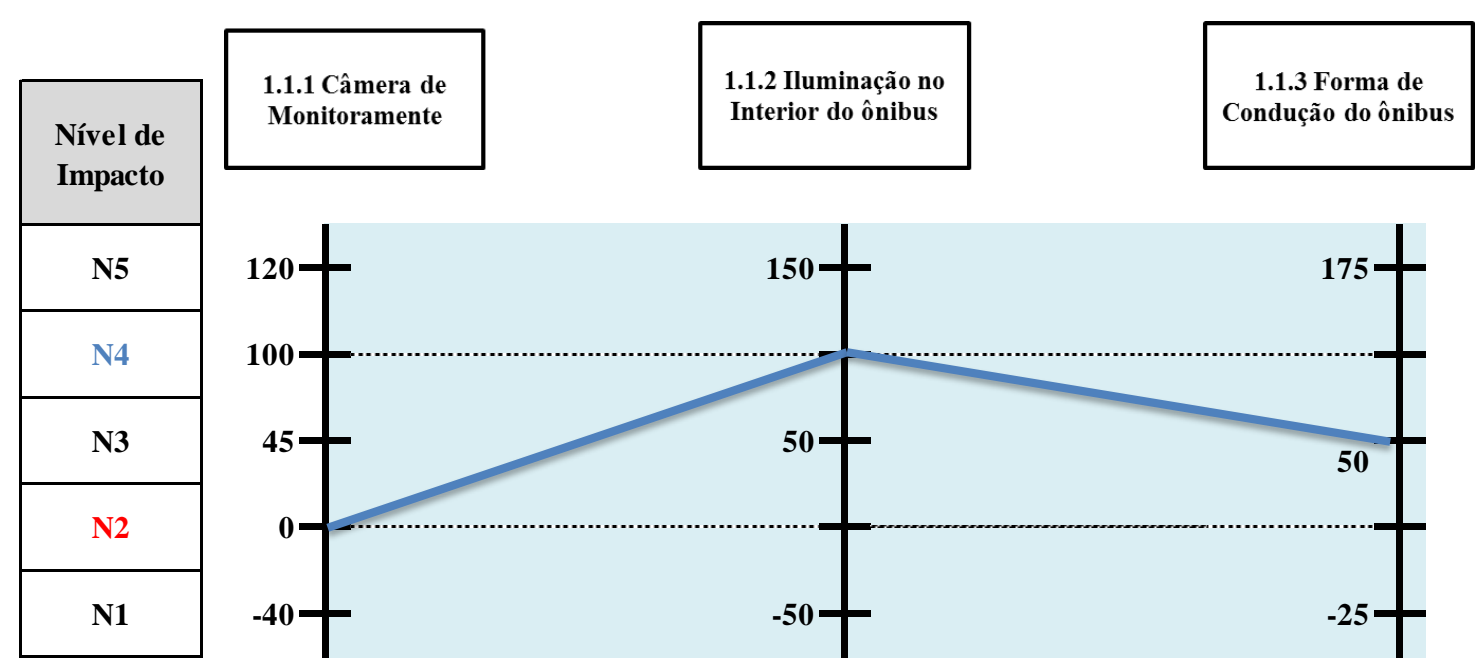

Figura 4-1 - Desempenho dos sub PVE componentes do PVE 1.1 - segurança física

b) Ponto de vista elementar 1.2 - segurança não física

Assim como no PVE 1.1 - segurança física, foram determinados os níveis de impacto dos sub PVE componentes do PVE 1.2 - segurança não física. Dessa forma, no sub PVE 1.2.1 agressão moral no interior do ônibus a posição da mediana correspondia ao nível de impacto N3, cujo valor correspondente na função de valor é 45 (quarenta e cinco), indicando que os usuários estão indiferentes a este aspecto, ou por não presenciarem com frequência esta situação, ou por não terem sido vitimas dela. No sub PVE 1.2.2 - discussão com a tripulação, a posição da mediana também correspondia ao nível de impacto N3, cujo valor na função de valor é 40 (quarenta), o comentário no item anterior se aplica aqui também. Assim, a representação gráfica da avaliação deste PVE é apresentado na Figura 4.2. Com a utilização 
da fórmula de agregação aditiva, foi possível calcular a pontuação do PVE 1.2 - segurança não física, que totalizou 43,35 pontos.

$$
\begin{aligned}
& \mathrm{V}(1.2)=\mathrm{w}(1.2 .1) \times \mathrm{v}(1.2 .1)+\mathrm{w}(1.2 .2) \times \mathrm{v}(1.2 .2) \\
& \mathrm{V}(1.2)=(0,67 \times 45)+(0,33 \times 40) \\
& \mathrm{V}(\mathbf{1 . 2})=\mathbf{4 3 3}, \mathbf{3 5}
\end{aligned}
$$

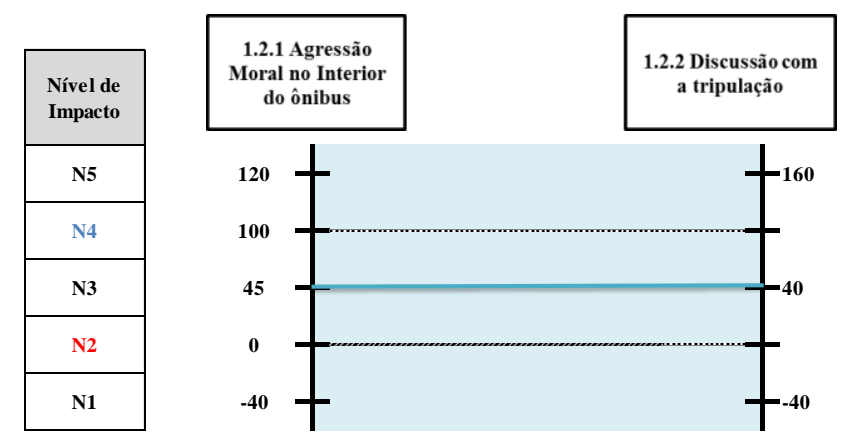

Figura 4-2 - Desempenho dos sub PVE componentes do PVE 1.2 - segurança não física

\subsubsection{AVALIAÇÃO DOS COMPONENTES DO PVF 2 - CONFIABILIDADE}

No PVE 2.1 - continuidade do serviço a posição da mediana correspondia ao nível de impacto N3, cujo valor na função de valor é 50 (cinquenta), indicando que o usuário está indiferente a este aspecto. Essa indiferença pode ser consequência do fato das linhas existentes não sofrerem cancelamentos, muito pelo contrário, com o crescimento populacional do entorno do Distrito Federal e o surgimento de novos bairros, existe a criação de novas linhas para atender as novas demandas. No PVE 2.2 - cumprimento da programação, a posição da mediana correspondia ao nível de impacto N2, cujo valor na função de valor é 0 (zero), mostrando que o usuário está insatisfeito com o cumprimento da programação. Alguns inclusive disseram desconhecer a existência de uma programação a ser cumprida pela empresa. Este aspecto está mais ligado ao PVF 4 - comunicação que será tratado mais a frente. No PVE 2.3 cumprimento de itinerários, a posição da mediana correspondia ao nível de impacto N4, cujo valor na função de valor é 100 (cem), indicando que os usuários se mostram satisfeitos com o serviço prestado em relação a este item, mostrando que os motoristas respeitam os itinerários das linhas operadas pela empresa. No PVE 2.4 - intervalo entre ônibus, a posição da mediana correspondia ao nível de impacto $\mathrm{N} 2$, cujo valor na função de valor é 0 (zero), indicando que 
os usuários se mostram insatisfeitos com o intervalo de saída dos ônibus da empresa pesquisada. Como existem linhas para diversos bairros nas cidades de destino, muitos usuários gostariam que esse espaço de tempo entre as saídas fosse menor. Por fim, no PVE 2.5 - interrupção de viagem por quebra, a posição da mediana correspondia ao nível de impacto N2, cujo valor na função de valor é 0 (zero), indicando uma insatisfação dos usuários com a frequência com que as viagens são interrompidas por quebra. Pela avaliação dos usuários, essas interrupções frequentes das viagens por quebra fazem com que não haja garantias de conclusão das viagens iniciadas.

A representação gráfica da avaliação deste PVE é apresentada na Figura 4.3. Assim, aplicando a fórmula de agregação aditiva, foi possível calcular a pontuação do PVF 2 confiabilidade, que totalizou 30,5 pontos.

$$
\begin{aligned}
& \mathrm{V}(2)=\mathrm{w}(2.1) \times \mathrm{v}(2.1)+\mathrm{w}(2.2) \times \mathrm{v}(2.2)+\mathrm{w}(2.3) \times \mathrm{v}(2.3)+\mathrm{w}(2.4) \times \mathrm{v}(2.4)+\mathrm{w}(2.5) \times \mathrm{v}(2.5) \\
& \mathrm{V}(2)=(0,23 \times 50)+(0,22 \times 0)+(0,19 \times 100)+(0,19 \times 0)+(0,17 \times 0) \\
& \mathbf{V}(\mathbf{2})=\mathbf{3 0 , 5}
\end{aligned}
$$

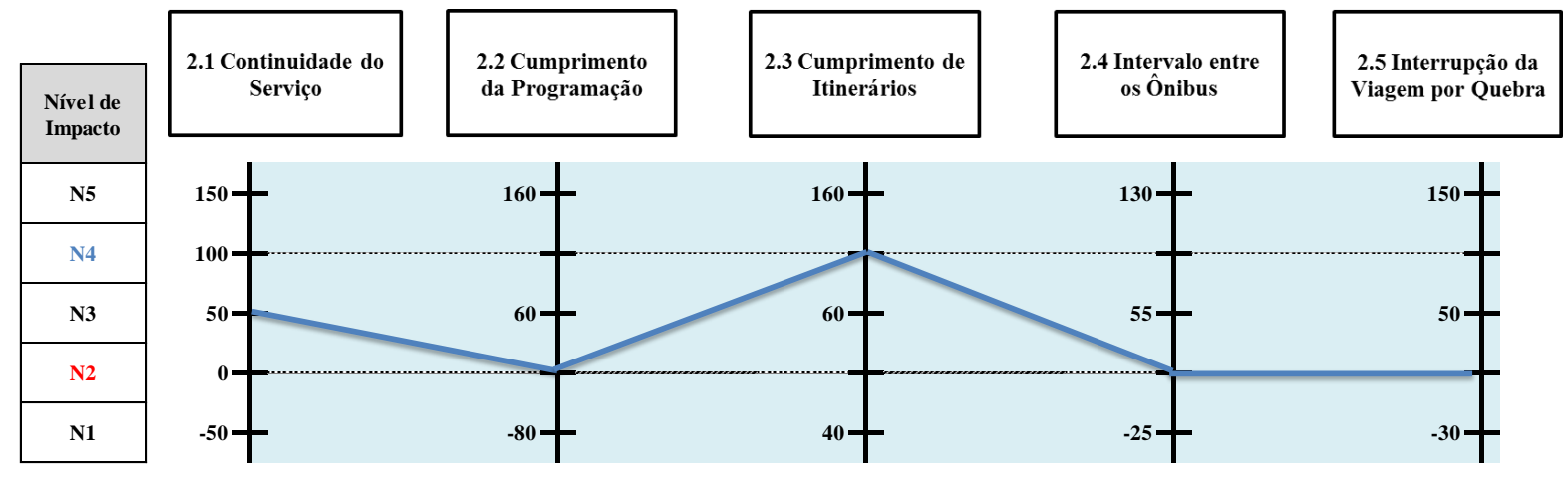

Figura 4-3 - Desempenho dos PVE componentes do PVF 2 - confiabilidade

\subsubsection{AVALIAÇÃO DOS COMPONENTES DO PVF 3 - ACESSIBILIDADE}

a) Ponto de vista elementar 3.1 - acessibilidade no embarque

Na avaliação deste PVE, o sub PVE 3.1.1 - tempo na fila dos terminais a posição da mediana correspondia ao nível de impacto N2, cujo valor na função de valor é 0 (zero), indicando que o usuário está insatisfeito com o tempo em que permanece na fila para ter acesso ao serviço. 
No sub PVE 3.1.2 - tempo de embarque, a posição da mediana também correspondia ao nível de impacto N2, cujo valor na função de valor é 0 (zero), mostrando que o usuário também está insatisfeito com o tempo que demora a embarcar no ônibus desde o momento da autorização. A representação gráfica da avaliação deste PVE é apresentada na Figura 4.4. Assim, aplicando a fórmula de agregação aditiva, foi possível calcular a pontuação do PVE 3.1 acessibilidade no embarque, que totalizou 0 (zero) pontos.

$\mathrm{V}(3.1)=\mathrm{w}(3.1 .1) \times \mathrm{v}(3.1 .1)+\mathrm{w}(3.1 .2) \times \mathrm{v}(3.1 .2)$

$\mathrm{V}(3.1)=(0,59 \times 0,00)+(0,41 \times 0,00)$

$\mathrm{V}(3.1)=0,00$

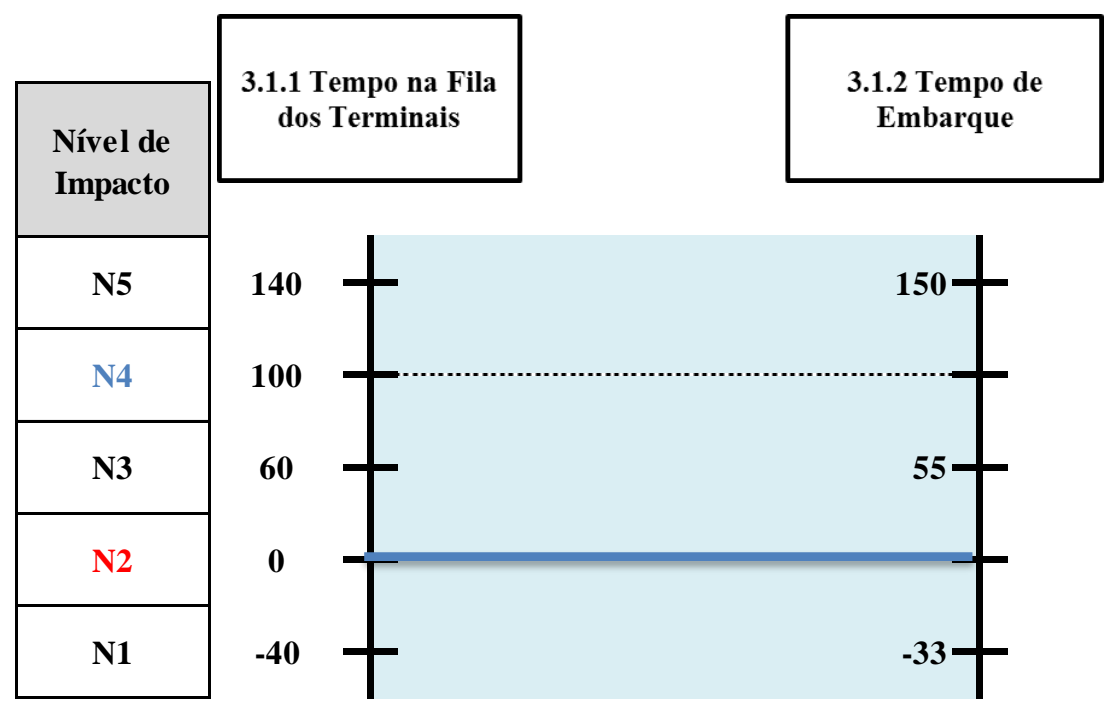

Figura 4-4 - Desempenho dos Sub PVE componentes do PVE 3.1 - acessibilidade no embarque

b) Ponto de vista elementar 3.2 - acessibilidade no interior do ônibus

Na avaliação do PVE 3.2, no sub PVE 3.2.1 - acesso a assentos especiais a posição da mediana correspondia ao nível de impacto N2, cujo valor na função de valor é 0 (zero), indicando que o usuário está insatisfeito com o controle que a empresa faz sobre o acesso aos acentos especiais. No sub PVE 3.2.2 - facilidade para pagamento das passagens, a posição da mediana correspondia ao nível de impacto N1, cujo valor na função de valor é -25 (vinte e cinco), mostrando que o usuário está plenamente insatisfeito com o procedimento da empresa no momento da cobrança da passagem. Por fim, o sub PVE 3.2.3 - controle de acesso pela 
catraca apresentou o melhor desempenho do PVE com a posição da mediana correspondendo ao nível de impacto N4, cujo valor na função de valor é 100 (cem), mostrando que os usuários estão satisfeitos com a facilidade que encontram para passar pela catraca. A representação gráfica da avaliação deste PVE é apresentada na Figura 4.5. Assim, aplicando a fórmula de agregação aditiva, foi possível calcular a pontuação do PVE 3.2 - acessibilidade no interior do ônibus, que totalizou 15,20 pontos.

$\mathrm{V}(3.2)=\mathrm{w}(3.2 .1) \times \mathrm{v}(3.2 .1)+\mathrm{w}(3.2 .2) \times \mathrm{v}(3.2 .2)+\mathrm{w}(3.2 .3) \times \mathrm{v}(3.2 .3)$

$\mathrm{V}(3.2)=(0,40 \times 0,00)+[0,32 \times(-40,00)]+(0,28 \times 100)$

$\mathrm{V}(3.2)=\mathbf{1 5 , 2 0}$

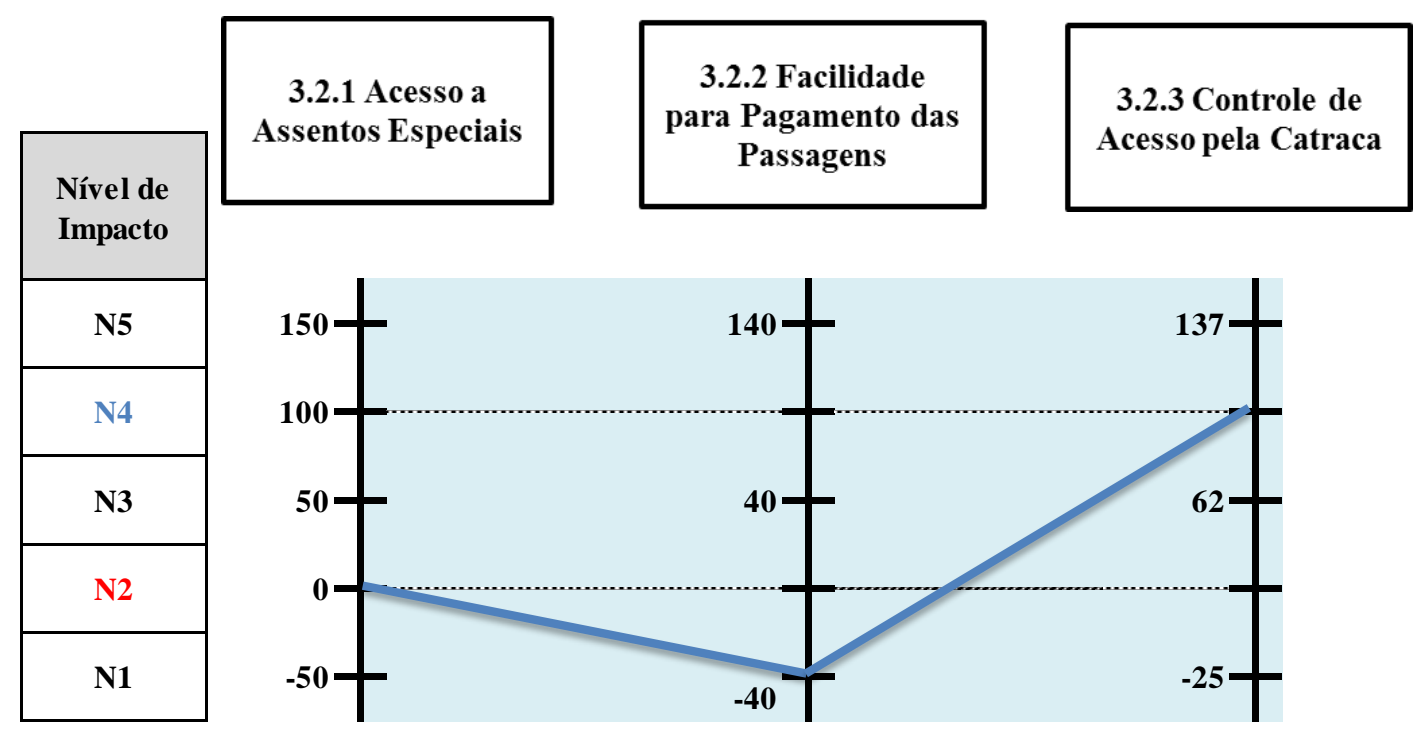

Figura 4-5 - Desempenho dos sub PVE componentes do PVE 3.2 - acessibilidade no interior do ônibus

c) Ponto de vista elementar 3.3 - acessibilidade no desembarque

No sub PVE 3.3.1 - parada correta no ponto de desembarque a posição da mediana correspondia ao nível de impacto N3, cujo valor na função de valor é 40 (quarenta), indicando que o usuário está indiferente a este aspecto do serviço. $\mathrm{O}$ mesmo posicionamento observouse quanto ao sub PVE 3.3.2 - tempo de parada adequado para o desembarque, a posição da mediana correspondia ao nível de impacto N3, cujo valor na função de valor é 50 (cinquenta). A representação gráfica da avaliação deste PVE é apresentada na Figura 4.6. Assim, 
aplicando a fórmula de agregação aditiva, foi possível calcular a pontuação do PVE 3.3 acessibilidade no desembarque, que totalizou 45,60 pontos.

$\mathrm{V}(3.3)=\mathrm{w}(3.3 .1) \times \mathrm{v}(3.3 .1)+\mathrm{w}(3.3 .2) \mathrm{x} \mathrm{v}(3.3 .2)$

$\mathrm{V}(3.2)=(0,56 \times 40,00)+(0,44 \times 50)$

$\mathrm{V}(3.2)=\mathbf{4 4 , 4 0}$

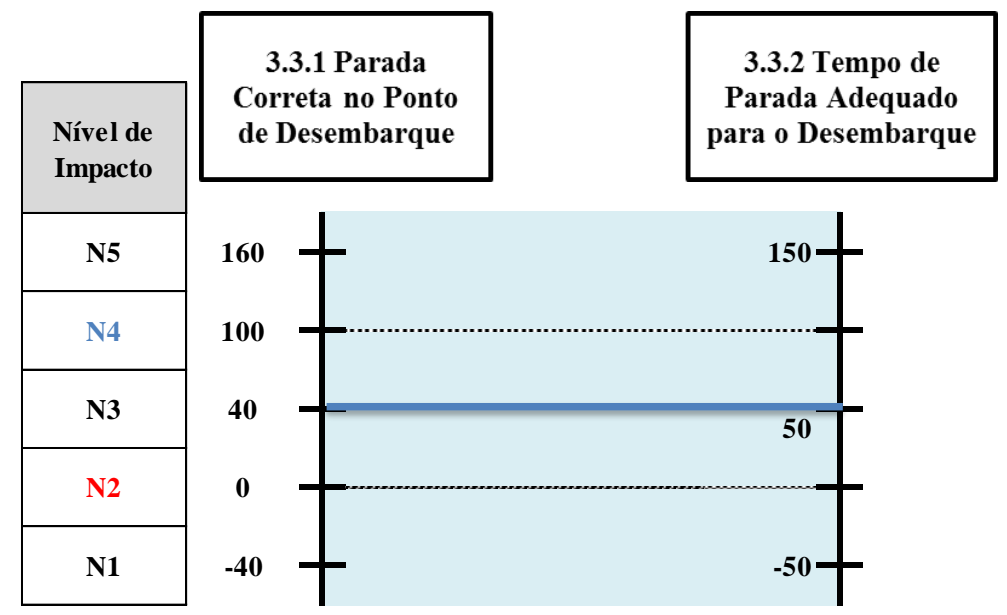

Figura 4-6 - Desempenho dos sub PVE componentes do PVE 3.3 - acessibilidade no desembarque

\subsubsection{AVALIAÇÃO DOS COMPONENTES DO PVF 4 - COMUNICAÇÃO}

a) Ponto de vista elementar 4.1 - informações nos terminais

No sub PVE 4.1.1 - sinalização horizontal para filas a posição da mediana correspondia ao nível de impacto N3, cujo valor na função de valor é 43 (quarenta e três), indicando que o usuário está satisfeito com as marcações no solo para formação das filas de espera. Porém, para os sub PVE 4.1.2 - identificação do local de saída dos ônibus, 4.1.3 - sinalização vertical das linhas e 4.1.4 - panfletos informativos, a posição da mediana correspondia ao nível de impacto N2, cujo valor na função de valor é 0 (zero), mostrando que o usuário está insatisfeito com estes aspectos da comunicação da empresa nos terminais de embarque. A representação gráfica da avaliação deste PVE é apresentada na Figura 4.7. Assim, aplicando a fórmula de agregação aditiva, foi possível calcular a pontuação do PVE 4.1 - informações nos terminais, que totalizou 11,18 pontos. 


$$
\begin{aligned}
& \mathrm{V}(4.1)=\mathrm{w}(4.1 .1) \times \mathrm{v}(4.1 .1)+\mathrm{w}(4.1 .2) \times \mathrm{v}(4.1 .2)+\mathrm{w}(4.1 .3) \times \mathrm{v}(4.1 .3)+\mathrm{w}(4.1 .4) \times \mathrm{v}(4.1 .4) \\
& \mathrm{V}(4.1)=(0,26 \times 43,00)+(0,29 \times 0,00)+(0,24 \times 0,00)+(0,21 \times 0,00) \\
& \mathrm{V}(\mathbf{4 . 1})=\mathbf{1 1 , 1 8}
\end{aligned}
$$

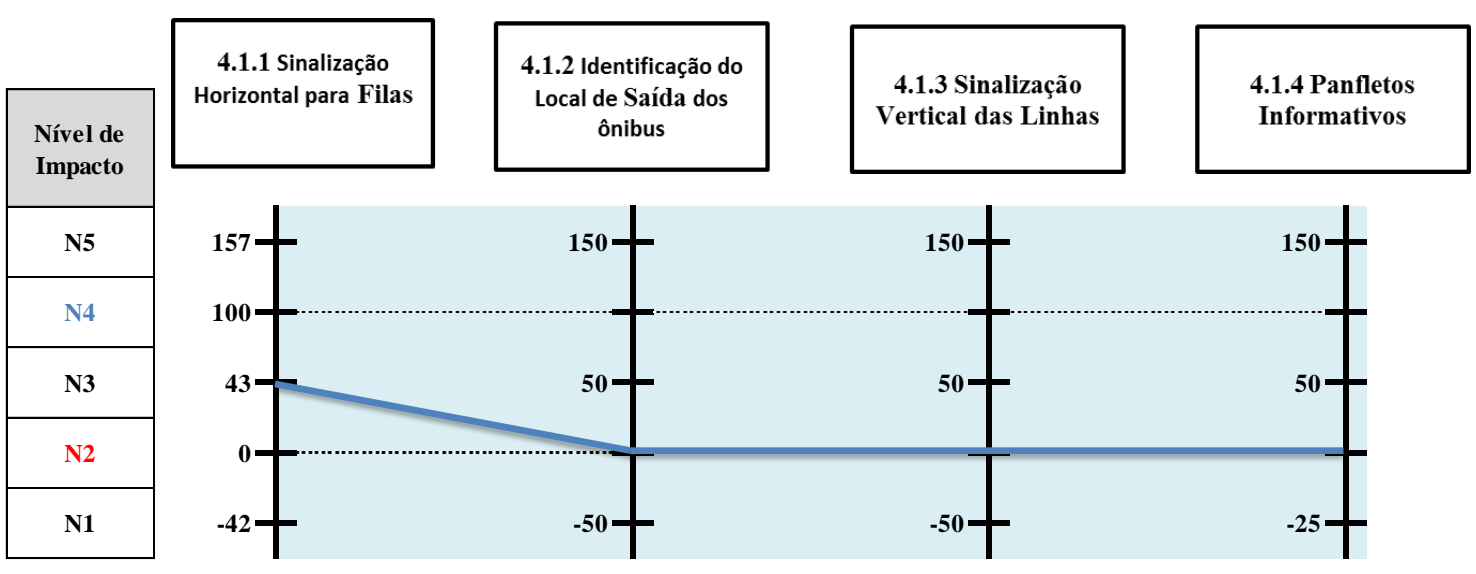

Figura 4-7 - Desempenho dos sub PVE componentes do PVE 4.1 - informações nos terminais

b) Ponto de vista elementar 4.2 - informações nas paradas

Em todos os sub PVE componentes do PVE 4.2 - informações nas paradas a posição da mediana correspondia ao nível de impacto N2, cujo valor na função de valor é 0 (zero), indicando que o usuário está insatisfeito com a comunicação que a empresa pesquisa mantém nas paradas ao longo dos itinerários das linhas que opera. A representação gráfica da avaliação deste PVE é apresentada na Figura 4.8. Assim, aplicando a fórmula de agregação aditiva, foi possível calcular a pontuação do PVE 4.2 - informações nas paradas, que totalizou 0 pontos.

$\mathrm{V}(4.2)=\mathrm{w}(4.2 .1) \mathrm{x} \mathrm{v}(4.2 .1)+\mathrm{w}(4.2 .2) \mathrm{xv}(4.2 .2)+\mathrm{w}(4.2 .3) \mathrm{x} \mathrm{v}(4.2 .3)$

$\mathrm{V}(4.2)=(0,37 \times 0,00)+(0,33 \times 0,00)+(0,30 \times 0,00)$

$\mathrm{V}(4.2)=0,00$ 


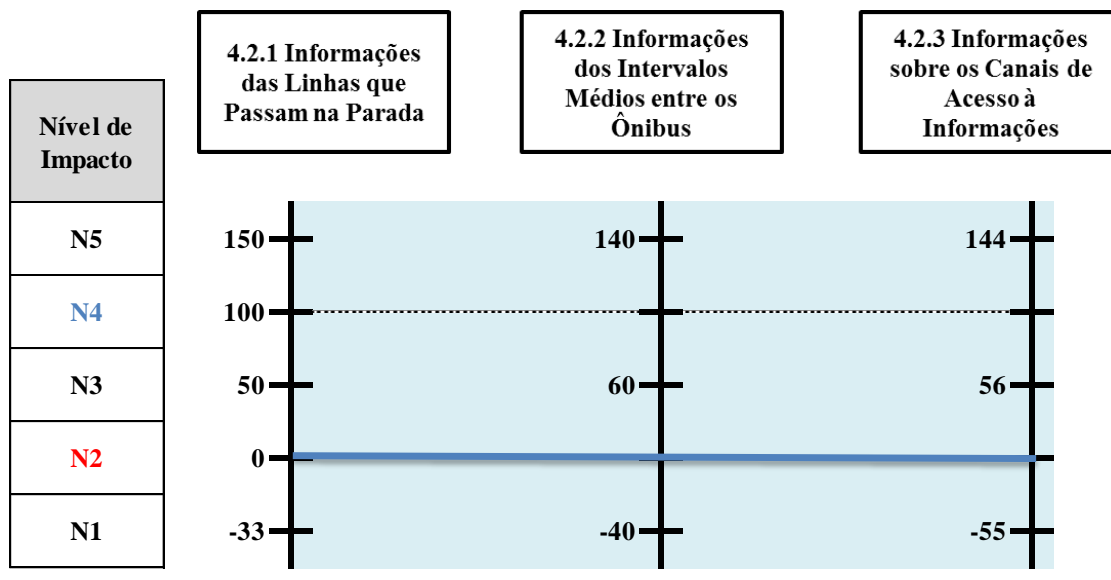

Figura 4-8 - Desempenho dos sub PVE componentes do PVE 4.2 - informações nas paradas

c) Ponto de vista elementar 4.3 - informações nos ônibus

Em todos os sub PVE componentes do PVE 4.3 - informações nos ônibus a posição da mediana correspondia ao nível de impacto N4 cujo valor na função de valor é 100 (cem), indicando que o usuário está satisfeito com a comunicação que a empresa pesquisa mantém com os usuários durante a prestação do serviço a bordo dos ônibus. A representação gráfica da avaliação deste PVE é apresentada na Figura 4.9. Assim, aplicando a fórmula de agregação aditiva, foi possível calcular a pontuação do PVE 4.3 - informações nos terminais, que totalizou 100 pontos.

$\mathrm{V}(4.3)=\mathrm{w}(4.3 .1) \mathrm{x} \mathrm{v}(4.3 .1)+\mathrm{w}(4.3 .2) \mathrm{x} \mathrm{v}(4.3 .2)+\mathrm{w}(4.3 .3) \mathrm{x} \mathrm{v}(4.3 .3)$

$\mathrm{V}(4.3)=(0,40 \times 100,00)+(0,32 \times 100,00)+(0,28 \times 100,00)$

$\mathrm{V}(4.3)=100,00$ 

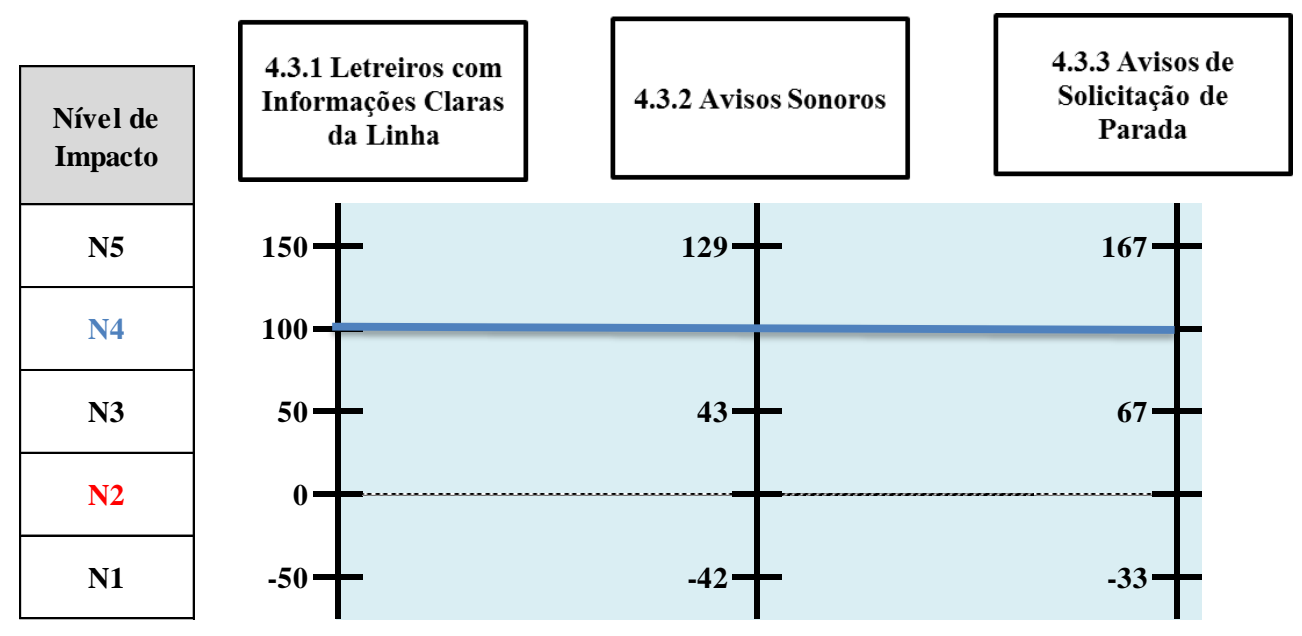

Figura 4-9 - Desempenho dos sub PVE componentes do PVE 4.3 - informações nos terminais

d) Ponto de vista elementar 4.4 - informações na internet

Assim como nos dois PVE anteriores, em todos os sub PVE a posição da mediana correspondia ao nível de impacto N3, cujos valores na função de valor são: 4.4.1 - mapas de horários - 40 (quarenta); 4.4.2 - valor das tarifas - 35 (trinta e cinco); 4.4 .3 - divulgação dos itinerários das linhas - 40 (quarenta); 4.4 .4 - formas de pagamento das tarifas - 67 (sessenta e sete); e 4.4.5 - informações sobre os canais de acesso à informações - 56 (cinquenta e seis), indicando que o usuário se mostra indiferente com as informações disponibilizadas neste canal. Durante as entrevistas, foi possível perceber que muitos não buscam a obtenção dessas informações pela internet, muitos até nem utilizam a internet. A representação gráfica da avaliação deste PVE é apresentada na Figura 4.10. Assim, aplicando a fórmula de agregação aditiva, foi possível calcular a pontuação do PVE 4.4 - informações na internet, que totalizou 46,32 pontos.

$$
\begin{aligned}
& \mathrm{V}(4.4)=\mathrm{w}(4.4 .1) \times \mathrm{v}(4.4 .1)+\mathrm{w}(4.4 .2) \times \mathrm{v}(4.4 .2)+\mathrm{w}(4.4 .3) \times \mathrm{v}(4.4 .3)+\mathrm{w}(4.4 .4) \times \mathrm{v}(4.4 .4) \\
& +\mathrm{w}(4.4 .5) \times \mathrm{v}(4.4 .5) \\
& \mathrm{V}(4.4)=(0,23 \times 40,00)+(0,22 \times 35,00)+(0,21 \times 40,00)+(0,18 \times 67,00)+(0,16 \times 56,00) \\
& \mathrm{V}(\mathbf{4 . 4})=\mathbf{4 6 , 3 2}
\end{aligned}
$$



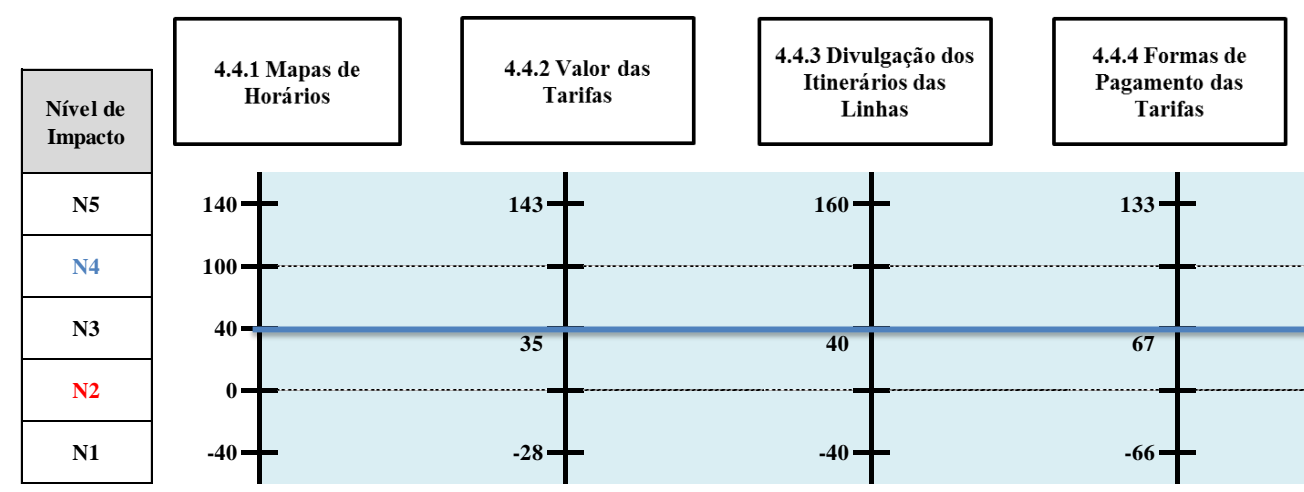
4.4.5 Informações sobre os Canais de Acesso à

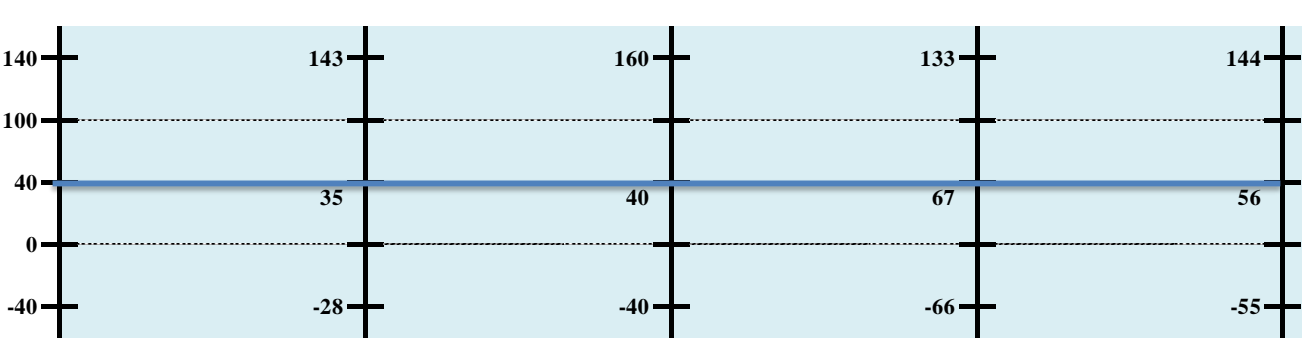

Figura 4-10 - Desempenho dos sub PVE componentes do PVE 4.4 - informações na internet

e) Ponto de vista elementar 4.5 - serviço de atendimento ao cliente

Também neste PVE, em todos os Sub PVE que o compõem, a posição da mediana correspondia ao nível de impacto N3, cujos valores na função de valor são: 4.5 .1 informações sobre tarifas - 50 (cinquenta); 4.5 .2 - informações de horários - 40 (quarenta); 4.5.3 - registro de reclamações - 50 (cinquenta); e 4.5.4 - informações sobre os canais de acesso à informações - 33 (trinta e três), indicando que o usuário se mostra indiferente com as informações disponibilizadas neste canal. Durante as entrevistas, foi possível perceber que poucos usuários buscam a obtenção dessas informações por este canal. A representação gráfica da avaliação deste PVE é apresentada na Figura 4.11. Assim, aplicando a fórmula de agregação aditiva, foi possível calcular a pontuação do PVE 4.5 - serviço de atendimento ao cliente, que totalizou 43,73 pontos.

$$
\begin{aligned}
& \mathrm{V}(4.5)=\mathrm{w}(4.5 .1) \times \mathrm{v}(4.5 .1)+\mathrm{w}(4.5 .2) \times \mathrm{v}(4.5 .2)+\mathrm{w}(4.5 .3) \times \mathrm{v}(4.5 .3)+\mathrm{w}(4.5 .4) \times \mathrm{v}(4.5 .4) \\
& \mathrm{V}(4.5)=(0,30 \times 50,00)+(0,27 \times 40,00)+(0,22 \times 50,00)+(0,21 \times 33,00) \\
& \mathbf{V}(\mathbf{4 . 5})=\mathbf{4 3 , 7 3}
\end{aligned}
$$



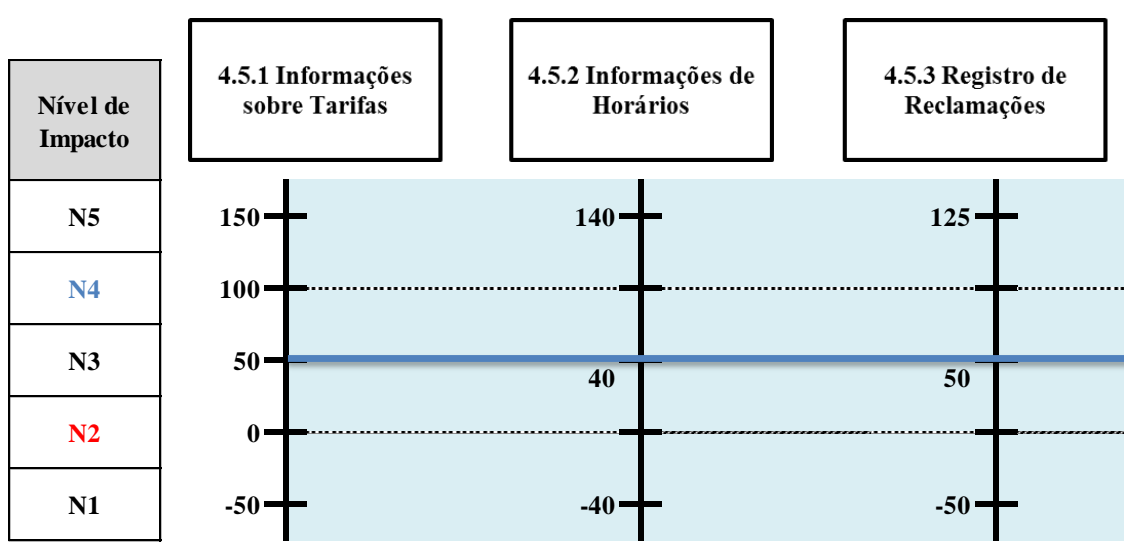
4.5.4 Informações
sobre os Canais de
Acesso à
informações

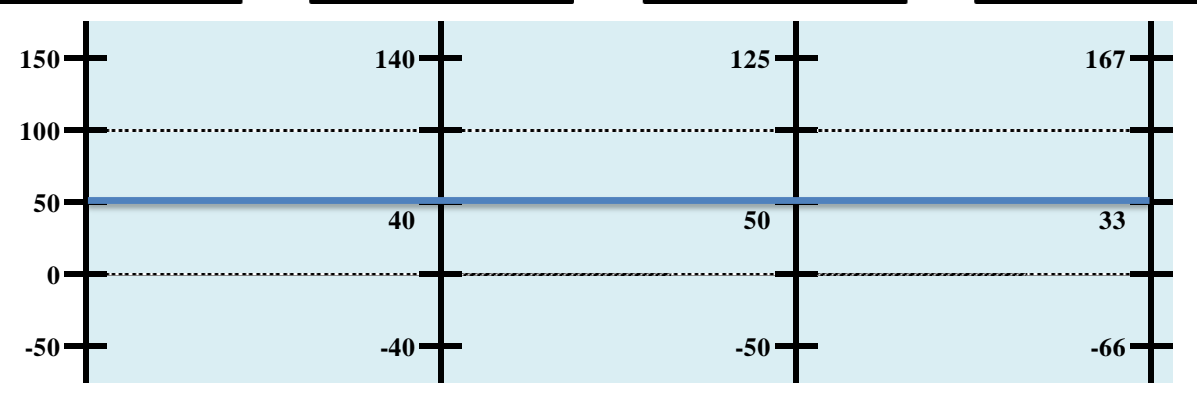

Figura 4-11 - Desempenho dos sub PVE componentes do PVE 4.5 - serviço de atendimento ao cliente

\subsubsection{AVALIAÇÃO DOS COMPONENTES DO PVF 5 - CONFORTO}

A partir das medianas foi possível determinar os níveis de impacto dos PVE componentes desse PVF. Dessa forma, no PVE 5.1 - atualidade da frota a posição da mediana correspondia ao nível de impacto N2, cujo valor na função de valor é 0 (zero), indicando que o usuário está insatisfeito com a idade da frota que opera as linhas da empresa. No PVE 5.2 - espaço entre os bancos, a posição da mediana correspondia ao nível de impacto $\mathrm{N} 2$, cujo valor na função de valor é 0 (zero), mostrando que o usuário está insatisfeito com o intervalo entre os bancos dos ônibus que operam as linhas da empresa pesquisada. No PVE 5.3 - espaço no corredor, a posição da mediana correspondia ao nível de impacto N3, cujo valor na função de valor é 0 (zero), indicando que os usuários se mostram insatisfeitos com o serviço prestado em relação a este item, inclusive durante a pesquisa de campo muitos disseram que o espaço é muito pequeno e que fica muito difícil a circulação dentro do veículo. No PVE 5.4 - lotação, a posição da mediana correspondia ao nível de impacto $\mathrm{N} 2$, cujo valor na função de valor é 0 (zero), indicando que os usuários se mostram insatisfeitos com a lotação dos ônibus durante as viagens, reclamando bastante do desconforto causado pela superlotação. No PVE 5.5 ventilação, a posição da mediana correspondia ao nível de impacto $\mathrm{N} 1$, cujo valor na função de valor é -50 (cinquenta) a avaliação indicou que os usuários estão plenamente insatisfeitos com a ventilação no interior dos ônibus durante as viagens. Por fim, no PVE 5.6 - temperatura 
no interior do ônibus, a posição da mediana correspondia ao nível de impacto N3, cujo valor na função de valor é 40 (quarenta), indicando que os usuários estão satisfeitos com a temperatura no interior dos ônibus durante a prestação do serviço. A representação gráfica da avaliação deste PVF é apresentada na Figura 4.12. Assim, aplicando a fórmula de agregação aditiva, foi possível calcular a pontuação do PVF 5 - conforto, que totalizou - 3,50 pontos.

$$
\begin{aligned}
& \mathrm{V}(5)=\mathrm{w}(5.1) \times \mathrm{v}(5.1)+\mathrm{w}(5.2) \times \mathrm{v}(5.2)+\mathrm{w}(5.3) \times \mathrm{v}(5.3)+\mathrm{w}(5.4) \times \mathrm{v}(5.4)+\mathrm{w}(5.3) \times \mathrm{v}(5.3) \\
& +\mathrm{w}(5.4) \times \mathrm{v}(5.4) \\
& \mathrm{V}(5)=(0,19 \times 0,00)+(0,11 \times 0,00)+(0,15 \times 0,00)+(0,20 \times 0,00)+[0,17 \times(-50,00)]+(0,18 \\
& \mathrm{x} 40,00) \\
& \mathrm{V}(\mathbf{5})=-\mathbf{3 , 5 0}
\end{aligned}
$$

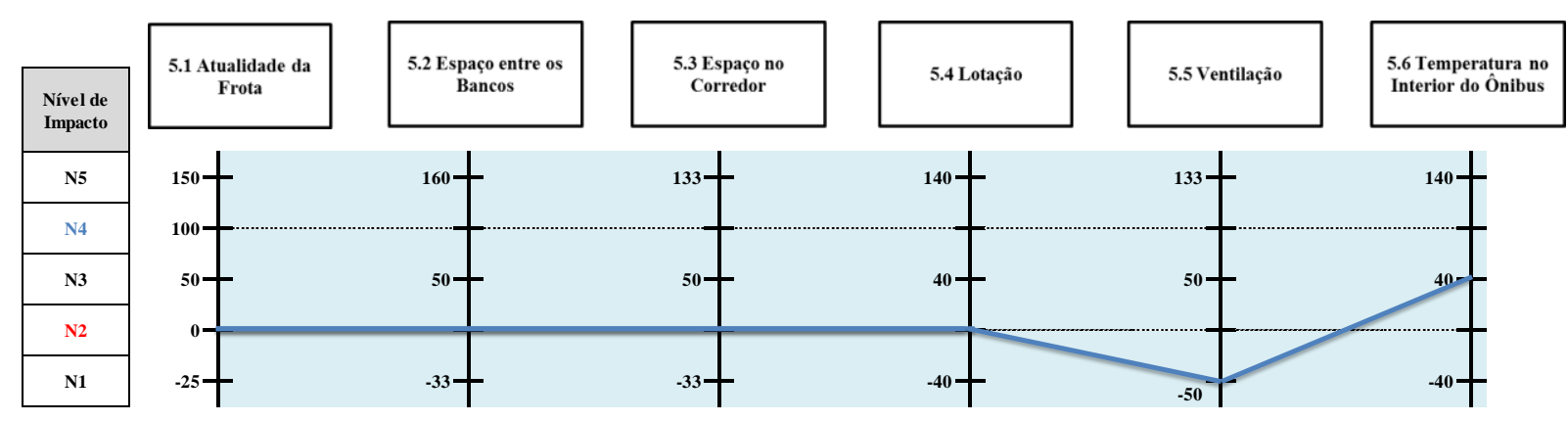

Figura 4-12 - Desempenho dos PVE componentes do PVF 5 - conforto

\subsubsection{AVALIAÇÃO DOS COMPONENTES DO PVF 6 - CUSTO}

O PVF 6 - custo não foi decomposto, dessa forma, sua avaliação será dada diretamente pelo Nível de impacto onde se encontra a mediana. O objetivo deste PVF era saber se o preço cobrado pelo serviço estava de acordo com a qualidade da contraprestação. A posição da mediana correspondeu ao nível de impacto N1, cujo valor na função de valor é -40 (menos quarenta), que indicou que os usuários estão plenamente insatisfeitos com os valores das tarifas, ou seja, as tarifas cobradas pelos serviços estão acima da qualidade ofertada. A representação gráfica da avaliação deste PVF é apresentada na Figura 4.13. Assim, aplicando a fórmula de agregação aditiva, foi possível calcular a pontuação deste PVF, que totalizou 4,40 pontos. 


$$
\begin{aligned}
& \mathrm{V}(6)=\mathrm{w}(6) \times \mathrm{v}(6) \\
& \mathrm{V}(6)=[0,11 \times(-40,00)] \\
& \mathrm{V}(\mathbf{6})=\mathbf{- 4}, \mathbf{4 0}
\end{aligned}
$$

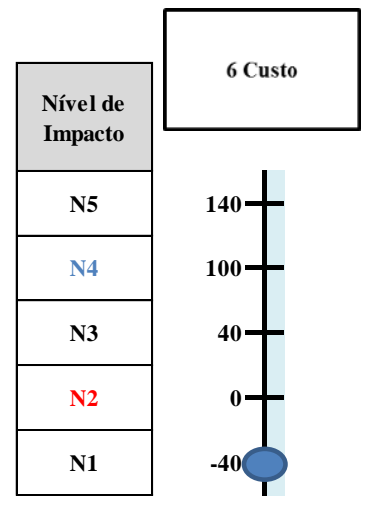

Figura 4-13 - Desempenho do PVF 6 - custo

\subsubsection{AVALIAÇÃO DOS COMPONENTES DO PVF 7 - COMPORTAMENTO DOS OPERADORES}

a) Ponto de vista elementar 7.1 - treinamento de pessoal

No sub PVE 7.1.1 - parada fora de pontos de parada/terminais a posição da mediana correspondia ao nível de impacto N2, cujo valor na função de valor é 0 (zero), indicando que o usuário está insatisfeito com a forma que os motoristas param os ônibus nas paradas/terminais durante as viagens. No sub PVE 7.1.2 - troca constante de tripulação, a posição da mediana correspondia ao nível de impacto N3, cujo valor na função de valor é 50 (cinquenta), mostrando que o usuário está indiferente com o tempo decorrido para troca de tripulantes das linhas. A representação gráfica da avaliação deste PVE é apresentada na Figura 4.14. Assim, aplicando a fórmula de agregação aditiva, foi possível calcular a pontuação do PVE 7.1 - treinamento de pessoal, que totalizou 20,50 pontos.

$$
\begin{aligned}
& \mathrm{V}(7.1)=\mathrm{w}(7.1 .1) \times \mathrm{v}(7.1 .1)+\mathrm{w}(7.1 .2) \times \mathrm{v}(7.1 .2) \\
& \mathrm{V}(7.1)=(0,59 \times 0,00)+(0,41 \times 50,00) \\
& \mathrm{V}(\mathbf{7} \cdot \mathbf{1})=\mathbf{2 0 , 5 0}
\end{aligned}
$$




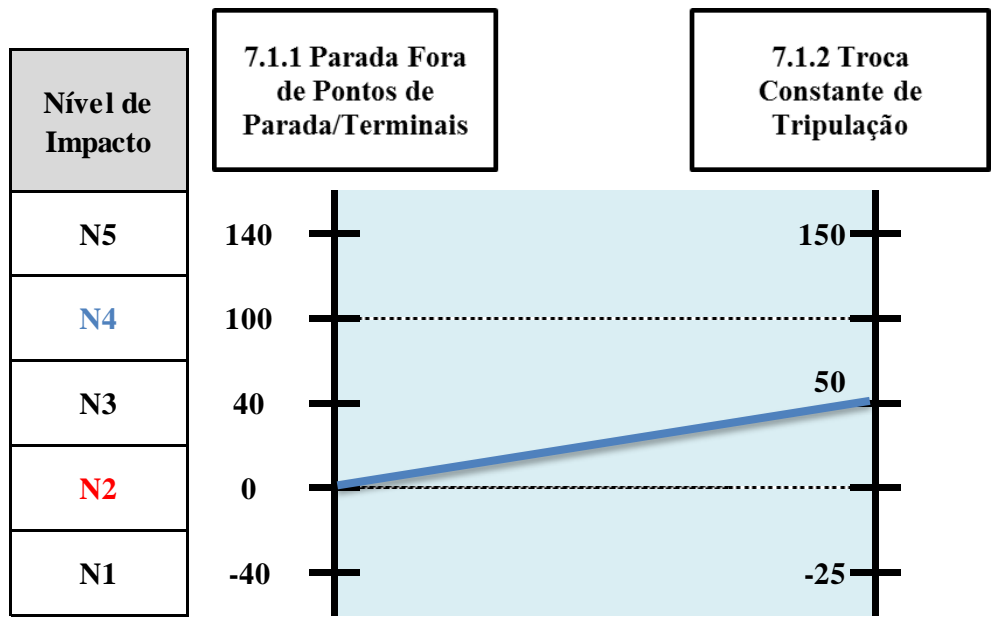

Figura 4-14 - Desempenho dos sub PVE componentes do PVE 7.1 - treinamento de pessoal

b) Ponto de vista elementar 7.2 - jornada de trabalho

No sub PVE 7.2.1 - tripulação com aparência de cansada a posição da mediana correspondia ao nível de impacto N3, cujo valor na função de valor é 60 (sessenta), indicando que o usuário está indiferente ao ânimo da tripulação durante as viagens, ou seja, essa situação não chamou a atenção. No sub PVE 7.2.2 - tripulação com alteração de comportamento, a posição da mediana também correspondia ao nível de impacto N3, cujo valor na função de valor é 50 (cinquenta), mostrando que o usuário está indiferente as variações de humor da tripulação durante as viagens. A representação gráfica da avaliação deste PVE é apresentada na Figura 4.15. Assim, aplicando a fórmula de agregação aditiva, foi possível calcular a pontuação do PVE, que totalizou 55,40 pontos.

$$
\begin{aligned}
& \mathrm{V}(7.2)=\mathrm{w}(7.2 .1) \times \mathrm{v}(7.2 .1)+\mathrm{w}(7.2 .2) \times \mathrm{v}(7.2 .2) \\
& \mathrm{V}(7.2)=(0,54 \times 60,00)+(0,46 \times 50,00) \\
& \mathrm{V}(\mathbf{7 . 2})=\mathbf{5 5 , 4 0}
\end{aligned}
$$




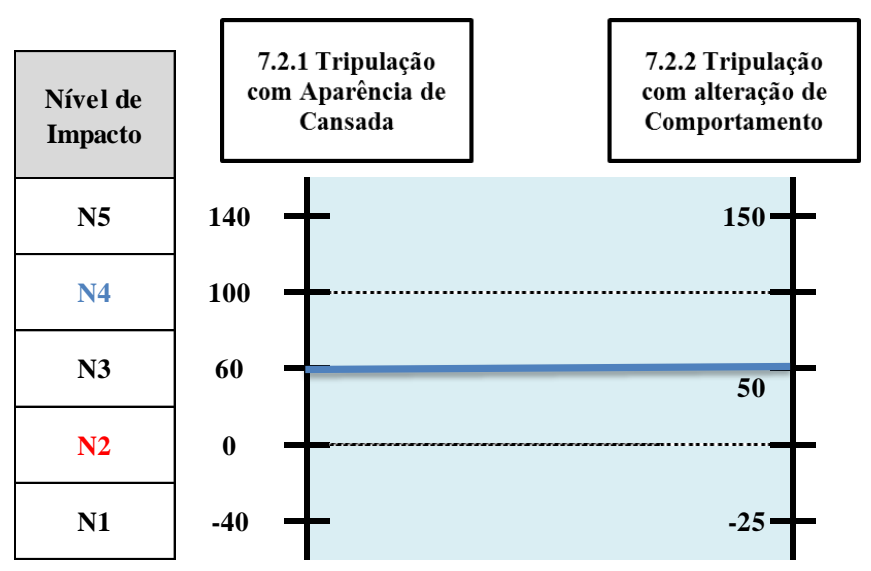

Figura 4-15 - Desempenho dos sub PVE componentes do PVE 7.2 - jornada de trabalho

c) Ponto de vista elementar 7.3 - cortesia

No sub PVE 7.3.1 - tripulação atende pedidos de informações a posição da mediana correspondia ao nível de impacto N3, cujo valor na função de valor é 50 (cinquenta), indicando que o usuário está indiferente ao tratamento dispensado pela tripulação quando atendem aos pedidos de informações. No sub PVE 7.3.2 - despachantes orientam formação de filas, a posição da mediana também correspondia ao nível de impacto N2, cujo valor na função de valor é 0 (zero), mostrando que o usuário está insatisfeito com a atuação dos despachantes quanto a orientação para formação das filas. A representação gráfica da avaliação deste PVE é apresentada na Figura 4.16. Assim, aplicando a fórmula de agregação aditiva, foi possível calcular a pontuação do PVE 7.3, que totalizou 41,50 pontos.

$\mathrm{V}(7.3)=\mathrm{w}(7.3 .1) \times \mathrm{v}(7.3 .1)+\mathrm{w}(7.3 .2) \mathrm{x} \mathrm{v}(7.3 .2)$

$\mathrm{V}(7.3)=(0,83 \times 50,00)+(0,17 \times 0,00)$

$\mathrm{V}(\mathbf{7 . 3})=\mathbf{4 1 , 5 0}$ 


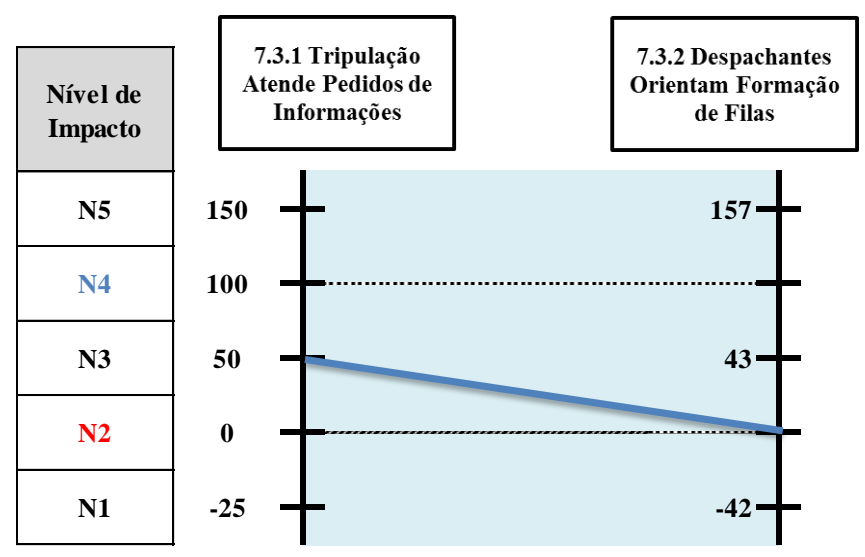

Figura 4-16 - Desempenho dos sub PVE componentes do PVE 7.3 - cortesia

\subsection{PERFIL DE IMPACTO}

O perfil de impacto mostra a performance da empresa nos eixos de avaliação por meio de um gráfico no qual são representadas todas as pontuações da ação potencial em cada eixo de avaliação e permite ao avaliador identificar os pontos fortes e fracos da empresa avaliada ( Gráfico 4.1).

\section{Perfil de Impacto da Empresa Pesquisada}

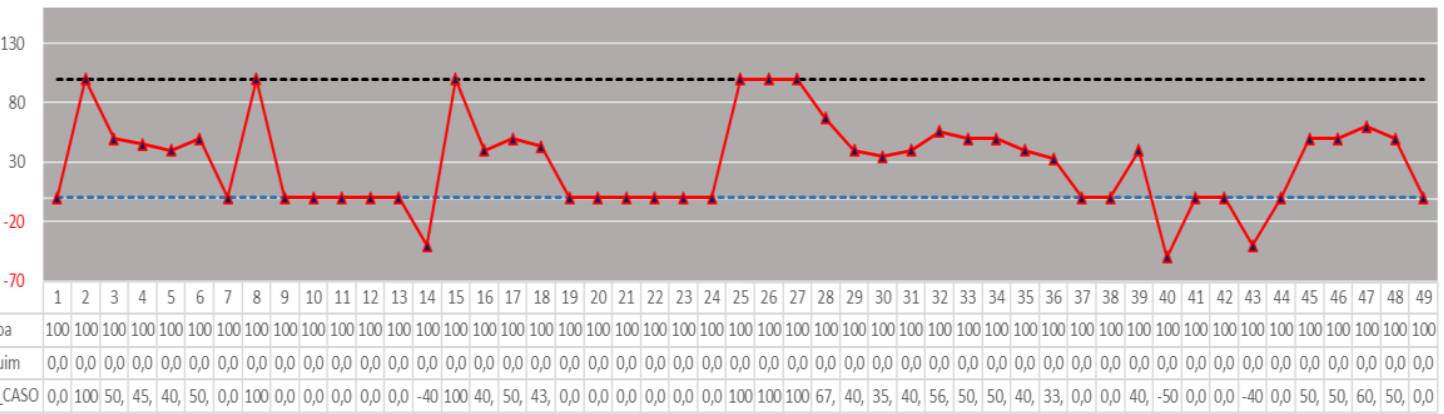

Gráfico 4.1 - Perfil de impacto da empresa pesquisada

No Gráfico 4.1, observa-se que três itens componentes do eixo de avaliação apresentaram desempenho abaixo do nível neutro, ou seja, um desempenho comprometedor. Foram eles: 3.2.2 - facilidade para pagamento das passagens; 5.5 - ventilação; e 6 - custo, que foram avaliados pelos usuários como itens que os deixavam plenamente insatisfeitos. É possível observar também que nenhum item do eixo de avaliação apresentou desempenho de 
excelência. Por fim, pode-se dizer que a empresa teve a maioria de seus itens avaliados entre o nível bom e o nível neutro.

\subsection{AVALIAÇÃO PARCIAL}

A avaliação parcial da empresa pesquisada em cada Ponto de Vista Fundamental é a soma dos pontos obtidos em cada um dos seus Pontos de Vista Elementar multiplicados por suas respectivas Taxas de Substituição. Por exemplo: a avaliação parcial da empresa pesquisada no PVF 1 - segurança foi obtida a partir da aplicação da fórmula de agregação aditiva e apresentou o seguinte resultado:

$\mathrm{V}(1)=\mathrm{w}(1.1) \mathrm{x} \mathrm{v}(1.1)+\mathrm{w}(1.2) \times \mathrm{v}(1.2)$

$\mathrm{V}(1)=0,67 \times 56+0,33 \times 43,35$

$\mathrm{V}(\mathbf{1})=\mathbf{5 1 , 8 3}$

Este procedimento foi repetido para os demais pontos de vista fundamentais e os resultados são apresentados no Gráfico 4.2 - Avaliação Parcial da empresa pesquisada no estudo de caso, onde observa-se que o PVF segurança foi o que obteve melhor desempenho, obtendo performance no Nível A, com os PVF acessibilidade, comunicação e comportamento dos operadores obtendo classificação no Nível C e, com desempenhos ruins, Nível D, estão os PVF confiabilidade, conforto e custo. 


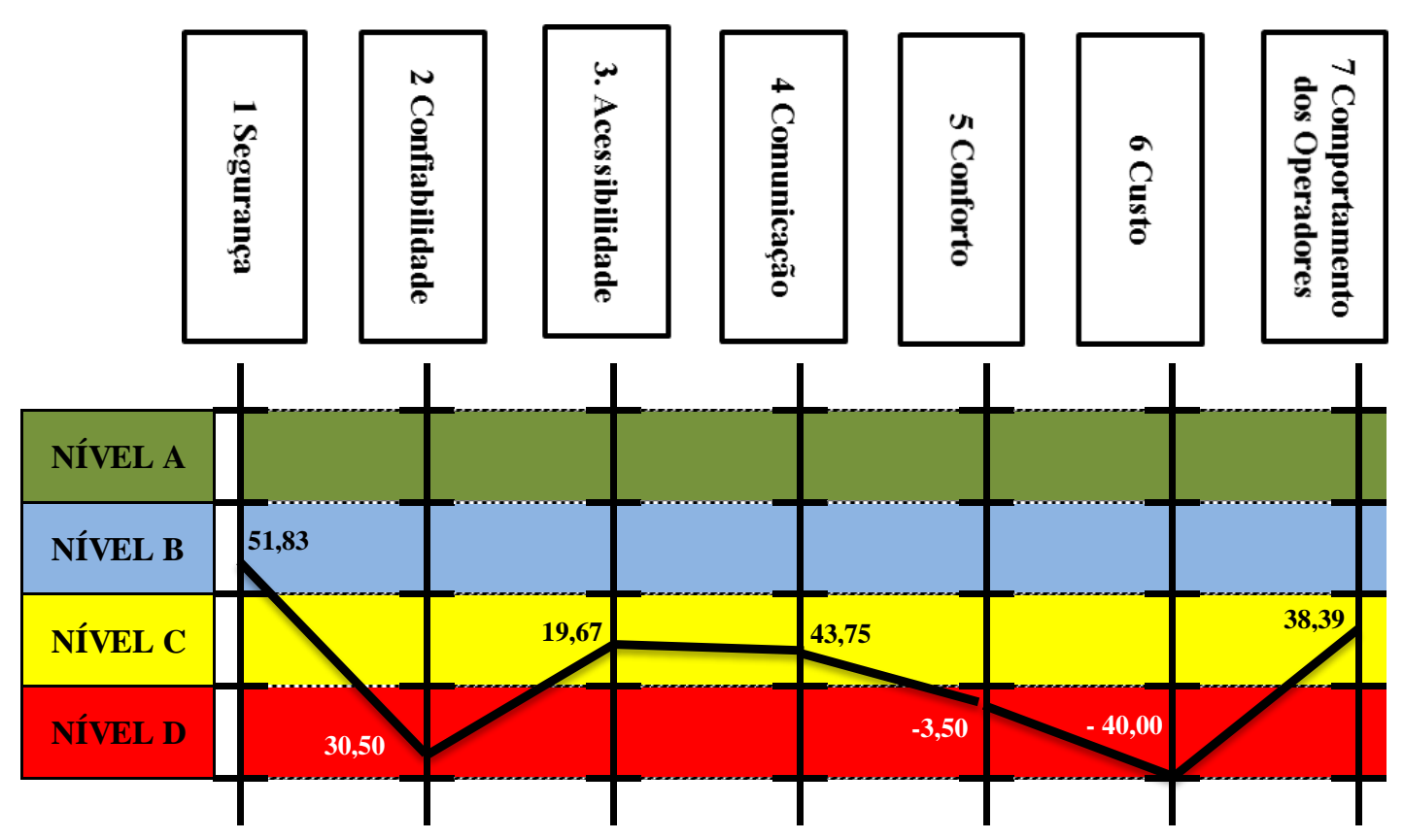

Gráfico 4.2 - Avaliação parcial da empresa pesquisada

\subsection{AVALIAÇÃO GLOBAL}

Para a obtenção da pontuação final da empresa avaliada, partiu-se da avaliação parcial. Na avaliação global, são agregados os resultados parciais da empresa pesquisada em cada critério, utilizando a fórmula de agregação aditiva.

$\mathrm{V}(\mathrm{G})=\mathrm{w}(1) \mathrm{xv}(1)+\mathrm{w}(2) \mathrm{xv}(2)+\mathrm{w}(3) \mathrm{xv}(3)+\mathrm{w}(4) \mathrm{xv}(4)+\mathrm{w}(5) \mathrm{xv}(5)+\mathrm{w}(6) \times \mathrm{v}(6)+$ $\mathrm{w}(7) \mathrm{x} v(7)$

$\mathrm{V}(\mathrm{G})=(0,18 \times 51,83)+(0,17 \times 30,50)+(0,17 \times 19,67)+(0,15 \times 43,75)+[0,13 \times(-3,50)]+$ $[0,11 \times(-40,00)]+(0,09 \times 38,39)$

$\mathbf{V}(\mathbf{G})=\mathbf{2 3 , 0 2}$

Diante da pontuação alcançada na avaliação global da empresa, conclui-se que a mesma se situa no Nível C do modelo construído, conforme apresentado na Figura 5.17 - Desempenho da Empresa Pesquisada. Apesar de se encontrar em um dos níveis que a apontam como competitiva, seria necessária uma melhoria na qualidade dos serviços prestados para chegar ao Nível B. 


\begin{tabular}{|c|c|c|}
\hline Nível A & $147,16<X>100,00$ & \multirow{2}{*}{ Excelência } \\
\hline Nível B & $48,55<X>100,00$ & \multirow{2}{*}{ Competitivo } \\
\cline { 1 - 2 } Nível C & $0,00<X>48,55$ & \\
\hline Nível D & $-40,57<X>0,00$ & Comprometedor \\
\hline
\end{tabular}

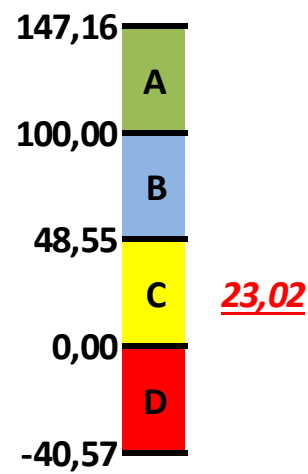

Figura 4-17 - Desempenho da empresa pesquisada 


\section{CONCLUSÕES}

Este estudo teve por objetivo a construção de um modelo, utilizando a Metodologia Multicritério de Apoio à Decisão - Construtivista (MCDA-C), para avaliar a qualidade dos serviços prestados pelas empresas de transporte rodoviário interestadual semiurbano de passageiros e classificá-las por nível de serviço.

Os resultados encontrados na aplicação do modelo multicritério para avaliar a qualidade do serviço interestadual semiurbano de passageiros mostraram-se consistentes e podem ser utilizados para que as empresas prestadoras possam melhorar os serviços a partir das avaliações que os usuários fizeram em cada item que compõe o modelo. Como, por exemplo, no caso dos itens 3.2.2 - facilidade para pagamento das passagens, 5.5 - ventilação e 6 custos que foram classificados no Nível de Impacto "N1 - Plenamente Insatisfeito". Se esses itens forem melhorados, passando para o nível de impacto imediatamente superior (N2 Insatisfeito), a empresa terá uma evolução de 26,46\%, passando de 23,02 para 29,11 pontos.

A grande vantagem da utilização do modelo multicritério para classificar as empresas prestadoras do serviço de transporte rodoviário interestadual semiurbano de passageiros é que a partir do nível de qualidade estabelecido pelo órgão fiscalizador e da percepção que os usuários têm da qualidade do serviço prestado, é possível para a empresa corrigir eventuais pontos críticos e prosseguir na busca pela excelência na prestação dos serviços. Por outro lado, o método apresenta um grau de dificuldade para coleta de dados juntos aos usuários, na medida em que o número de itens a serem avaliados aumenta. Neste trabalho, o formulário aplicado possuía, além dos 49 itens avaliados, mais 5 itens socioeconômicos, ou seja, o usuário deveria responder a 54 itens, o que demandou muito tempo para cada aplicação, consequentemente aumentando o tempo de coleta de dados.

Para futuras pesquisas, sugere-se a aplicação da metodologia utilizada neste trabalho para construção de um modelo que vise classificar empresas de transporte de passageiros por nível de serviço em outros modos de transporte, como o metroferroviário; a aplicação do modelo em diferentes cenários para calibrar as faixas de indicadores; e relacionar a avaliação de desempenho às renovações dos contratos de concessão ou ao reajuste tarifário. 
Este estudo alcançou seu objetivo primário ao construir um modelo utilizando a Metodologia Multicritério de Apoio à Decisão - Construtivista (MCDA-C) para avaliar a qualidade dos serviços prestados pelas empresas de transporte rodoviário interestadual semiurbano de passageiros para classificá-las por nível de serviço. O modelo construído poderá nortear os órgãos reguladores e fiscalizadores no estabelecimento de mecanismos para que as empresas operadoras possam melhorar a qualidade dos serviços que ofertam. Inclusive com o estabelecimento de incentivos para aquelas que forem classificadas no nível de excelência e, por outro lado, aplicar penalidades nas que se classificarem no nível comprometedor. 


\section{REFERÊNCIAS BIBLIOGRÁFICAS}

ANATEL (2015). Resolução $n^{o}$ 654, de 13 de julho de 2015. http://www.anatel.gov.br/legislacao/resolucoes/2015/829-resolucao-654\#art5res. Acessado em 15 jan. 2016.

ANEEL (2015). Regulamento IASC. http://www.aneel.gov.br/area.cfm?idArea=192. Acessado em 15 jan. 2016.

ANTT (2005). Resolução $n^{o}$ 1159, de 05 de outubro de 2005. http://www.antt.gov.br/index.php/content/view/2159/Resolucao_n_1159.html.

Acessado em 29 out 2014.

ANTT (2011). Plano de Outorga dos Serviços de Transporte Rodoviário Interestadual de Passageiros, operados por onibus do tipo rodoviário. http://www.antt.gov.br/index.php/content/view/15920/Anexo_VIII_Plano_de_Outorg a_e_Projetos_Basicos.html. Acessado em: 29 out. 2014.

ANTT (2011b). Projeto da Rede Nacional de Transporte Rodoviário Interestadual e Internacional de Passageiros - ProPass Brasil. http://propass.antt.gov.br/index.php/content/view/105719/Pesquisa Operacional servicos interestaduais com extensao igual ou inferior a $75 \mathrm{~km}$.html\#lista. Acessado em: 29 out. 2014.

ANTT (2013a). Relatório Anual 2013.

http://www.antt.gov.br/index.php/content/view/5561/Institucional.html. Acessado em: 29 out 2014.

ANTT (2013b). Plano de Outorga dos Serviços de Transporte Rodoviário Semiurbano de Passageiros que atendem a Região do Distrito federal e dos Municípios de seu Entorno, operados por ônibus do tipo urbano. http://www.antt.gov.br/index.php/content/view/18927/129_2012.html. Acessado em: 29 out 2014.

ANTT (2014). Edital de Licitação $N^{o} 2 / 2014$, Anexo V do Contrato de Permissão - Sistema de Avaliação de Desempenho. fille:///C:/Users/paulo.costa/Downloads/anexo_v_sistema_de_avalia\%C3\%A7\%C3\%A3o_de_desempenhocorre\%C3\%A7\%C3\%A3o_18 12.pdf. Acessado em: 15 jan 2015.

ANTT (2014b). Pesquisa de Satisfação dos Usuários 2014. http://www.antt.gov.br/index.php/content/view/36487/Relatorio_III Transporte_Rod oviario_Interestadual_de_Passageiros.html. Acessado em: 20 maio 2015.

ANTT (2015). Resolução $n^{o}$ 4.777, de 6 de julho de 2015. http://www.antt.gov.br/index.php/content/view/40407/Resolucao_n_4777.html.

Acessado em: 13/11/2015. 
ANTT (2015b). Sistema de controle de dados dos serviços de transportes rodoviário de passageiros

(SISDAP). http://www.antt.gov.br/index.php/content/view/42827/Estatisticas_e_Estudos.html\#lista Acessado em: 05/11/2015.

ARRUDA, B. D. L. D., SILVA, L. R., ANTUNES, R. T., GOMES, H. A. D. S., \& YAMASHITA, Y. (2012). Uma proposta de avaliação de desempenho para os sistemas de transporte rodoviário interurbano de passageiros. Revista Transportes. V.20. n.1. Pg. 41-49.

BANA E COSTA, C. A. (1992). Structuration, Construction et Exploitation d'um Modèle Multicritère d'aide à la Décision. Tese de Doutorado, Universidade Técnica de Lisboa, Portugal.

BANA E COSTA, C. A., ENSSLIN, L., CORNÊA, É. C., \& VANSNICK, J. C. (1999). Decision support systems in action: integrated application in a multicriteria decision aid process. European Journal of Operational Research, 113(2), 315-335.

BANA E COSTA, C. A. (1999). Decision Support Systems in Action - Integrated Application in a Multicriteria Decision Aid Process. European Journal of Operational RESEARCH, n. 113 , n. 2, p. 315-335.

BANA E COSTA, C. A.; CORTE, J.M.; VANSNICK, J.C. (2005) M-MACBETH (Measuring Attractiveness by a Categorical Based Evaluation Technique). Guia do Utilizador.

BEINAT, E. (1995). Multiattribute Value Functions for Environmental Management. Amsterdam: Tinbergen Institute Research Series.

BERTOZZI, P.P.; LIMA JR, O.F. (1998). A qualidade no serviço de transporte público sob as óticas do usuário, do operador e do órgão gestor. Revista dos Transportes Públicos - ANTP, São Paulo, ano 21, p. 53-61, $4^{\circ}$ trimestre 1998.

BOUYSSOU, D. (1986). Some remarks on the notion of compensation in MCDM. European Journal of Operational Research, v. 26, n. 1, p. 150-160.

BRASIL (1998). Decreto 2.521, de 20 de março de 1998. Dispõe sobre a exploração, mediante permissão e autorização, de serviços de transporte rodoviário interestadual e internacional de passageiros e dá outras providências. Disponível em: http://www.planalto.gov.br/ccivil_03/decreto/D2521.htm Acessado em: 29 out. 2014.

EBTU, Empresa Brasileira de Transportes Urbanos. (1988). Gerência do sistema de transporte público de passageiros: planejamento da operação. Organizado por: TTC Trânsito, Transportes Coletivos e Comunicações. Brasília.

ENSSLIN, L; MONTIBELLER NETO, G.; ZANELLA, I.; NORONHA, S. (2001). Apoio à Decisão - Metodologia para Estruturação de Problemas e Avaliação Multicritério de Alternativas. INSULAR: Florianópolis.

FERRAZ, A. C. P; TORRES, I. G. E. (2004). Transporte Público Urbano. $2^{\mathrm{a}}$ Ed. Ampliada e atualizada. Rima: São Carlos. 
FREITAS, A. L. P. (2005). A qualidade em serviços no contexto da competitividade. Revista Produção Online, 5(1), 1-24.

FREITAS, A. L. P., REIS FILHO, C. A. C., \& RODRIGUES, F. R. (2011). Avaliação da qualidade do transporte rodoviário intermunicipal de passageiros: uma abordagem exploratória. Revista Transportes, V. 19. n.3. Pg. 49-61.

GARVIN, D.A. (1984). What does "product quality" really mean? Sloan Management Reviw. USA. V. 26, n. 1, p. 25-43, fall.

GHOBADIAN, A.; SPELLER, S.; JONES, M. (1994). Service quality: concepts and models. International Journal of Quality \& Reliability Management. UK. V. 11, n. 9, p. 43-66.

GOMES, P.A. (2004). Evolução do conceito de Qualidade: dos bens manufaturados aos serviços de informação. Cadernos BAD. v. 2, pp. 6-18.

GRONROOS, C. (1984). A service quality model and its marketing implications. European Journal of marketing, 18(4), 36-44.

HU, K. C., \& JEN, W. (1999). Developing City Bus Service Quality Dimensions - Taipei as an Example. Journal of The Eastern Asia Society for Transportation Studies. Vol. 3, n.2, September, 349-363.

IATA, International Air Transport Association. (2004). Airport Development Refrence Manual. 9 ed., Canadá.

KEENEY, R. L. (1992). Value-foused Thinking: a Path to Creative Decisionmaking. London, England: Harvard University Press.

KEENEY, R. L., \& RAIFFA, H. (1993). Decisions with multiple objectives: preferences and value trade-offs. Cambridge, England: Cambridge university press.

LUBECK, R. M., WITTMANN, M. L., BATTISTELlA, L. F., RICHTER, A. S., SCHENDLER, S.G. (2011). Qualidade no transporte coletivo urbano. FACEF PESQUISA, Franca, v.14, n.3, p. 264-277, set./out./nov./dez.

MURAlHA, M. (1990). Contribuição para Análise do Desempenho do Sistema de Transporte de Passageiros por Ônibus. Dissertação de Mestrado. COPPE/UFRJ, Rio de Janeiro, RJ, Brasil.

PALADINI, E. P., BRIDI, E. (2013). Gestão e avaliação da qualidade em serviços para organizações competitivas: estratégias básicas e o cliente misterioso. São Paulo: Atlas.

PALADINI. E. P. (2011). Gestão da Qualidade: Teoria e Prática. 2. ed. - 11. Reimpressão. São Paulo: Atlas.

PARASURAMAN, A., ZEITHAML, V. A., \& BERRY, L. L. (1988). Servqual. Journal of retailing, 64(1), 12-40. 
PEREIRA NETO, W. A. (2001). Modelo Multicritério de Avaliação do Desempenho Operacional do Transporte Coletivo por ônibus no Município de Fortaleza. Dissertação de Mestrado. EFCE. Fortaleza-CE.

QUIRINO, M. G. (2002). Incorporação das Relações de Subordinação na Matriz de Ordenação - Roberts em MCDA quando os Axiomas de Assimetria e Transitividade Negativa são Violados. Tese de Doutorado em Engenharia de Produção, Universidade Federal de Santa Catarina. Florianópolis, SC, Brasil.

RIBEIRO, A. C. S. e FREITAS, A. L. P. (2012). Emprego da análise de regressão múltipla na identificação dos fatores relevantes na qualidade do transporte rodoviário intermunicipal de passageiros. XIX Simpósio de Engenharia de Produção - SIMPEP. Baurú-SP.

RODRIGUES, M. A., \& SORRATINI, J. A. (2008). A qualidade no transporte coletivo urbano. XXII Congresso de Pesquisa e Ensino em Transportes, Fortaleza, CE. Panorama nacional da pesquisa em transportes 2008: XXII ANPET. Rio de Janeiro, RJ: ANPET - Associação Nacional de Pesquisa e Ensino em Transportes, p. 1081-1092.

ROY, B. (1996). Multicriteria methodology for decision aiding (Vol. 12). Dordrecht. Netherlands: Springer Science \& Business Media.

SLACK, N.; CHAMBERS, S.; JOHNSTON, R. (2009). Administração da Produção. Tradução de Maria Teresa Corrêa de Oliveira. 3. ed. - São Paulo: Atlas.

SILVA, G. R., SANTOS, J. G., AGUIAR, E. C., SANTOS, J. G. (2014). Qualidade na percepção dos usuários de ônibus: uma aplicação da escala Servqual em Caruaru-PE. Revista Eletrônica Interdisciplinar em Negócios Hospitalares - REINH, ano I, vol. 01, N. 1, Jaboatão dos Guararapes - PE.

TEBOUL, J. (1991). Gerenciando a Dinâmica da Qualidade. Tradução de Heloisa MartinsCosta. Rio de Janeiro: Qualitymark editora.

TRB (2000). Highway Capacity Manual. Transportation Research Board. Nacional Research Council, Washington, D.C.

VERGARA, S. C. (2011). Projetos e relatórios de pesquisa em administração. $13^{\mathrm{a}}$ Ed. São Paulo: Atlas.

VINCKE, P. (1992). Multicriteria decision-aid. Nova Jérsei. EUA: John Wiley \& Sons.

Wagner, H. M. (1986). Pesquisa operacional. 2. ed. Traduzido por Paulo Antônio Mariotto, sob a supervisão de Fábio Luiz Mariotto. Rio de Janeiro: Prentice-hall do Brasil.

ZAMCOPÉ, F. C.; ENSSLIN, L.; ENSSLIN, S. R. (2012). Construção de um Modelo para Avaliação da Sustentabilidade Corporativa: Um Estudo de Caso na Indústria Têxtil. Revista Gestão e Produção, vol. 19, n. 2, p. 303-321.

ZEINTHAML, V. A., BITNER, M. J., GREMLER, D. D. (2014). Marketing de serviços: a empresa com foco no cliente. Tradução de Felix Nonnenmacher. $6^{\mathrm{a}}$ ed. Porto Alegre: AMGH. 
APÊNDICES 


\section{APÊNDICE A - Matrizes de Julgamento Semântico}

\begin{tabular}{|c|c|c|c|c|c|c|c|}
\hline \multicolumn{7}{|c|}{ yㅡㄹ Câmera de Monitoramento } & 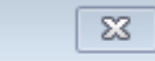 \\
\hline 圈 & $A$ & B & C & $\mathrm{D}$ & $E$ & $\begin{array}{l}\text { Escala } \\
\text { actual }\end{array}$ & extrema \\
\hline$A$ & nula & frac-mod & moderada & forte & mt. forte & 120 & mt. forte \\
\hline$B$ & & nula & moderada & positiva & fort-mfort & 100 & forte \\
\hline C & & & nula & fraca & forte & 45 & moderada \\
\hline D & & & & nula & mfrac-frac & 0 & fraca \\
\hline$E$ & & & & & nula & -40 & nula \\
\hline
\end{tabular}

Matriz de Julgamento Semântico do item de avaliação 1.1.1 - Câmera de Monitoramento

\begin{tabular}{|c|c|c|c|c|c|c|c|}
\hline \multicolumn{7}{|c|}{ Wy lluminação no Interior do Ônibus } & 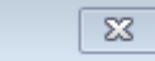 \\
\hline 畻 & $A$ & B & C & $\mathrm{D}$ & $E$ & $\begin{array}{l}\text { Escala } \\
\text { actual }\end{array}$ & extrema \\
\hline $\mathrm{A}$ & nula & frac-mod & mod-fort & forte & fort-mfort & 150 & mt. forte \\
\hline B & & nula & fraca & positiva & forte & 100 & forte \\
\hline C & & & nula & frac-mod & mod-fort & 50 & moderada \\
\hline D & & & & nula & fraca & 0 & fraca \\
\hline$E$ & & & & & nula & -50 & nula \\
\hline
\end{tabular}

Matriz de Julgamento Semântico do item de avaliação 1.1.2 - Iluminação no Interior do Ônibus

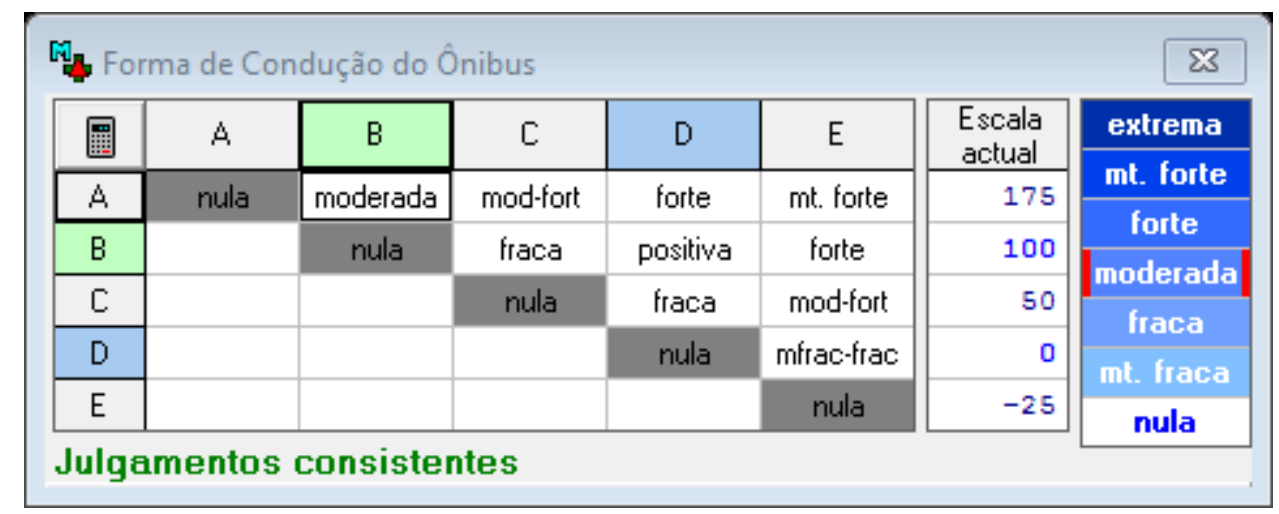

Matriz de Julgamento Semântico do item de avaliação 1.1.3 - Forma de Condução do Ônibus 


\begin{tabular}{|c|c|c|c|c|c|c|c|}
\hline \multicolumn{7}{|c|}{ 글 Agressão Moral no Interior do Ônibus } & $\Sigma 3$ \\
\hline 峴 & A & B & C & D & $E$ & $\begin{array}{l}\text { Escala } \\
\text { actual }\end{array}$ & extrema \\
\hline$A$ & nula & frac-mod & moderada & forte & mfort-extr & 120 & mt. forte \\
\hline B & & nula & moderada & positiva & fort-mfort & 100 & forte \\
\hline C & & & nula & fraca & forte & 45 & moderada \\
\hline D & & & & nula & fraca & 0 & fraca \\
\hline$E$ & & & & & nula & -40 & nula \\
\hline Julg & . & nsis & & & & & \\
\hline
\end{tabular}

Matriz de Julgamento Semântico do item de avaliação 1.2.1 - Agressão Moral do Interior do Ônibus

\begin{tabular}{|c|c|c|c|c|c|c|c|}
\hline \multicolumn{7}{|c|}{ Why Discussão com a Tripulação } & $\mathscr{E}$ \\
\hline 瞒 & $A$ & $B$ & C & D & $E$ & $\begin{array}{l}\text { Escala } \\
\text { actual }\end{array}$ & extrema \\
\hline$A$ & nula & moderada & mod-fort & mt. forte & mfort-extr & 160 & mt. forte \\
\hline B & & nula & moderada & positiva & mt. forte & 100 & forte \\
\hline C & & & nula & frac-mod & fort-mfort & 40 & moderada \\
\hline D & & & & nula & fraca & 0 & fraca \\
\hline$E$ & & & & & nula & -40 & nula \\
\hline
\end{tabular}

Matriz de Julgamento Semântico do item de avaliação 1.2.2 - Discussão com a Tripulação

\begin{tabular}{|c|c|c|c|c|c|c|c|}
\hline \multicolumn{7}{|c|}{ Wy Continuidade do Serviço } & $\Sigma 3$ \\
\hline 觧 & A & B & C & D & $E$ & $\begin{array}{l}\text { Escala } \\
\text { actual }\end{array}$ & extrema \\
\hline$A$ & nula & forte & fort-mfort & mfort-extr & extrema & 150 & mt. forte \\
\hline B & & nula & fort-mfort & positiva & mfort-extr & 100 & forte \\
\hline C & & & nula & forte & mt. forte & 50 & moderada \\
\hline D & & & & nula & fort-mfort & 0 & fraca \\
\hline$E$ & & & & & nula & -50 & mt. fraca \\
\hline Julg & 100 & & & & & & nula \\
\hline
\end{tabular}

Matriz de Julgamento Semântico do item de avaliação 2.1 - Continuidade do Serviço 


\begin{tabular}{|c|c|c|c|c|c|c|c|}
\hline \multicolumn{7}{|c|}{ Wh Cumprimento da Programação } & 83 \\
\hline 眻 & $A$ & $\mathrm{~B}$ & C & D & $E$ & $\begin{array}{l}\text { Escala } \\
\text { actual }\end{array}$ & extrema \\
\hline$A$ & nula & moderada & forte & mt. forte & mfort-extr & 160 & mt. forte \\
\hline$B$ & & nula & frac-mod & positiva & mt. forte & 100 & forte \\
\hline C & & & nula & moderada & fort-mfort & 60 & moderada \\
\hline D & & & & nula & forte & 0 & fraca \\
\hline$E$ & & & & & nula & -80 & nula \\
\hline
\end{tabular}

Matriz de Julgamento Semântico do item de avaliação 2.2 - Cumprimento de Programação

\begin{tabular}{|c|c|c|c|c|c|c|c|}
\hline \multicolumn{7}{|c|}{ M. Cumprimento de Itinerários } & 83 \\
\hline 眻 & $A$ & B & C & D & $\mathrm{E}$ & $\begin{array}{l}\text { Escala } \\
\text { actual }\end{array}$ & extrema \\
\hline$A$ & nula & moderada & mod-fort & mt. forte & mfort-extr & 160 & mit. forte \\
\hline B & & nula & frac-mod & positiva & mt. forte & 100 & Ionte \\
\hline C & & & nula & mod-fort & fort-mfort & 60 & mutratad \\
\hline D & & & & nula & frac-mod & 0 & fraca \\
\hline & & & & & & & mt. fraca \\
\hline$E$ & & & & & nula & -40 & nula \\
\hline
\end{tabular}

Matriz de Julgamento Semântico do item de avaliação 2.3 - Cumprimento de Itinerários

\begin{tabular}{|c|c|c|c|c|c|c|c|}
\hline \multicolumn{7}{|c|}{ In Intervalo entre os Onibus } & $\mathbb{X}$ \\
\hline 圈 & $A$ & B & C & D & $E$ & Escala & extrema \\
\hline A & nula & frac-mod & moderada & forte & $\mathrm{mt}$ forte & 130 & mt. forte \\
\hline B & & nula & moderada & positiva & fort-mfort & 100 & forte \\
\hline C & & & nula & frac-mod & forte & 55 & moderada \\
\hline D & & & & noln & fraos & & fraca \\
\hline & & & & & rusta & -20 & nula \\
\hline
\end{tabular}

Matriz de Julgamento Semântico do item de avaliação 2.4 - Intervalo entre os Ônibus 


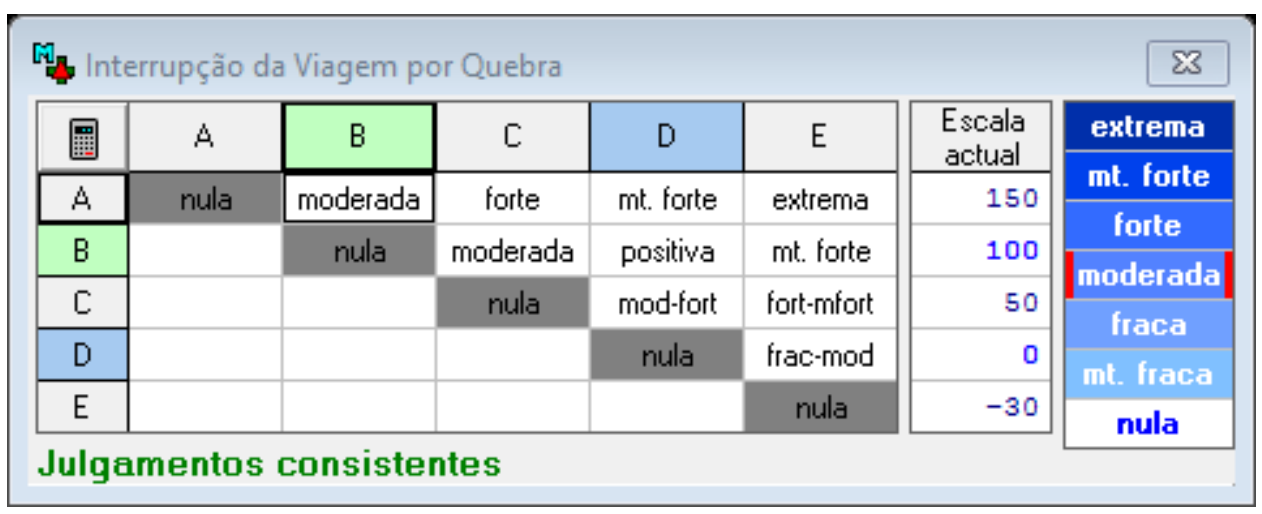

Matriz de Julgamento Semântico do item de avaliação 2.5 - Interrupção da Viagem por Quebra

\begin{tabular}{|c|c|c|c|c|c|c|c|}
\hline \multicolumn{7}{|c|}{ Wempo na Fila dos Terminais } & $\mathbb{3}$ \\
\hline 睠 & A & B & C & D & $E$ & $\begin{array}{l}\text { Escala } \\
\text { actual }\end{array}$ & extrema \\
\hline A & nula & frac-mod & mod-fort & fort-mfort & mfort-extr & 140 & mt. forte \\
\hline B & & nula & frac-mod & positiva & fort-mfort & 100 & forte \\
\hline C & & & nula & mod-fort & forte & 60 & moderada \\
\hline D & & & & nula & frac-mod & 0 & fraca \\
\hline $\mathrm{E}$ & & & & & nula & -40 & mt. fraca \\
\hline & & & & & & & nula \\
\hline
\end{tabular}

Matriz de Julgamento Semântico do item de avaliação 3.1.1 - Tempo na Fila dos Terminais

\begin{tabular}{|c|c|c|c|c|c|c|c|}
\hline \multicolumn{7}{|c|}{ 的 Tempo de Embarque } & $\Sigma 3$ \\
\hline 峴 & $A$ & B & C & D & $E$ & $\begin{array}{l}\text { Escala } \\
\text { actual }\end{array}$ & extrema \\
\hline$A$ & nula & mod-fort & forte & mt. forte & mfort-extr & 150 & mt. forte \\
\hline B & & nula & moderada & positiva & mt. forte & 100 & forte \\
\hline C & & & nula & moderada & fort-mfort & 50 & moderada \\
\hline D & & & & nula & faca & & fraca \\
\hline & & & & & & & mt. fraca \\
\hline$E$ & & & & & nula & -33 & nula \\
\hline
\end{tabular}

Matriz de Julgamento Semântico do item de avaliação 3.1.1 - Tempo de Embarque 


\begin{tabular}{|c|c|c|c|c|c|c|c|}
\hline \multicolumn{7}{|c|}{ Acesso a Assentos Especiais } & 83 \\
\hline 眻 & $A$ & $B$ & C & D & $E$ & $\begin{array}{l}\text { Escala } \\
\text { actual }\end{array}$ & extrema \\
\hline A & nula & frac-mod & mod-fort & forte & mt. forte & 150 & mt. forte \\
\hline$B$ & & nula & frac-mod & positiva & forte & 100 & forte \\
\hline C & & & nula & fraca & mod-fort & 50 & moderada \\
\hline D & & & & nula & fraca & 0 & fraca \\
\hline$E$ & & & & & nula & -50 & nula \\
\hline Julc & & nsis & & & & & \\
\hline
\end{tabular}

Matriz de Julgamento Semântico do item de avaliação 3.2.1 - Acesso a Assentos Especiais

\begin{tabular}{|c|c|c|c|c|c|c|c|}
\hline \multicolumn{7}{|c|}{ Facilidade para Pagamento das Passagens } & $\mathbb{X}$ \\
\hline 䊫 & A & B & C & D & $E$ & $\begin{array}{l}\text { Escala } \\
\text { actual }\end{array}$ & extrema \\
\hline A & nula & fraca & mod-fort & fort-mfort & mfort-extr & 140 & mt. forte \\
\hline B & & nula & mod-fort & positiva & mt. forte & 100 & forte \\
\hline C & & & nula & frac-mod & forte & 40 & moderada \\
\hline & & & & & & & fraca \\
\hline & & & & nula & rlaca & & mt. fraca \\
\hline$E$ & & & & & nula & -40 & nula \\
\hline Julg & nto & nsis & & & & & \\
\hline
\end{tabular}

Matriz de Julgamento Semântico do item de avaliação 3.2.2 - Facilidade para Pagamento das Passagens

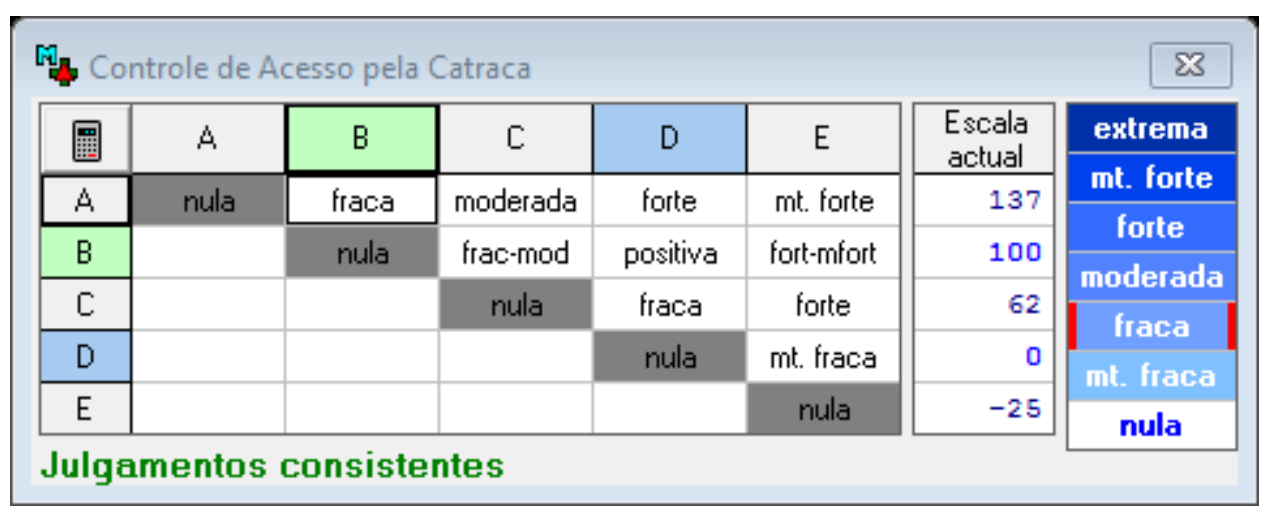

Matriz de Julgamento Semântico do item de avaliação 3.2.3 - Controle de Acesso pela Catraca 


\begin{tabular}{|c|c|c|c|c|c|c|c|}
\hline \multicolumn{7}{|c|}{ Parada Correta no Ponto de Desembarque } & $\Sigma 3$ \\
\hline 峴 & $A$ & B & C & D & $E$ & $\begin{array}{l}\text { Escala } \\
\text { actual }\end{array}$ & extrema \\
\hline $\mathrm{A}$ & nula & mod-fort & forte & mt. forte & mfort-extr & 160 & mt. forte \\
\hline$B$ & & nula & moderada & positiva & mt. forte & 100 & forte \\
\hline C & & & nula & frac-mod & forte & 40 & moderada \\
\hline D & & & & nula & fraca & 0 & fraca \\
\hline$E$ & & & & & nula & -40 & nula \\
\hline Julg & inte & nsis & & & & & \\
\hline
\end{tabular}

Matriz de Julgamento Semântico do item de avaliação 3.3.1 - Parada Correta no Ponto de Desembarque

\begin{tabular}{|c|c|c|c|c|c|c|c|}
\hline \multicolumn{7}{|c|}{ M. Tempo de Parada Adequado para o Desembarque } & 83 \\
\hline 峴 & A & B & C & D & $E$ & $\begin{array}{l}\text { Escala } \\
\text { actual }\end{array}$ & extrema \\
\hline$A$ & nula & frac-mod & mod-fort & fort-mfort & mfort-extr & 150 & mt. forte \\
\hline$B$ & & nula & frac-mod & positiva & mt. forte & 100 & forte \\
\hline C & & & nula & fraca & forte & 50 & moderada \\
\hline D & & & & nula & frac-mod & 0 & fraca \\
\hline$E$ & & & & & nula & -50 & \multirow{2}{*}{ nula } \\
\hline Julg & ento & nsist & & & & & \\
\hline
\end{tabular}

Matriz de Julgamento Semântico do item de avaliação 3.3.2 - Tempo de Parada Adequado para o Desembarque

\begin{tabular}{|c|c|c|c|c|c|c|c|}
\hline \multicolumn{7}{|c|}{ Wy Sinalização Horizontal para Filas } & 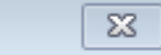 \\
\hline 眻 & A & B & C & D & $\mathrm{E}$ & $\begin{array}{l}\text { Escala } \\
\text { actual }\end{array}$ & extrema \\
\hline$A$ & nula & frac-mod & moderada & mod-fort & forte & 157 & mt. forte \\
\hline B & & nula & frac-mod & positiva & mod-fort & 100 & forte \\
\hline C & & & nula & mfrac-frac & moderada & 43 & moderada \\
\hline D & & & & nula & mfrac-frac & 0 & fraca \\
\hline$E$ & & & & & nula & -42 & nula \\
\hline Julg & nto & nsist & tes & & & & \\
\hline
\end{tabular}

Matriz de Julgamento Semântico do item de avaliação 4.1.1 - Sinalização Horizontal para Filas 


\begin{tabular}{|c|c|c|c|c|c|c|c|}
\hline \multicolumn{7}{|c|}{ W. Identificação do Local de Saída dos Ônibus } & $\Sigma 3$ \\
\hline 峴 & $A$ & B & C & D & $E$ & $\begin{array}{l}\text { Escala } \\
\text { actual }\end{array}$ & extrema \\
\hline $\mathrm{A}$ & nula & frac-mod & moderada & mod-fort & forte & 150 & mt. forte \\
\hline B & & nula & fraca & positiva & mod-fort & 100 & forte \\
\hline C & & & nula & fraca & moderada & 50 & moderada \\
\hline D & & & & nula & fraca & 0 & fraca \\
\hline$E$ & & & & & nula & -50 & nula \\
\hline Julg & inte & nsis & & & & & \\
\hline
\end{tabular}

Matriz de Julgamento Semântico do item de avaliação 4.1.2 - Identificação do Local de Saída dos Ônibus

\begin{tabular}{|c|c|c|c|c|c|c|c|}
\hline \multicolumn{7}{|c|}{ yㅡㄹ Sinalização Vertical das Linhas } & $\mathbb{Z}$ \\
\hline 䊫 & A & B & C & D & $E$ & $\begin{array}{l}\text { Escala } \\
\text { actual }\end{array}$ & extrema \\
\hline $\mathrm{A}$ & nula & frac-mod & mod-fort & forte & fort-mfort & 150 & mt. forte \\
\hline B & & nula & frac-mod & positiva & forte & 100 & forte \\
\hline C & & & = & fraca & mod fort & 50 & moderada \\
\hline & & & & & & & fraca \\
\hline & & & & & Iraca & 0 & mt. fraca \\
\hline$E$ & & & & & nula & -50 & nula \\
\hline
\end{tabular}

Matriz de Julgamento Semântico do item de avaliação 4.1.3 - Sinalização Vertical das Linhas

\begin{tabular}{|c|c|c|c|c|c|c|c|}
\hline \multicolumn{7}{|c|}{ Whanfletos Informativos } & $\mathbb{3}$ \\
\hline 踾 & A & B & C & D & $E$ & $\begin{array}{l}\text { Escala } \\
\text { actual }\end{array}$ & extrema \\
\hline A & nula & frac-mod & moderada & forte & mt. forte & 150 & mt. forte \\
\hline B & & nula & frac-mod & positiva & forte & 100 & forte \\
\hline C & & & salo & frangen & modint & & moderada \\
\hline & & & & & & & fraca \\
\hline D & & & & nula & mfrac-frac & 0 & mt. fraca \\
\hline$E$ & & & & & nula & -25 & nula \\
\hline Julg & nto & nsiste & es & & & & \\
\hline
\end{tabular}

Matriz de Julgamento Semântico do item de avaliação 4.1.4 - Panfletos Informativos 


\begin{tabular}{|c|c|c|c|c|c|c|c|}
\hline \multicolumn{7}{|c|}{ W. Informações das Linhas que Passam na Parada } & 83 \\
\hline 眻 & A & B & C & D & $E$ & $\begin{array}{l}\text { Escala } \\
\text { actual }\end{array}$ & extrema \\
\hline $\mathrm{A}$ & nula & moderada & forte & fort-mfort & mfort-extr & 150 & mt. forte \\
\hline$B$ & & nula & mod-fort & positiva & mt. forte & 100 & forte \\
\hline C & & & nula & mod-fort & fort-mfort & 50 & moderada \\
\hline $\mathrm{D}$ & & & & nula & frac-mod & 0 & fraca \\
\hline$E$ & & & & & nula & -33 & \multirow{2}{*}{ nula } \\
\hline Julg & not & Insis & & & & & \\
\hline
\end{tabular}

Matriz de Julgamento Semântico do item de avaliação 4.2.1 - Informações das Linhas que Passam na Parada

\begin{tabular}{|c|c|c|c|c|c|c|c|}
\hline \multicolumn{7}{|c|}{ Wh Informações dos Intervalos Médios entre os Ônibus } & $\mathbb{E}$ \\
\hline 畻 & $A$ & B & C & $\mathrm{D}$ & $\mathrm{E}$ & $\begin{array}{l}\text { Escala } \\
\text { actual }\end{array}$ & extrema \\
\hline A & nula & frac-mod & forte & mt. forte & mfort-extr & s & mt. forte \\
\hline & & $\frac{40}{\text { nula }}$ & frac-mod & $\frac{140}{\text { positiva }}$ & $\frac{180}{m \text { forte }}$ & 170 & forte \\
\hline B & & 0 & 40 & 100 & 140 & 100 & moderada \\
\hline C & & & nula & $\bmod _{60}$ & $\begin{array}{l}\text { fort-mfort } \\
100\end{array}$ & 60 & fraca \\
\hline D & & & & nula & $\underset{40}{\text { frac-mod }}$ & 0 & mt. fraca \\
\hline $\mathrm{E}$ & & & & & nula & -40 & nula \\
\hline \multicolumn{8}{|c|}{ Julgamentos consistentes } \\
\hline
\end{tabular}

Matriz de Julgamento Semântico do item de avaliação 4.2.2 - Informações dos Intervalos Médios entre os Ônibus

\begin{tabular}{|c|c|c|c|c|c|c|c|}
\hline \multicolumn{7}{|c|}{ M. Informações sobre os Canais de Acesso a Informações nas Paradas } & $\mathbb{X}$ \\
\hline 畻 & A & B & C & D & $\mathrm{E}$ & $\begin{array}{l}\text { Escala } \\
\text { actual }\end{array}$ & extrema \\
\hline A & nula & fraca & moderada & mod-fort & fort-mfort & 144 & mt. forte \\
\hline B & & nula & fraca & positiva & forte & 100 & forte \\
\hline C & & & nula & frac-mod & forte & 56 & moderada \\
\hline$D$ & & & & nula & fra & & fraca \\
\hline ᄃ & & & & & & & mt. fraca \\
\hline & & & & & Mula & -50 & nula \\
\hline \multicolumn{8}{|c|}{ Julgamentos consistentes } \\
\hline
\end{tabular}

Matriz de Julgamento Semântico do item de avaliação 4.2.3 - Informações sobre os Canais de Acesso a Informações nas Paradas 


\begin{tabular}{|c|c|c|c|c|c|c|c|}
\hline \multicolumn{7}{|c|}{ Wh Letreiros com Informações Claras das Linhas } & $\Sigma$ \\
\hline 踾 & $\mathrm{A}$ & B & C & D & $E$ & $\begin{array}{l}\text { Escala } \\
\text { actual }\end{array}$ & extrema \\
\hline$A$ & nula & frac-mod & mod-fort & fort-mfort & mt. forte & 150 & mt. forte \\
\hline B & & nula & frac-mod & positiva & fort-mfort & 100 & forte \\
\hline C & & & nula & fraca & forte & 50 & moderada \\
\hline D & & & & nula & mfrac-frac & 0 & fraca \\
\hline$E$ & & & & & nula & -50 & mt. fraca \\
\hline Julg & 10 & nsist & & & & & nula \\
\hline
\end{tabular}

Matriz de Julgamento Semântico do item de avaliação 4.3.1 - Letreiros com Informações Claras das Linhas

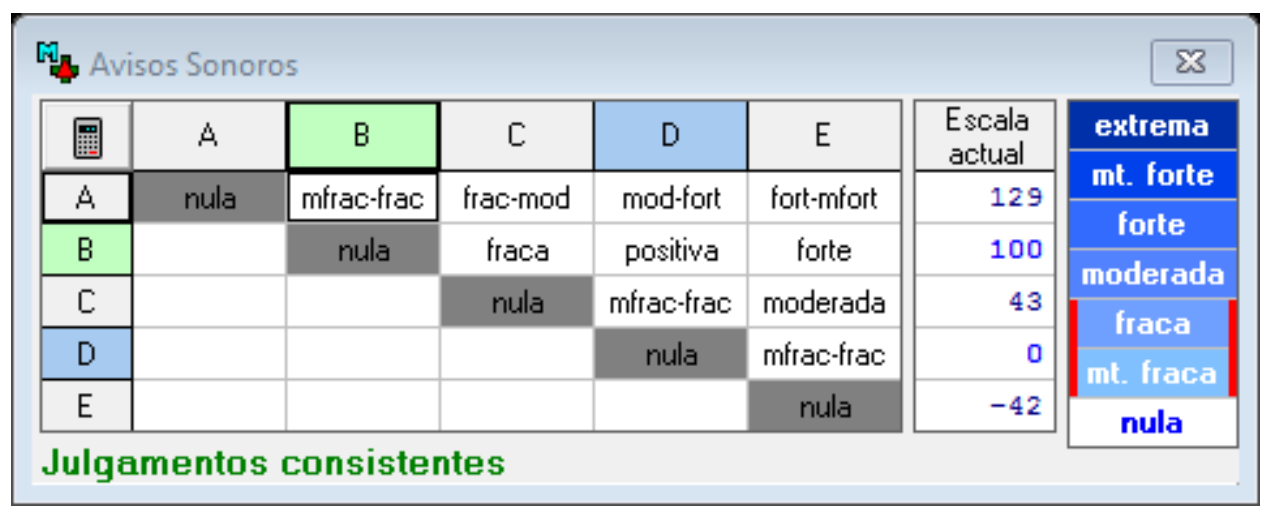

Matriz de Julgamento Semântico do item de avaliação 4.3.2 - Avisos Sonoros

\begin{tabular}{|c|c|c|c|c|c|c|c|}
\hline \multicolumn{7}{|c|}{ Aviso de Solicitação de Parada } & $\sqrt{3}$ \\
\hline 眻 & $A$ & B & C & D & $E$ & $\begin{array}{l}\text { Escala } \\
\text { actual }\end{array}$ & extrema \\
\hline A & nula & fraca & moderada & mod-fort & fort-mfort & 167 & mt. forte \\
\hline B & & nula & mfrac-frac & positiva & Forte & 100 & forte \\
\hline C & & & nula & fraca & mod-fort & 67 & moderada \\
\hline D & & & & nula & mfrac-frac & 0 & fraca \\
\hline F & & & & & nula & -32 & mt. fraca \\
\hline & & & & & & 50 & nula \\
\hline
\end{tabular}

Matriz de Julgamento Semântico do item de avaliação 4.3.3 - Avisos de Solicitação de Paradas 


\begin{tabular}{|c|c|c|c|c|c|c|c|}
\hline \multicolumn{7}{|c|}{ ‥ Mapas de Horários } & $\Sigma 3$ \\
\hline 眻 & $\mathrm{A}$ & B & C & D & $E$ & $\begin{array}{l}\text { Escala } \\
\text { actual }\end{array}$ & extrema \\
\hline $\mathrm{A}$ & nula & frac-mod & forte & fort-mfort & mfort-extr & 140 & mt. forte \\
\hline B & & nula & moderada & positiva & fort-mfort & 100 & forte \\
\hline C & & & nula & frac-mod & mod-fort & 40 & moderada \\
\hline $\mathrm{D}$ & & & & nula & fraca & 0 & fraca \\
\hline$E$ & & & & & nula & -40 & nula \\
\hline Julg & & nsist & & & & & \\
\hline
\end{tabular}

Matriz de Julgamento Semântico do item de avaliação 4.4.1 - Mapas de Horários

\begin{tabular}{|c|c|c|c|c|c|c|c|}
\hline \multicolumn{7}{|c|}{ 的 Valor da Tarifa } & $\Sigma 3$ \\
\hline 嗞 & $A$ & B & C & D & $E$ & $\begin{array}{l}\text { Escala } \\
\text { actual }\end{array}$ & extrema \\
\hline $\mathrm{A}$ & nula & moderada & mod-fort & fort-mfort & mfort-extr & 143 & mt. forte \\
\hline$B$ & & nula & forte & positiva & mt. forte & 100 & forte \\
\hline C & & & nula & frac-mod & moderada & 35 & moderada \\
\hline D & & & & nula & fraca & 0 & fraca \\
\hline$E$ & & & & & nula & -28 & nula \\
\hline Julg & Into & onsiste & & & & & \\
\hline
\end{tabular}

Matriz de Julgamento Semântico do item de avaliação 4.4.2 - Valor da Tarifa

\begin{tabular}{|c|c|c|c|c|c|c|c|}
\hline \multicolumn{7}{|c|}{ Wh Divulgação dos Itinerários das Linhas } & $\mathbb{3}$ \\
\hline 畻 & $A$ & B & C & D & $\mathrm{E}$ & $\begin{array}{l}\text { Escala } \\
\text { actual }\end{array}$ & extrema \\
\hline$A$ & nula & moderada & forte & fort-mfort & mfort-extr & 160 & mt. forte \\
\hline B & & nula & moderada & positiva & mt. forte & 100 & forte \\
\hline C & & & nula & frac-mod & mod-fort & 40 & moderada \\
\hline D & & & & nula & frac-mod & 0 & mt. fraca \\
\hline$E$ & & & & & nula & -40 & nula \\
\hline Julg & nto & onsiste & tes & & & & \\
\hline
\end{tabular}

Matriz de Julgamento Semântico do item de avaliação 4.4.3 - Divulgação dos Itinerários das Linhas 


\begin{tabular}{|c|c|c|c|c|c|c|c|}
\hline \multicolumn{7}{|c|}{ Formas de Pagamento das Tarifas } & $\Sigma 3$ \\
\hline 圈 & $\mathrm{A}$ & B & C & D & $E$ & $\begin{array}{l}\text { Escala } \\
\text { actual }\end{array}$ & extrema \\
\hline$A$ & nula & mfrac-frac & frac-mod & mod-fort & fort-mfort & 133 & mt. forte \\
\hline$B$ & & nula & mfrac-frac & positiva & mod-fort & 100 & forte \\
\hline C & & & nula & fraca & moderada & 67 & moderada \\
\hline D & & & & nula & fraca & 0 & fraca \\
\hline$E$ & & & & & nula & -66 & nula \\
\hline
\end{tabular}

Matriz de Julgamento Semântico do item de avaliação 4.4.4 - Formas de Pagamento das Tarifas

\begin{tabular}{|c|c|c|c|c|c|c|c|}
\hline \multicolumn{7}{|c|}{ W. Informações sobre os Canais de Acesso a Informações Via Internet } & \multirow[b]{2}{*}{ extrema } \\
\hline 圈 & $\mathrm{A}$ & B & C & D & $E$ & $\begin{array}{l}\text { Escala } \\
\text { actual }\end{array}$ & \\
\hline$A$ & nula & fraca & moderada & mod-fort & fort-mfort & 144 & mt. forte \\
\hline$B$ & & nula & fraca & positiva & forte & 100 & forte \\
\hline C & & & nula & frac-mod & forte & 56 & moderada \\
\hline D & & & & nula & fraca & 0 & fraca \\
\hline$E$ & & & & & nula & -55 & nula \\
\hline Julg & & sis & & & & & \\
\hline
\end{tabular}

Matriz de Julgamento Semântico do item de avaliação 4.4.5 - Informações sobre os Canais de Acesso a Informações Via Internet

\begin{tabular}{|c|c|c|c|c|c|c|c|}
\hline \multicolumn{7}{|c|}{ 的 Informações sobre Tarifas } & $\mathbb{3}$ \\
\hline 畻 & A & B & C & D & $\mathrm{E}$ & $\begin{array}{l}\text { Escala } \\
\text { actual }\end{array}$ & extrema \\
\hline A & nula & frac-mod & mod-fort & fort-mfort & mfort-extr & 150 & mt. forte \\
\hline B & & nula & frac-mod & positiva & mt. forte & 100 & forte \\
\hline C & & & nula & flaca & forte & 50 & moderada \\
\hline & & & & & & & fraca \\
\hline & & & & & & & mt. fraca \\
\hline$E$ & & & & & nula & -50 & nula \\
\hline
\end{tabular}

Matriz de Julgamento Semântico do item de avaliação 4.5.1 - Informações sobre Tarifas 


\begin{tabular}{|c|c|c|c|c|c|c|c|}
\hline \multicolumn{7}{|c|}{ Why Informações de Horários } & $\mathbb{E}$ \\
\hline 眻 & $A$ & B & C & D & $E$ & $\begin{array}{l}\text { Escala } \\
\text { actual }\end{array}$ & extrema \\
\hline$A$ & nula & frac-mod & mod-fort & mt. forte & mfort-extr & 140 & mt. forte \\
\hline$B$ & & nula & moderada & positiva & mt. forte & 100 & forte \\
\hline C & & & nula & frac-mod & fort-mfort & 40 & moderada \\
\hline D & & & & nula & fraca & 0 & fraca \\
\hline$E$ & & & & & nula & -40 & mt. fraca \\
\hline & & & & & & & nula \\
\hline
\end{tabular}

Matriz de Julgamento Semântico do item de avaliação 4.5.2 - Informações de Horários

\begin{tabular}{|c|c|c|c|c|c|c|c|}
\hline \multicolumn{7}{|c|}{ Whegistro de Reclamações } & $\mathbb{E}$ \\
\hline 峴 & A & B & C & D & $\mathrm{E}$ & $\begin{array}{l}\text { Escala } \\
\text { actual }\end{array}$ & extrema \\
\hline A & nula & mfrac-frac & frac-mod & mod-fort & fort-mfort & 125 & mt. Forte \\
\hline B & & nula & fraca & positiva & mod-fort & 100 & forte \\
\hline C & & & nula & fraca & moderada & 50 & Illoueraud \\
\hline & & & & & & & fraca \\
\hline U & & & & nula & rrac-mod & 0 & mt. fraca \\
\hline $\mathrm{E}$ & & & & & nula & -50 & nula \\
\hline
\end{tabular}

Matriz de Julgamento Semântico do item de avaliação 4.5.3 - Registro de Reclamações

\begin{tabular}{|c|c|c|c|c|c|c|c|}
\hline \multicolumn{7}{|c|}{ In Informações sobre os Canais de Acesso a Informações via SAC } & $\mathfrak{X}$ \\
\hline 圈 & A & B & C & D & $\mathrm{E}$ & $\begin{array}{l}\text { Escala } \\
\text { actual }\end{array}$ & extrema \\
\hline A & nula & frac-mod & moderada & forte & fort-mfort & 167 & mt. Torte \\
\hline B & & nula & fraca & positiva & forte & 100 & ronte \\
\hline C & & & nula & mfrac-frac & frac-mod & 33 & moderada \\
\hline D & & & & nula & fraca & 0 & mot fore \\
\hline $\mathrm{E}$ & & & & & nula & -66 & nula \\
\hline
\end{tabular}

Matriz de Julgamento Semântico do item de avaliação 4.5.4 - Informações sobre os Canais de Acesso a Informações via SAC 


\begin{tabular}{|c|c|c|c|c|c|c|c|}
\hline \multicolumn{7}{|c|}{ Atualidade da Frota } & 83 \\
\hline 峴 & A & B & C & D & $E$ & $\begin{array}{l}\text { Escala } \\
\text { actual }\end{array}$ & extrema \\
\hline$A$ & nula & frac-mod & mod-fort & fort-mfort & mt. forte & 150 & mt. forte \\
\hline B & & nula & fraca & positiva & fort-mfort & 100 & forte \\
\hline C & & & nula & fraca & mod-fort & 50 & moderada \\
\hline $\mathrm{D}$ & & & & nula & mfrac-frac & 0 & fraca \\
\hline$E$ & & & & & nula & -25 & \multirow{2}{*}{ nula } \\
\hline Julg & & nsist & & & & & \\
\hline
\end{tabular}

Matriz de Julgamento Semântico do item de avaliação 5.1 - Atualidade da Frota

\begin{tabular}{|c|c|c|c|c|c|c|c|}
\hline \multicolumn{7}{|c|}{ Espaço entre os Bancos } & $\mathbb{Z}$ \\
\hline 峴 & $A$ & B & C & D & $E$ & $\begin{array}{l}\text { Escala } \\
\text { actual }\end{array}$ & extrema \\
\hline A & nula & frac-mod & mod-fort & fort-mfort & mfort-extr & 133 & mt. forte \\
\hline B & & nula & moderada & positiva & fort-mfort & 100 & forte \\
\hline C & & & 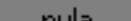 & & & & moderada \\
\hline & & & & & & & fraca \\
\hline & & & & nula & Trac-mou & 0 & mt. fraca \\
\hline $\mathrm{E}$ & & & & & nula & -33 & nula \\
\hline
\end{tabular}

Matriz de Julgamento Semântico do item de avaliação 5.2 - Espaço entre os Bancos

\begin{tabular}{|c|c|c|c|c|c|c|c|}
\hline \multicolumn{7}{|c|}{ Espaço no Corredor } & $\mathscr{E}$ \\
\hline 畻 & A & B & C & D & $\mathrm{E}$ & $\begin{array}{l}\text { Escala } \\
\text { actual }\end{array}$ & extrema \\
\hline$A$ & nula & frac-mod & mod-fort & mt. forte & mfort-extr & 133 & mt. forte \\
\hline$B$ & & nula & moderada & positiva & mt. forte & 100 & forte \\
\hline C & & & nula & moderada & forte & 50 & moderada \\
\hline D & & & & nula & fraca & 0 & fraca \\
\hline $\mathrm{E}$ & & & & & nula & -33 & mt. fraca \\
\hline & & & & & & & nula \\
\hline
\end{tabular}

Matriz de Julgamento Semântico do item de avaliação 5.3 - Espaço no Corredor 


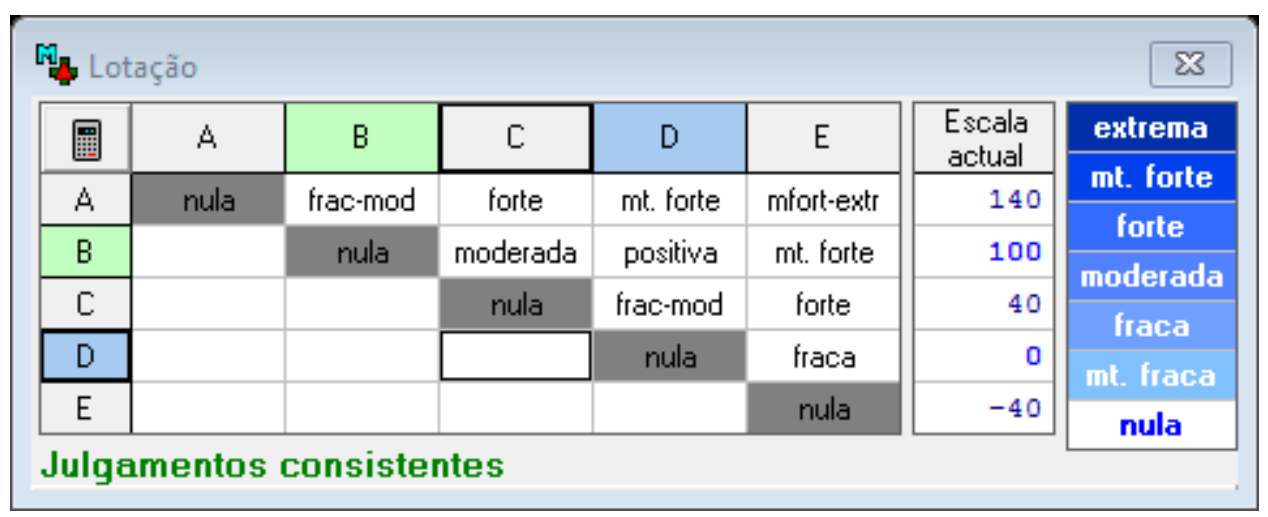

Matriz de Julgamento Semântico do item de avaliação 5.4 - Lotação

\begin{tabular}{|c|c|c|c|c|c|c|c|}
\hline \multicolumn{7}{|c|}{ ㄲy Ventilação } & $\mathbb{X}$ \\
\hline 畻 & $A$ & B & C & D & $E$ & $\begin{array}{l}\text { Escala } \\
\text { actual }\end{array}$ & extrema \\
\hline A & nula & frac-mod & moderada & forte & $\mathrm{mt}$. forte & 150 & mt. forte \\
\hline B & & nula & fraca & positiva & fort-mfort & 100 & forte \\
\hline C & & & nula & fraca & mod-fort & 50 & moderada \\
\hline D & & & & nula & frac-mod & 0 & fraca \\
\hline$E$ & & & & & nula & -50 & nula \\
\hline Julg & & insiste & tes & & & & \\
\hline
\end{tabular}

Matriz de Julgamento Semântico do item de avaliação 5.5 - Ventilação

\begin{tabular}{|c|c|c|c|c|c|c|c|}
\hline \multicolumn{7}{|c|}{ 골 Temperatura no Interior do Ônibus } & $\mathscr{E}$ \\
\hline 眻 & A & B & C & D & $E$ & $\begin{array}{l}\text { Escala } \\
\text { actual }\end{array}$ & extrema \\
\hline$A$ & nula & frac-mod & mod-fort & fort-mfort & mt. forte & 140 & mt. forte \\
\hline B & & nula & moderada & positiva & fort-mfort & 100 & forte \\
\hline C & & & nula & frac-mod & mod-fort & 40 & moderada \\
\hline D & & & & nula & frac-mod & & fraca \\
\hline & & & & & & & mt. fraca \\
\hline$E$ & & & & & nula & -40 & nula \\
\hline \multicolumn{8}{|c|}{ Julgamentos consistentes } \\
\hline
\end{tabular}

Matriz de Julgamento Semântico do item de avaliação 5.6 - Temperatura no Interior do Ônibus 


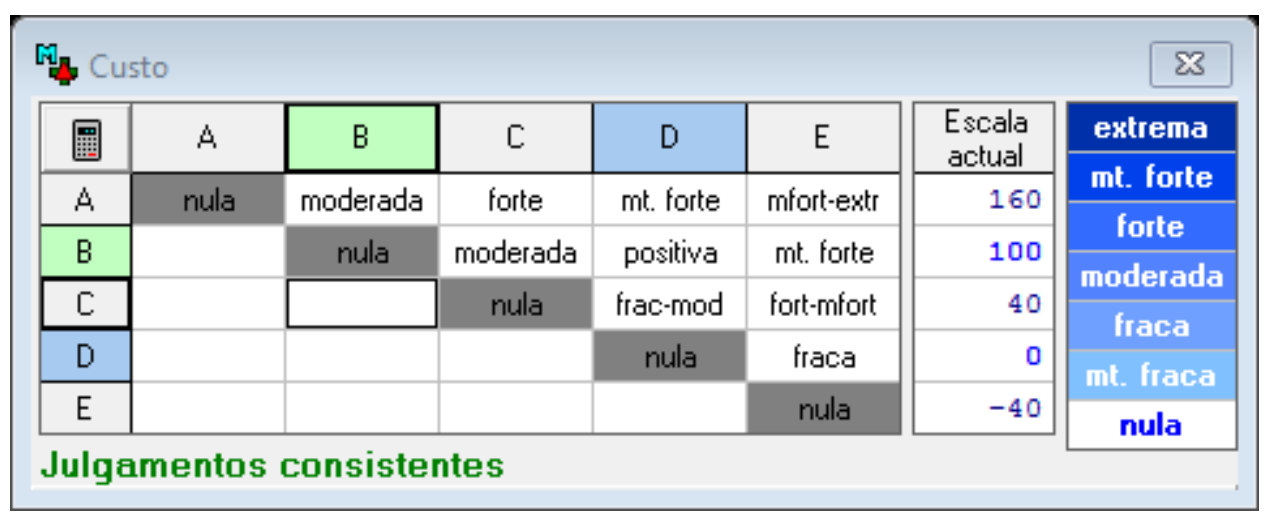

Matriz de Julgamento Semântico do item de avaliação 6 - Custo

\begin{tabular}{|c|c|c|c|c|c|c|c|}
\hline \multicolumn{7}{|c|}{ Wy Parada Fora dos Pontos de Parada/Terminais } & $\mathscr{E}$ \\
\hline 囬 & $\mathrm{A}$ & B & C & $\mathrm{D}$ & $\mathrm{E}$ & $\begin{array}{l}\text { Escala } \\
\text { actual }\end{array}$ & extrema \\
\hline$A$ & nula & frac-mod & mod-fort & fort-mfort & mfort-extr & 140 & mt. forte \\
\hline B & & nula & moderada & positiva & mt. forte & 100 & forte \\
\hline C & & & nula & frac-mod & forte & 40 & moderada \\
\hline & & & & & & & fraca \\
\hline 0 & & & & nula & fraca & 0 & mt. fraca \\
\hline $\mathrm{E}$ & & & & & nula & -40 & nula \\
\hline \multicolumn{8}{|c|}{ Julgamentos consistentes } \\
\hline
\end{tabular}

Matriz de Julgamento Semântico do item de avaliação 7.1.1 - Parada Fora dos pontos de Parada/Terminais

\begin{tabular}{|c|c|c|c|c|c|c|c|}
\hline \multicolumn{7}{|c|}{ Troca Constante de Tripulação } & $\mathbb{3}$ \\
\hline 畻 & A & B & C & D & $\mathrm{E}$ & $\begin{array}{l}\text { Escala } \\
\text { actual }\end{array}$ & extrema \\
\hline A & nula & frac-mod & mod-fort & forte & mt. forte & 150 & mt. forte \\
\hline B & & nula & frac-mod & positiva & fort-mfort & 100 & forte \\
\hline C & & & nula & fraca & mod fort & 50 & moderada \\
\hline D & & & & & & & fraca \\
\hline $\mathrm{E}$ & & & & & nula & -25 & nula \\
\hline
\end{tabular}

Matriz de Julgamento Semântico do item de avaliação 7.1.2 - Troca Constante de Tripulação 


\begin{tabular}{|c|c|c|c|c|c|c|c|}
\hline \multicolumn{7}{|c|}{ Wh Tripulação com Aparência de Cansada } & $\Sigma 3$ \\
\hline 咩 & $A$ & B & C & D & $E$ & $\begin{array}{l}\text { Escala } \\
\text { actual }\end{array}$ & extrema \\
\hline$A$ & nula & fraca & mod-fort & fort-mfort & mfort-extr & 140 & mt. forte \\
\hline$B$ & & nula & frac-mod & positiva & fort-mfort & 100 & forte \\
\hline C & & & nula & moderada & fort-mfort & 60 & moderada \\
\hline D & & & & nula & frac-mod & 0 & fraca \\
\hline$E$ & & & & & nula & -40 & nula \\
\hline Julg & & si & & & & & \\
\hline
\end{tabular}

Matriz de Julgamento Semântico do item de avaliação 7.2.1 - Tripulação com Aparência de Cansada

\begin{tabular}{|c|c|c|c|c|c|c|c|}
\hline \multicolumn{7}{|c|}{ Wy. Tripulação com Alteração de Comportamento } & \multirow[b]{2}{*}{ extrema } \\
\hline 眻 & $\mathrm{A}$ & B & C & D & $E$ & $\begin{array}{l}\text { Escala } \\
\text { actual }\end{array}$ & \\
\hline$A$ & nula & frac-mod & forte & fort-mfort & mt. forte & 150 & mt. forte \\
\hline$B$ & & nula & fraca & positiva & fort-mfort & 100 & forte \\
\hline C & & & nula & frac-mod & mod-fort & 50 & moderada \\
\hline D & & & & nula & mfrac-frac & 0 & fraca \\
\hline$E$ & & & & & nula & -25 & mt. fraca \\
\hline & & & & & & & nula \\
\hline
\end{tabular}

Matriz de Julgamento Semântico do item de avaliação 7.2.2 - Tripulação com Alteração de Comportamento

\begin{tabular}{|c|c|c|c|c|c|c|c|}
\hline \multicolumn{7}{|c|}{ Mr Tripulação Atende Pedido de Informações } & $\sqrt{3}$ \\
\hline 囬 & A & B & C & D & E & $\begin{array}{l}\text { Escala } \\
\text { actual }\end{array}$ & extrema \\
\hline A & nula & fraca & mod-fort & fort-mfort & mt. forte & 150 & mt. forte \\
\hline B & & nula & fraca & positiva & forte & 100 & forte \\
\hline C & & & ב & $f_{r}=0 \mathrm{mod}$ & mod for & & moderada \\
\hline & & & & & & & fraca \\
\hline D & & & & nula & mfrac-frac & 0 & mt. fraca \\
\hline $\mathrm{E}$ & & & & & nula & -25 & nula \\
\hline Julg & nto & sis & & & & & \\
\hline
\end{tabular}

Matriz de Julgamento Semântico do item de avaliação 7.3.1 - Tripulação Atende Pedido de Informações 


\begin{tabular}{|c|c|c|c|c|c|c|c|}
\hline \multicolumn{7}{|c|}{ W. Despachantes Orientam Formação de Filas } & 83 \\
\hline 峴 & A & B & C & D & $\mathrm{E}$ & Escala & extrema \\
\hline A & nula & fraca & frac-mod & forte & mt. forte & 157 & mt. forte \\
\hline $\bar{B}$ & & nula & fraca & positiva & forte & 100 & forte \\
\hline$\Gamma$ & & & $2=$ & menoth & mod tort & 42 & moderada \\
\hline & & & riula & Tinat-mat & 17000 & 70 & fraca \\
\hline D & & & & nula & mfrac-frac & 0 & mt. fraca \\
\hline $\mathrm{E}$ & & & & & nula & -42 & nula \\
\hline \multicolumn{8}{|l|}{ Julg } \\
\hline
\end{tabular}

Matriz de Julgamento Semântico do item de avaliação 7.3.2 - Despachantes Orientam Formação de Filas 
APÊNDICE B - Descritores

\begin{tabular}{|c|c|l|c|}
\hline \multicolumn{5}{|c|}{ 1.1.1 - Câmera de Monitoramento } \\
\hline $\begin{array}{c}\text { Níveis } \\
\text { de } \\
\text { Impacto }\end{array}$ & $\begin{array}{c}\text { Níveis de } \\
\text { Referência }\end{array}$ & Descrição & $\begin{array}{c}\text { Função } \\
\text { de Valor }\end{array}$ \\
\hline N5 & & Plenamente Satisfeito & 120 \\
\hline N4 & Bom & Satisfeito & 100 \\
\hline N3 & & Indiferente & 45 \\
\hline N2 & Neutro & Insatisfeito & 0 \\
\hline N1 & & Plenamente Insatisfeito & -40 \\
\hline
\end{tabular}

Descritor do item de avaliação 1.1.1 - Câmera de Monitoramento

\begin{tabular}{|c|c|l|c|}
\hline \multicolumn{5}{|c|}{1.1 .2 - Iluminação no Interior do Ônibus } \\
\hline $\begin{array}{c}\text { Níveis } \\
\text { de } \\
\text { Impacto }\end{array}$ & $\begin{array}{c}\text { Níveis de } \\
\text { Referência }\end{array}$ & Descrição & $\begin{array}{c}\text { Função } \\
\text { de Valor }\end{array}$ \\
\hline N5 & & Plenamente Satisfeito & 150 \\
\hline N4 & Bom & Satisfeito & 100 \\
\hline N3 & & Indiferente & 50 \\
\hline N2 & Neutro & Insatisfeito & 0 \\
\hline N1 & & Plenamente Insatisfeito & -50 \\
\hline
\end{tabular}

Descritor do item de avaliação 1.1.2 - Iluminação no Interior do Ônibus 


\begin{tabular}{|c|c|l|c|}
\hline \multicolumn{5}{|c|}{1.1 .3 - Forma de Condução do Ônibus } \\
\hline $\begin{array}{c}\text { Níveis } \\
\text { de } \\
\text { Impacto }\end{array}$ & $\begin{array}{c}\text { Níveis de } \\
\text { Referência }\end{array}$ & Descrição & $\begin{array}{c}\text { Função } \\
\text { de Valor }\end{array}$ \\
\hline N5 & & Plenamente Satisfeito & 175 \\
\hline N4 & Bom & Satisfeito & 100 \\
\hline N3 & & Indiferente & 50 \\
\hline N2 & Neutro & Insatisfeito & 0 \\
\hline N1 & & Plenamente Insatisfeito & -25 \\
\hline
\end{tabular}

Descritor do item de avaliação 1.1.3 - Forma de Condução do Ônibus

\begin{tabular}{|c|c|l|c|}
\hline \multicolumn{3}{|c|}{ 1.2.1 - Agressão Moral no Interior do Ônibus } \\
\hline $\begin{array}{c}\text { Níveis } \\
\text { de } \\
\text { Impacto }\end{array}$ & $\begin{array}{c}\text { Níveis de } \\
\text { Referência }\end{array}$ & Descrição & $\begin{array}{c}\text { Função } \\
\text { de Valor }\end{array}$ \\
\hline N5 & & Plenamente Satisfeito & 120 \\
\hline N4 & Bom & Satisfeito & 100 \\
\hline N3 & & Indiferente & 45 \\
\hline N2 & Neutro & Insatisfeito & 0 \\
\hline N1 & & Plenamente Insatisfeito & -40 \\
\hline
\end{tabular}

Descritor do item de avaliação 1.2.1 - Agressão Moral no Interior do Ônibus 


\begin{tabular}{|c|c|l|c|}
\hline \multicolumn{5}{|c|}{ 1.2.2 - Discussão com a Tripulação } \\
\hline $\begin{array}{c}\text { Níveis } \\
\text { de } \\
\text { Impacto }\end{array}$ & $\begin{array}{c}\text { Níveis de } \\
\text { Referência }\end{array}$ & Descrição & $\begin{array}{c}\text { Função } \\
\text { de Valor }\end{array}$ \\
\hline N5 & & Plenamente Satisfeito & 160 \\
\hline N4 & Bom & Satisfeito & 100 \\
\hline N3 & & Indiferente & 40 \\
\hline N2 & Neutro & Insatisfeito & 0 \\
\hline N1 & & Plenamente Insatisfeito & -40 \\
\hline
\end{tabular}

Descritor do item de avaliação 1.2.2 - Discussão com a Tripulação

\begin{tabular}{|c|c|l|c|}
\hline \multicolumn{5}{|c|}{ 2.1 - Continuidade do Serviço } \\
\hline $\begin{array}{c}\text { Níveis } \\
\text { de } \\
\text { Impacto }\end{array}$ & $\begin{array}{c}\text { Níveis de } \\
\text { Referência }\end{array}$ & Descrição & $\begin{array}{c}\text { Função } \\
\text { de Valor }\end{array}$ \\
\hline N5 & & Plenamente Satisfeito & 150 \\
\hline N4 & Bom & Satisfeito & 100 \\
\hline N3 & & Indiferente & 50 \\
\hline N2 & Neutro & Insatisfeito & 0 \\
\hline N1 & & Plenamente Insatisfeito & -50 \\
\hline
\end{tabular}

Descritor do item de avaliação 2.1 - Continuidade do Serviço 


\begin{tabular}{|c|c|l|c|}
\hline \multicolumn{5}{|c|}{2.2 - Cumprimento da Programação } \\
\hline $\begin{array}{c}\text { Níveis } \\
\text { de } \\
\text { Impacto }\end{array}$ & $\begin{array}{c}\text { Níveis de } \\
\text { Referência }\end{array}$ & Descrição & $\begin{array}{c}\text { Função } \\
\text { de Valor }\end{array}$ \\
\hline N5 & & Plenamente Satisfeito & 160 \\
\hline N4 & Bom & Satisfeito & 100 \\
\hline N3 & & Indiferente & 60 \\
\hline N2 & Neutro & Insatisfeito & 0 \\
\hline N1 & & Plenamente Insatisfeito & -80 \\
\hline
\end{tabular}

Descritor do item de avaliação 2.2 - Cumprimento da Programação

\begin{tabular}{|c|c|l|c|}
\hline \multicolumn{3}{|c|}{ 2.3 - Cumprimento de Itinerários } \\
\hline $\begin{array}{c}\text { Níveis } \\
\text { de } \\
\text { Impacto }\end{array}$ & $\begin{array}{c}\text { Níveis de } \\
\text { Referência }\end{array}$ & Descrição & $\begin{array}{c}\text { Função } \\
\text { de Valor }\end{array}$ \\
\hline N5 & & Plenamente Satisfeito & 160 \\
\hline N4 & Bom & Satisfeito & 100 \\
\hline N3 & & Indiferente & 60 \\
\hline N2 & Neutro & Insatisfeito & 0 \\
\hline N1 & & Plenamente Insatisfeito & -40 \\
\hline
\end{tabular}

Descritor do item de avaliação 2.3 - Cumprimento de Itinerários 


\begin{tabular}{|c|c|l|c|}
\hline \multicolumn{5}{|c|}{$\mathbf{2 . 4}$ - Intervalo Entre os Ônibus } \\
\hline $\begin{array}{c}\text { Níveis } \\
\text { de } \\
\text { Impacto }\end{array}$ & $\begin{array}{c}\text { Níveis de } \\
\text { Referência }\end{array}$ & $\begin{array}{c}\text { Função } \\
\text { de Valor }\end{array}$ \\
\hline N5 & & Plenão & 130 \\
\hline N4 & Bom & Satisfeito & 100 \\
\hline N3 & & Indiferente & 55 \\
\hline N2 & Neutro & Insatisfeito & 0 \\
\hline N1 & & Plenamente Insatisfeito & -25 \\
\hline
\end{tabular}

Descritor do item de avaliação 2.4 - Intervalo Entre os Ônibus

\begin{tabular}{|c|c|l|c|}
\hline \multicolumn{3}{|c|}{2.5 - Interrupção da Viagem por Quebra } \\
\hline $\begin{array}{c}\text { Níveis } \\
\text { de } \\
\text { Impacto }\end{array}$ & $\begin{array}{c}\text { Níveis de } \\
\text { Referência }\end{array}$ & Descrição & $\begin{array}{c}\text { Função } \\
\text { de Valor }\end{array}$ \\
\hline N5 & & Plenamente Satisfeito & 150 \\
\hline N4 & Bom & Satisfeito & 100 \\
\hline N3 & & Indiferente & 50 \\
\hline N2 & Neutro & Insatisfeito & 0 \\
\hline N1 & & Plenamente Insatisfeito & -30 \\
\hline
\end{tabular}

Descritor do item de avaliação 2.5 - Interrupção da Viagem por Quebra 


\begin{tabular}{|c|c|l|c|}
\hline \multicolumn{5}{|c|}{ 3.1.1 - Tempo na Fila dos Terminais } \\
\hline $\begin{array}{c}\text { Níveis } \\
\text { de } \\
\text { Impacto }\end{array}$ & $\begin{array}{c}\text { Níveis de } \\
\text { Referência }\end{array}$ & Descrição & $\begin{array}{c}\text { Função } \\
\text { de Valor }\end{array}$ \\
\hline N5 & & Plenamente Satisfeito & 140 \\
\hline N4 & Bom & Satisfeito & 100 \\
\hline N3 & & Indiferente & 60 \\
\hline N2 & Neutro & Insatisfeito & 0 \\
\hline N1 & & Plenamente Insatisfeito & -40 \\
\hline
\end{tabular}

Descritor do item de avaliação 3.1.1 - Tempo na Fila dos terminais

\begin{tabular}{|c|c|l|c|}
\hline \multicolumn{5}{|c|}{ 3.1.2 - Tempo de Embarque } \\
\hline $\begin{array}{c}\text { Níveis } \\
\text { de } \\
\text { Impacto }\end{array}$ & $\begin{array}{c}\text { Níveis de } \\
\text { Referência }\end{array}$ & Descrição & $\begin{array}{c}\text { Função } \\
\text { de Valor }\end{array}$ \\
\hline N5 & & Plenamente Satisfeito & 150 \\
\hline N4 & Bom & Satisfeito & 100 \\
\hline N3 & & Indiferente & 55 \\
\hline N2 & Neutro & Insatisfeito & 0 \\
\hline N1 & & Plenamente Insatisfeito & -33 \\
\hline
\end{tabular}

Descritor do item de avaliação 3.1.2 - Tempo de Embarque 


\begin{tabular}{|c|c|l|c|}
\hline \multicolumn{5}{|c|}{ 3.2.1 - Acesso a Assentos Especiais } \\
\hline $\begin{array}{c}\text { Níveis } \\
\text { de } \\
\text { Impacto }\end{array}$ & $\begin{array}{c}\text { Níveis de } \\
\text { Referência }\end{array}$ & Descrição & $\begin{array}{c}\text { Função } \\
\text { de Valor }\end{array}$ \\
\hline N5 & & Plenamente Satisfeito & 150 \\
\hline N4 & Bom & Satisfeito & 100 \\
\hline N3 & & Indiferente & 50 \\
\hline N2 & Neutro & Insatisfeito & 0 \\
\hline N1 & & Plenamente Insatisfeito & -50 \\
\hline
\end{tabular}

Descritor do item de avaliação 3.2.1 - Acesso a Assentos Especiais

\begin{tabular}{|c|c|l|c|}
\hline \multicolumn{3}{|c|}{ 3.2.2 - Facilidade para Pagamento das Passagens } \\
\hline $\begin{array}{c}\text { Níveis } \\
\text { de } \\
\text { Impacto }\end{array}$ & $\begin{array}{c}\text { Níveis de } \\
\text { Referência }\end{array}$ & Descrição & $\begin{array}{c}\text { Função } \\
\text { de Valor }\end{array}$ \\
\hline N5 & & Plenamente Satisfeito & 140 \\
\hline N4 & Bom & Satisfeito & 100 \\
\hline N3 & & Indiferente & 40 \\
\hline N2 & Neutro & Insatisfeito & 0 \\
\hline N1 & & Plenamente Insatisfeito & -40 \\
\hline
\end{tabular}

Descritor do item de avaliação 3.2.2 - Facilidade para Pagamento das Passagens 


\begin{tabular}{|c|c|l|c|}
\hline \multicolumn{5}{|c|}{3.2 .3 - Controle de Acesso pela Catraca } \\
\hline $\begin{array}{c}\text { Níveis } \\
\text { de } \\
\text { Impacto }\end{array}$ & $\begin{array}{c}\text { Níveis de } \\
\text { Referência }\end{array}$ & Descrição & $\begin{array}{c}\text { Função } \\
\text { de Valor }\end{array}$ \\
\hline N5 & & Plenamente Satisfeito & 137 \\
\hline N4 & Bom & Satisfeito & 100 \\
\hline N3 & & Indiferente & 62 \\
\hline N2 & Neutro & Insatisfeito & 0 \\
\hline N1 & & Plenamente Insatisfeito & -25 \\
\hline
\end{tabular}

Descritor do item de avaliação 3.2.3 - Controle de Acesso pela Catraca

\begin{tabular}{|c|c|l|c|}
\hline \multicolumn{3}{|c|}{ 3.3.1 - Parada Correta no Ponto de Desembarque } \\
\hline $\begin{array}{c}\text { Níveis } \\
\text { de } \\
\text { Impacto }\end{array}$ & $\begin{array}{c}\text { Níveis de } \\
\text { Referência }\end{array}$ & $\begin{array}{c}\text { Função } \\
\text { de Valor }\end{array}$ \\
\hline N5 & & Plenamente Satisfeito & 160 \\
\hline N4 & Bom & Satisfeito & 100 \\
\hline N3 & & Indiferente & 40 \\
\hline N2 & Neutro & Insatisfeito & 0 \\
\hline N1 & & Plenamente Insatisfeito & -40 \\
\hline
\end{tabular}

Descritor do item de avaliação 3.3.1 - Parada Correta no Ponto de Desembarque 


\begin{tabular}{|c|c|l|c|}
\hline \multicolumn{3}{|c|}{ 3.3.2 - Tempo de Parada Adequado para o Desembarque } \\
\hline $\begin{array}{c}\text { Níveis } \\
\text { de } \\
\text { Impacto }\end{array}$ & $\begin{array}{c}\text { Níveis de } \\
\text { Referência }\end{array}$ & Descrição & $\begin{array}{c}\text { Função } \\
\text { de Valor }\end{array}$ \\
\hline N5 & & Plenamente Satisfeito & 150 \\
\hline N4 & Bom & Satisfeito & 100 \\
\hline N3 & & Indiferente & 50 \\
\hline N2 & Neutro & Insatisfeito & 0 \\
\hline N1 & & Plenamente Insatisfeito & -50 \\
\hline
\end{tabular}

Descritor do item de avaliação 3.3.2 - Tempo de Parada Adequado para o Desembarque

\begin{tabular}{|c|c|l|c|}
\hline \multicolumn{3}{|c|}{ 4.1.1 - Sinalização Horizontal para Filas } \\
\hline $\begin{array}{c}\text { Níveis } \\
\text { de } \\
\text { Impacto }\end{array}$ & $\begin{array}{c}\text { Níveis de } \\
\text { Referência }\end{array}$ & Descrição & $\begin{array}{c}\text { Função } \\
\text { de Valor }\end{array}$ \\
\hline N5 & & Plenamente Satisfeito & 157 \\
\hline N4 & Bom & Satisfeito & 100 \\
\hline N3 & & Indiferente & 43 \\
\hline N2 & Neutro & Insatisfeito & 0 \\
\hline N1 & & Plenamente Insatisfeito & -42 \\
\hline
\end{tabular}

Descritor do item de avaliação 4.1.1 - Sinalização Horizontal para Filas 


\begin{tabular}{|c|c|l|c|}
\hline \multicolumn{3}{|c|}{ 4.1.2 - Identificação do Local de Saída dos Ônibus } \\
\hline $\begin{array}{c}\text { Níveis } \\
\text { de } \\
\text { Impacto }\end{array}$ & $\begin{array}{c}\text { Níveis de } \\
\text { Referência }\end{array}$ & Descrição & $\begin{array}{c}\text { Função } \\
\text { de Valor }\end{array}$ \\
\hline N5 & & Plenamente Satisfeito & 150 \\
\hline N4 & Bom & Satisfeito & 100 \\
\hline N3 & & Indiferente & 50 \\
\hline N2 & Neutro & Insatisfeito & 0 \\
\hline N1 & & Plenamente Insatisfeito & -50 \\
\hline
\end{tabular}

Descritor do item de avaliação 4.1.2 - Identificação do Local de Saída dos Ônibus

\begin{tabular}{|c|c|l|c|}
\hline \multicolumn{5}{|c|}{ 4.1.3 - Sinalização Vertical das Linhas } \\
\hline $\begin{array}{c}\text { Níveis } \\
\text { de } \\
\text { Impacto }\end{array}$ & $\begin{array}{c}\text { Níveis de } \\
\text { Referência }\end{array}$ & Descrição & $\begin{array}{c}\text { Função } \\
\text { de Valor }\end{array}$ \\
\hline N5 & & Plenamente Satisfeito & 150 \\
\hline N4 & Bom & Satisfeito & 100 \\
\hline N3 & & Indiferente & 50 \\
\hline N2 & Neutro & Insatisfeito & 0 \\
\hline N1 & & Plenamente Insatisfeito & -50 \\
\hline
\end{tabular}

Descritor do item de avaliação 4.1.3 - Sinalização Vertical das Linhas 


\begin{tabular}{|c|c|l|c|}
\hline \multicolumn{5}{|c|}{ 4.1.4 - Panfletos Informativos } \\
\hline $\begin{array}{c}\text { Níveis } \\
\text { de } \\
\text { Impacto }\end{array}$ & $\begin{array}{c}\text { Níveis de } \\
\text { Referência }\end{array}$ & Descrição & $\begin{array}{c}\text { Função } \\
\text { de Valor }\end{array}$ \\
\hline N5 & & Plenamente Satisfeito & 150 \\
\hline N4 & Bom & Satisfeito & 100 \\
\hline N3 & & Indiferente & 50 \\
\hline N2 & Neutro & Insatisfeito & 0 \\
\hline N1 & & Plenamente Insatisfeito & -25 \\
\hline
\end{tabular}

Descritor do item de avaliação 4.1.4 - Panfletos Informativos

\begin{tabular}{|c|c|l|c|}
\hline \multicolumn{3}{|c|}{ 4.2.1 - Informações das Linhas que Passam na Parada } \\
\hline $\begin{array}{c}\text { Níveis } \\
\text { de } \\
\text { Impacto }\end{array}$ & $\begin{array}{c}\text { Níveis de } \\
\text { Referência }\end{array}$ & Descrição & $\begin{array}{c}\text { Função } \\
\text { de Valor }\end{array}$ \\
\hline N5 & & Plenamente Satisfeito & 150 \\
\hline N4 & Bom & Satisfeito & 100 \\
\hline N3 & & Indiferente & 50 \\
\hline N2 & Neutro & Insatisfeito & 0 \\
\hline N1 & & Plenamente Insatisfeito & -33 \\
\hline
\end{tabular}

Descritor do item de avaliação 4.2.1 - Informações das Linhas que Passam na Parada 


\begin{tabular}{|c|c|l|c|}
\hline \multicolumn{3}{|c|}{ 4.2.2 - Informações dos Intervalos Médios entre os Ônibus } \\
\hline $\begin{array}{c}\text { Níveis } \\
\text { de } \\
\text { Impacto }\end{array}$ & $\begin{array}{c}\text { Níveis de } \\
\text { Referência }\end{array}$ & Descrição & $\begin{array}{c}\text { Função } \\
\text { de Valor }\end{array}$ \\
\hline N5 & & Plenamente Satisfeito & 140 \\
\hline N4 & Bom & Satisfeito & 100 \\
\hline N3 & & Indiferente & 60 \\
\hline N2 & Neutro & Insatisfeito & 0 \\
\hline N1 & & Plenamente Insatisfeito & -40 \\
\hline
\end{tabular}

Descritor do item de avaliação 4.2.2 - Informações dos Intervalos Médios entre os Ônibus

\begin{tabular}{|c|c|l|c|}
\hline \multicolumn{2}{|c|}{ 4.2.3 - Informações sobre os Canais de Acesso à Informação } \\
\hline $\begin{array}{c}\text { Níveis } \\
\text { de } \\
\text { Impacto }\end{array}$ & $\begin{array}{c}\text { Níveis de } \\
\text { Referência }\end{array}$ & $\begin{array}{c}\text { Função } \\
\text { de Valor }\end{array}$ \\
\hline N5 & & Plenamenão & 144 \\
\hline N4 & Bom & Satisfeito & 100 \\
\hline N3 & & Indiferente & 56 \\
\hline N2 & Neutro & Insatisfeito & 0 \\
\hline N1 & & Plenamente Insatisfeito & -55 \\
\hline
\end{tabular}

Descritor do item de avaliação 4.2.3 - Informações sobre os Canais de Acesso à Informação 


\begin{tabular}{|c|c|l|c|}
\hline \multicolumn{3}{|c|}{ 4.3.1 - Letreiros com Informações Claras das Linhas } \\
\hline $\begin{array}{c}\text { Níveis } \\
\text { de } \\
\text { Impacto }\end{array}$ & $\begin{array}{c}\text { Níveis de } \\
\text { Referência }\end{array}$ & $\begin{array}{c}\text { Fescrição } \\
\text { função } \\
\text { de Valor }\end{array}$ \\
\hline N5 & & Plenamente Satisfeito & 150 \\
\hline N4 & Bom & Satisfeito & 100 \\
\hline N3 & & Indiferente & 50 \\
\hline N2 & Neutro & Insatisfeito & 0 \\
\hline N1 & & Plenamente Insatisfeito & -50 \\
\hline
\end{tabular}

Descritor do item de avaliação 4.3.1 - Letreiros com Informações Claras das Linhas

\begin{tabular}{|c|c|l|c|}
\hline \multicolumn{2}{|c|}{ 4.3.2 - Avisos Sonoros } \\
\hline $\begin{array}{c}\text { Níveis } \\
\text { de } \\
\text { Impacto }\end{array}$ & $\begin{array}{c}\text { Níveis de } \\
\text { Referência }\end{array}$ & Descrição & $\begin{array}{c}\text { Função } \\
\text { de Valor }\end{array}$ \\
\hline N5 & & Plenamente Satisfeito & 129 \\
\hline N4 & Bom & Satisfeito & 100 \\
\hline N3 & & Indiferente & 43 \\
\hline N2 & Neutro & Insatisfeito & 0 \\
\hline N1 & & Plenamente Insatisfeito & -42 \\
\hline
\end{tabular}

Descritor do item de avaliação 4.3.2 - Avisos Sonoros 


\begin{tabular}{|c|c|l|c|}
\hline \multicolumn{5}{|c|}{4.3 .3 - Avisos de Solicitação de Parada } \\
\hline $\begin{array}{c}\text { Níveis } \\
\text { de } \\
\text { Impacto }\end{array}$ & $\begin{array}{c}\text { Níveis de } \\
\text { Referência }\end{array}$ & Descrição & $\begin{array}{c}\text { Função } \\
\text { de Valor }\end{array}$ \\
\hline N5 & & Plenamente Satisfeito & 167 \\
\hline N4 & Bom & Satisfeito & 100 \\
\hline N3 & & Indiferente & 67 \\
\hline N2 & Neutro & Insatisfeito & 0 \\
\hline N1 & & Plenamente Insatisfeito & -33 \\
\hline
\end{tabular}

Descritor do item de avaliação 4.3.3 - Avisos de Solicitação de Parada

\begin{tabular}{|c|c|l|c|}
\hline \multicolumn{3}{|c|}{ 4.4.1 - Mapas de Horários } \\
\hline $\begin{array}{c}\text { Níveis } \\
\text { de } \\
\text { Impacto }\end{array}$ & $\begin{array}{c}\text { Níveis de } \\
\text { Referência }\end{array}$ & $\begin{array}{c}\text { Função } \\
\text { de Valor }\end{array}$ \\
\hline N5 & & Plenamão & 140 \\
\hline N4 & Bom & Satisfeito & 100 \\
\hline N3 & & Indiferente & 40 \\
\hline N2 & Neutro & Insatisfeito & 0 \\
\hline N1 & & Plenamente Insatisfeito & -40 \\
\hline
\end{tabular}

Descritor do item de avaliação 4.4.1 - Mapas de Horários 


\begin{tabular}{|c|c|l|c|}
\hline \multicolumn{2}{|c|}{ 4.4.2 - Valor da Tarifa } \\
\hline $\begin{array}{c}\text { Níveis } \\
\text { de } \\
\text { Impacto }\end{array}$ & $\begin{array}{c}\text { Níveis de } \\
\text { Referência }\end{array}$ & Descrição & $\begin{array}{c}\text { Função } \\
\text { de Valor }\end{array}$ \\
\hline N5 & & Plenamente Satisfeito & 143 \\
\hline N4 & Bom & Satisfeito & 100 \\
\hline N3 & & Indiferente & 35 \\
\hline N2 & Neutro & Insatisfeito & 0 \\
\hline N1 & & Plenamente Insatisfeito & -28 \\
\hline
\end{tabular}

Descritor do item de avaliação 4.4.2 - Valor da Tarifa

\begin{tabular}{|c|c|l|c|}
\hline \multicolumn{3}{|c|}{4.4 .3 - Divulgação dos Itinerários das Linhas } \\
\hline $\begin{array}{c}\text { Níveis } \\
\text { de } \\
\text { Impacto }\end{array}$ & $\begin{array}{c}\text { Níveis de } \\
\text { Referência }\end{array}$ & Descrição & $\begin{array}{c}\text { Função } \\
\text { de Valor }\end{array}$ \\
\hline N5 & & Plenamente Satisfeito & 160 \\
\hline N4 & Bom & Satisfeito & 100 \\
\hline N3 & & Indiferente & 40 \\
\hline N2 & Neutro & Insatisfeito & 0 \\
\hline N1 & & Plenamente Insatisfeito & -40 \\
\hline
\end{tabular}

Descritor do item de avaliação 4.4.3 - Divulgação dos Itinerários das Linhas 


\begin{tabular}{|c|c|l|c|}
\hline \multicolumn{3}{|c|}{ 4.4.4 - Formas de Pagamento das Tarifas } \\
\hline $\begin{array}{c}\text { Níveis } \\
\text { de } \\
\text { Impacto }\end{array}$ & $\begin{array}{c}\text { Níveis de } \\
\text { Referência }\end{array}$ & Descrição & $\begin{array}{c}\text { Função } \\
\text { de Valor }\end{array}$ \\
\hline N5 & & Plenamente Satisfeito & 133 \\
\hline N4 & Bom & Satisfeito & 100 \\
\hline N3 & & Indiferente & 67 \\
\hline N2 & Neutro & Insatisfeito & 0 \\
\hline N1 & & Plenamente Insatisfeito & -66 \\
\hline
\end{tabular}

Descritor do item de avaliação 4.4.4 - Formas de Pagamento das Tarifas

\begin{tabular}{|c|c|l|c|}
\hline \multicolumn{3}{|c|}{ 4.4.5 - Informações Sobre os Canais de Acesso à Informações } \\
\hline $\begin{array}{c}\text { Níveis } \\
\text { de } \\
\text { Impacto }\end{array}$ & $\begin{array}{c}\text { Níveis de } \\
\text { Referência }\end{array}$ & Descrição & $\begin{array}{c}\text { Função } \\
\text { de Valor }\end{array}$ \\
\hline N5 & & Plenamente Satisfeito & 144 \\
\hline N4 & Bom & Satisfeito & 100 \\
\hline N3 & & Indiferente & 56 \\
\hline N2 & Neutro & Insatisfeito & 0 \\
\hline N1 & & Plenamente Insatisfeito & -55 \\
\hline
\end{tabular}

Descritor do item de avaliação 4.4.5 - Informações Sobre os Canais de Acesso à Informação 


\begin{tabular}{|c|c|l|c|}
\hline \multicolumn{5}{|c|}{ 4.5.1 - Informações Sobre Tarifas } \\
\hline $\begin{array}{c}\text { Níveis } \\
\text { de } \\
\text { Impacto }\end{array}$ & $\begin{array}{c}\text { Níveis de } \\
\text { Referência }\end{array}$ & Descrição & $\begin{array}{c}\text { Função } \\
\text { de Valor }\end{array}$ \\
\hline N5 & & Plenamente Satisfeito & 150 \\
\hline N4 & Bom & Satisfeito & 100 \\
\hline N3 & & Indiferente & 50 \\
\hline N2 & Neutro & Insatisfeito & 0 \\
\hline N1 & & Plenamente Insatisfeito & -50 \\
\hline
\end{tabular}

Descritor do item de avaliação 4.5.1 - Informações Sobre Tarifas

\begin{tabular}{|c|c|l|c|}
\hline \multicolumn{5}{|c|}{ 4.5.2 - Informações de Horários } \\
\hline $\begin{array}{c}\text { Níveis } \\
\text { de } \\
\text { Impacto }\end{array}$ & $\begin{array}{c}\text { Níveis de } \\
\text { Referência }\end{array}$ & Descrição & $\begin{array}{c}\text { Função } \\
\text { de Valor }\end{array}$ \\
\hline N5 & & Plenamente Satisfeito & 140 \\
\hline N4 & Bom & Satisfeito & 100 \\
\hline N3 & & Indiferente & 40 \\
\hline N2 & Neutro & Insatisfeito & 0 \\
\hline N1 & & Plenamente Insatisfeito & -40 \\
\hline
\end{tabular}

Descritor do item de avaliação 4.5.2 - Informações de Horários 


\begin{tabular}{|c|c|l|c|}
\hline \multicolumn{5}{|c|}{ 4.5.3 - Registro de Reclamações } \\
\hline $\begin{array}{c}\text { Níveis } \\
\text { de } \\
\text { Impacto }\end{array}$ & $\begin{array}{c}\text { Níveis de } \\
\text { Referência }\end{array}$ & Descrição & $\begin{array}{c}\text { Função } \\
\text { de Valor }\end{array}$ \\
\hline N5 & & Plenamente Satisfeito & 125 \\
\hline N4 & Bom & Satisfeito & 100 \\
\hline N3 & & Indiferente & 50 \\
\hline N2 & Neutro & Insatisfeito & 0 \\
\hline N1 & & Plenamente Insatisfeito & -50 \\
\hline
\end{tabular}

Descritor do item de avaliação 4.5.3 - Registro de Reclamações

\begin{tabular}{|c|c|l|c|}
\hline \multicolumn{3}{|c|}{ 4.5.4 - Informações Sobre os Canais de Acesso à Informações } \\
\hline $\begin{array}{c}\text { Níveis } \\
\text { de } \\
\text { Impacto }\end{array}$ & $\begin{array}{c}\text { Níveis de } \\
\text { Referência }\end{array}$ & Descrição & $\begin{array}{c}\text { Função } \\
\text { de Valor }\end{array}$ \\
\hline N5 & & Plenamente Satisfeito & 167 \\
\hline N4 & Bom & Satisfeito & 100 \\
\hline N3 & & Indiferente & 33 \\
\hline N2 & Neutro & Insatisfeito & 0 \\
\hline N1 & & Plenamente Insatisfeito & -66 \\
\hline
\end{tabular}

Descritor do item de avaliação 4.5.4 - Informações Sobre os Canais de Acesso a Informações 


\begin{tabular}{|c|c|l|c|}
\hline \multicolumn{5}{|c|}{5.1 - Atualidade da Frota } \\
\hline $\begin{array}{c}\text { Níveis } \\
\text { de } \\
\text { Impacto }\end{array}$ & $\begin{array}{c}\text { Níveis de } \\
\text { Referência }\end{array}$ & $\begin{array}{c}\text { Função } \\
\text { de Valor }\end{array}$ \\
\hline N5 & & Plenão & 150 \\
\hline N4 & Bom & Satisfeito & 100 \\
\hline N3 & & Indiferente & 50 \\
\hline N2 & Neutro & Insatisfeito & 0 \\
\hline N1 & & Plenamente Insatisfeito & -25 \\
\hline
\end{tabular}

Descritor do item de avaliação 5.1 - Atualidade da Frota

\begin{tabular}{|c|c|l|c|}
\hline \multicolumn{5}{|c|}{5.2 - Espaço Entre os Bancos } \\
\hline $\begin{array}{c}\text { Níveis } \\
\text { de } \\
\text { Impacto }\end{array}$ & $\begin{array}{c}\text { Níveis de } \\
\text { Referência }\end{array}$ & Descrição & $\begin{array}{c}\text { Função } \\
\text { de Valor }\end{array}$ \\
\hline N5 & & Plenamente Satisfeito & 133 \\
\hline N4 & Bom & Satisfeito & 100 \\
\hline N3 & & Indiferente & 50 \\
\hline N2 & Neutro & Insatisfeito & 0 \\
\hline N1 & & Plenamente Insatisfeito & -33 \\
\hline
\end{tabular}

Descritor do item de avaliação 5.2 - Espaço Entre os Bancos 


\begin{tabular}{|c|c|l|c|}
\hline \multicolumn{5}{|c|}{5.3 - Espaço no Corredor } \\
\hline $\begin{array}{c}\text { Níveis } \\
\text { de } \\
\text { Impacto }\end{array}$ & $\begin{array}{c}\text { Níveis de } \\
\text { Referência }\end{array}$ & Descrição & $\begin{array}{c}\text { Função } \\
\text { de Valor }\end{array}$ \\
\hline N5 & & Plenamente Satisfeito & 133 \\
\hline N4 & Bom & Satisfeito & 100 \\
\hline N3 & & Indiferente & 50 \\
\hline N2 & Neutro & Insatisfeito & 0 \\
\hline N1 & & Plenamente Insatisfeito & -33 \\
\hline
\end{tabular}

Descritor do item de avaliação 5.3 - Espaço no Corredor

\begin{tabular}{|c|c|l|c|}
\hline \multicolumn{2}{|c|}{ 5.4 - Lotação } \\
\hline $\begin{array}{c}\text { Níveis } \\
\text { de } \\
\text { Impacto }\end{array}$ & $\begin{array}{c}\text { Níveis de } \\
\text { Referência }\end{array}$ & Descrição & $\begin{array}{c}\text { Função } \\
\text { de Valor }\end{array}$ \\
\hline N5 & & Plenamente Satisfeito & 140 \\
\hline N4 & Bom & Satisfeito & 100 \\
\hline N3 & & Indiferente & 40 \\
\hline N2 & Neutro & Insatisfeito & 0 \\
\hline N1 & & Plenamente Insatisfeito & -40 \\
\hline
\end{tabular}

Descritor do item de avaliação 5.4 - Lotação 


\begin{tabular}{|c|c|l|c|}
\hline \multicolumn{2}{|c|}{5.5 - Ventilação } \\
\hline $\begin{array}{c}\text { Níveis } \\
\text { de } \\
\text { Impacto }\end{array}$ & $\begin{array}{c}\text { Níveis de } \\
\text { Referência }\end{array}$ & Descrição & $\begin{array}{c}\text { Função } \\
\text { de Valor }\end{array}$ \\
\hline N5 & & Plenamente Satisfeito & 150 \\
\hline N4 & Bom & Satisfeito & 100 \\
\hline N3 & & Indiferente & 50 \\
\hline N2 & Neutro & Insatisfeito & 0 \\
\hline N1 & & Plenamente Insatisfeito & -50 \\
\hline
\end{tabular}

Descritor do item de avaliação 5.5 - Ventilação

\begin{tabular}{|c|c|l|c|}
\hline \multicolumn{5}{|c|}{5.6 - Temperatura no Interior do Ônibus } \\
\hline $\begin{array}{c}\text { Níveis } \\
\text { de } \\
\text { Impacto }\end{array}$ & $\begin{array}{c}\text { Níveis de } \\
\text { Referência }\end{array}$ & Descrição & $\begin{array}{c}\text { Função } \\
\text { de Valor }\end{array}$ \\
\hline N5 & & Plenamente Satisfeito & 140 \\
\hline N4 & Bom & Satisfeito & 100 \\
\hline N3 & & Indiferente & 40 \\
\hline N2 & Neutro & Insatisfeito & 0 \\
\hline N1 & & Plenamente Insatisfeito & -40 \\
\hline
\end{tabular}

Descritor do item de avaliação 5.6 - Temperatura no Interior do Ônibus 


\begin{tabular}{|c|c|l|c|}
\hline \multicolumn{2}{|c|}{ 6 - Custo } \\
\hline $\begin{array}{c}\text { Níveis } \\
\text { de } \\
\text { Impacto }\end{array}$ & $\begin{array}{c}\text { Níveis de } \\
\text { Referência }\end{array}$ & Descrição & $\begin{array}{c}\text { Função } \\
\text { de Valor }\end{array}$ \\
\hline N5 & & Plenamente Satisfeito & 140 \\
\hline N4 & Bom & Satisfeito & 100 \\
\hline N3 & & Indiferente & 40 \\
\hline N2 & Neutro & Insatisfeito & 0 \\
\hline N1 & & Plenamente Insatisfeito & -40 \\
\hline
\end{tabular}

Descritor do item de avaliação 6 - Custo

\begin{tabular}{|c|c|l|c|}
\hline \multicolumn{3}{|c|}{ 7.1.1 - Parada Fora de Pontos de Parada/Terminais } \\
\hline $\begin{array}{c}\text { Níveis } \\
\text { de } \\
\text { Impacto }\end{array}$ & $\begin{array}{c}\text { Níveis de } \\
\text { Referência }\end{array}$ & Descrição & $\begin{array}{c}\text { Função } \\
\text { de Valor }\end{array}$ \\
\hline N5 & & Plenamente Satisfeito & 140 \\
\hline N4 & Bom & Satisfeito & 100 \\
\hline N3 & & Indiferente & 40 \\
\hline N2 & Neutro & Insatisfeito & 0 \\
\hline N1 & & Plenamente Insatisfeito & -40 \\
\hline
\end{tabular}

Descritor do item de avaliação 7.1.1 - Parada Fora de Pontos de Parada/Terminais 


\begin{tabular}{|c|c|l|c|}
\hline \multicolumn{5}{|c|}{7.1 .2 - Troca Constante de Tripulação } \\
\hline $\begin{array}{c}\text { Níveis } \\
\text { de } \\
\text { Impacto }\end{array}$ & $\begin{array}{c}\text { Níveis de } \\
\text { Referência }\end{array}$ & Descrição & $\begin{array}{c}\text { Função } \\
\text { de Valor }\end{array}$ \\
\hline N5 & & Plenamente Satisfeito & 150 \\
\hline N4 & Bom & Satisfeito & 100 \\
\hline N3 & & Indiferente & 50 \\
\hline N2 & Neutro & Insatisfeito & 0 \\
\hline N1 & & Plenamente Insatisfeito & -25 \\
\hline
\end{tabular}

Descritor do item de avaliação 7.1.2 - Troca Constante de Tripulação

\begin{tabular}{|c|c|l|c|}
\hline \multicolumn{3}{|c|}{ 7.2.1 - Tripulação com Aparência de Cansada } \\
\hline $\begin{array}{c}\text { Níveis } \\
\text { de } \\
\text { Impacto }\end{array}$ & $\begin{array}{c}\text { Níveis de } \\
\text { Referência }\end{array}$ & Descrição & $\begin{array}{c}\text { Função } \\
\text { de Valor }\end{array}$ \\
\hline N5 & & Plenamente Satisfeito & 140 \\
\hline N4 & Bom & Satisfeito & 100 \\
\hline N3 & & Indiferente & 60 \\
\hline N2 & Neutro & Insatisfeito & 0 \\
\hline N1 & & Plenamente Insatisfeito & -40 \\
\hline
\end{tabular}

Descritor do item de avaliação 7.2.1 - Tripulação com Aparência de Cansada 


\begin{tabular}{|c|c|l|c|}
\hline \multicolumn{3}{|c|}{7.2 - Tripulação com Alteração de Comportamento } \\
\hline $\begin{array}{c}\text { Níveis } \\
\text { de } \\
\text { Impacto }\end{array}$ & $\begin{array}{c}\text { Níveis de } \\
\text { Referência }\end{array}$ & Descrição & $\begin{array}{c}\text { Função } \\
\text { de Valor }\end{array}$ \\
\hline N5 & & Plenamente Satisfeito & 150 \\
\hline N4 & Bom & Satisfeito & 100 \\
\hline N3 & & Indiferente & 50 \\
\hline N2 & Neutro & Insatisfeito & 0 \\
\hline N1 & & Plenamente Insatisfeito & -25 \\
\hline
\end{tabular}

Descritor do item de avaliação 7.2.2 - Tripulação com Alteração de Comportamento

\begin{tabular}{|c|c|l|c|}
\hline \multicolumn{3}{|c|}{ 7.3.1 - Tripulação Atende Pedidos de Informações } \\
\hline $\begin{array}{c}\text { Níveis } \\
\text { de } \\
\text { Impacto }\end{array}$ & $\begin{array}{c}\text { Níveis de } \\
\text { Referência }\end{array}$ & Descrição & $\begin{array}{c}\text { Função } \\
\text { de Valor }\end{array}$ \\
\hline N5 & & Plenamente Satisfeito & 150 \\
\hline N4 & Bom & Satisfeito & 100 \\
\hline N3 & & Indiferente & 50 \\
\hline N2 & Neutro & Insatisfeito & 0 \\
\hline N1 & & Plenamente Insatisfeito & -25 \\
\hline
\end{tabular}

Descritor do item de avaliação 7.3.1 - Tripulação Atende Pedidos de Informações 


\begin{tabular}{|c|c|l|c|}
\hline \multicolumn{3}{|c|}{7.3 .2 - Despachantes Orientam Formação de Filas } \\
\hline $\begin{array}{c}\text { Níveis } \\
\text { de } \\
\text { Impacto }\end{array}$ & $\begin{array}{c}\text { Níveis de } \\
\text { Referência }\end{array}$ & $\begin{array}{c}\text { Função } \\
\text { de Valor }\end{array}$ \\
\hline N5 & & Plenamenão & 157 \\
\hline N4 & Bom & Satisfeito & 100 \\
\hline N3 & & Indiferente & 43 \\
\hline N2 & Neutro & Insatisfeito & 0 \\
\hline N1 & & Plenamente Insatisfeito & -42 \\
\hline
\end{tabular}

Descritor do item de avaliação 7.3.2 - Despachantes Orientam Formação de Filas 


\section{APÊNDICE C - Formulário de Pesquisa}

Pág. 1

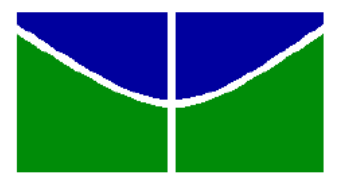

QUESTIONÁRIO SOBRE A QUALIDADE DOS SERVIÇOS DE TRANSPORTE SEMIURBANO DO DF NA VISÃO DOS USUÁRIOS: EMPRESA (

Prezado (a);

Este questionário foi elaborado para a busca de informações relevantes cujo tema é: "CLASSIFICAÇÃO DAS EMPRESAS PRESTADORAS DE TRANSPORTE RODOVIÁRIO INTERESTADUAL SEMIURBANO DE PASSAGEIROS NO BRASIL A PARTIR DA QUALIDADE DOS SERVIÇOS OFERTADOS". O fundamento dos dados coletados por este questionário está focado em estudo e relatório acadêmico do PPGT da Universidade de Brasília - UnB.

O formulário está composto de questões fechadas, que estão fundamentadas na escala "Likert" e poderão ser respondidas pelos usuários do serviço de transporte rodoviário semiurbano de passageiros do DF de modo voluntário. Garantimos preservar sua identidade, bem como o sigilo das individualidades das informações obtidas.

\section{PESQUISA DE CAMPO - TRANSPORTE SEMIURBANO DO DF}

\begin{tabular}{|c|c|c|c|}
\hline Gênero & ( ) Masculino & ( ) Feminino & \\
\hline \multirow{2}{*}{ Faixa Etária } & ( ) De 16 a 25 anos & ( ) De 26 a 35 anos & ( ) De 36 a 45 anos \\
\hline & ( ) De 46 a 55 anos & ( ) De 56 a 65 anos & ( ) Acima de 65 anos \\
\hline \multirow{3}{*}{ Motivo da Viagem } & ( ) Trabalho/Negócios & ( ) Estudo & ( ) Saúde \\
\hline & ( ) Visita a amigos/Parentes & ( ) Lazer/Turismo & ( ) Compras \\
\hline & ( ) Outros & & \\
\hline \multirow{3}{*}{$\begin{array}{l}\text { Frequência de viagens } \\
\text { no trecho }\end{array}$} & ( ) Eventual & ( ) Diária & ( ) Semanal \\
\hline & ( ) Quinzenal & ( ) Mensal & ( ) Trimestral \\
\hline & ( ) Semestral & ( ) Anual & \\
\hline
\end{tabular}

Assinale um " $X$ " na opção mais apropriada para os SERVIÇOS DE TRANSPORTE RODOVIÁRIO COLETIVO INTERESTADUAL SEMIURBANO DE PASSAGEIROS DO DF E DOS MUNICIPIOS DE SEU ENTORNO.

\begin{tabular}{|c|c|c|c|c|c|c|}
\hline \multirow{2}{*}{ Itens } & & \multicolumn{5}{|c|}{ Classificaçōes/Likert } \\
\hline & & 1 & 2 & $\mathbf{3}$ & 4 & 5 \\
\hline 1 & Em relação as câmeras de monitoramento nos ônibus, o(a) Sr(a) está & $\begin{array}{l}\text { ( ) Plenamente } \\
\text { Insatisfeito }\end{array}$ & ( ) Insatisfeito & ( ) Indiferente & ( ) Satisfeito & $\begin{array}{l}\text { ( ) Plenamente } \\
\text { Satisfeito }\end{array}$ \\
\hline 2 & Em relação a iluminação no interior dos ônibus, o(a) Sr(a) está & $\begin{array}{l}\text { ( ) Plenamente } \\
\text { Insatisfeito }\end{array}$ & ( ) Insatisfeito & ( ) Indiferente & ( ) Satisfeito & $\begin{array}{l}\text { ( ) Plenamente } \\
\text { Satisfeito }\end{array}$ \\
\hline 3 & Em relação a forma que o motorista conduz o ônibus, o(a) Sr(a) está & $\begin{array}{l}\text { ( ) Plenamente } \\
\text { Insatisfeito }\end{array}$ & ( ) Insatisfeito & ( ) Indiferente & ( ) Satisfeito & $\begin{array}{l}\text { ( ) Plenamente } \\
\text { Satisfeito }\end{array}$ \\
\hline 4 & Em relação aos casos de assédio dentro do ônibus, o(a) sr(a) está & $\begin{array}{l}\text { ( ) Plenamente } \\
\text { Insatisfeito }\end{array}$ & ( ) Insatisfeito & ( ) Indiferente & ( ) Satisfeito & $\begin{array}{l}\text { ( ) Plenamente } \\
\text { Satisfeito }\end{array}$ \\
\hline 5 & $\begin{array}{l}\text { Em relação a frequência com que a tripulação (motorista/trocador) se envolve } \\
\text { em discussão com os passageiros, o(a) Sr(a) está }\end{array}$ & $\begin{array}{l}\text { ( ) Plenamente } \\
\text { Insatisfeito }\end{array}$ & ( ) Insatisfeito & ( ) Indiferente & ( ) Satisfeito & $\begin{array}{l}\text { ( ) Plenamente } \\
\text { Satisfeito }\end{array}$ \\
\hline 6 & $\begin{array}{l}\text { Em relação a continuidade do serviço } \\
\text { (troca/paralisação/suspensão/cancelamento de linha), o(a) Sr(a) está }\end{array}$ & $\begin{array}{l}\text { ( ) Plenamente } \\
\text { Insatisfeito }\end{array}$ & ( ) Insatisfeito & ( ) Indiferente & ( ) Satisfeito & $\begin{array}{l}\text { ( ) Plenamente } \\
\text { Satisfeito }\end{array}$ \\
\hline 7 & Em relação ao cumprimento dos horários da programação, o(a) Sr(a) está & $\begin{array}{l}\text { ( ) Plenamente } \\
\text { Insatisfeito }\end{array}$ & ( ) Insatisfeito & ( ) Indiferente & ( ) Satisfeito & $\begin{array}{l}\text { ( ) Plenamente } \\
\text { Satisfeito }\end{array}$ \\
\hline 8 & Em relação ao cumprimento do itinerário (não desvia a rota), o(a) Sr(a) está & $\begin{array}{l}\text { ( ) Plenamente } \\
\text { Insatisfeito }\end{array}$ & ( ) Insatisfeito & ( ) Indiferente & ( ) Satisfeito & $\begin{array}{l}\text { ( ) Plenamente } \\
\text { Satisfeito }\end{array}$ \\
\hline 9 & Em relação ao intervalo de saída dos ônibus, o(a) Sr(a) está & $\begin{array}{l}\text { ( ) Plenamente } \\
\text { Insatisfeito }\end{array}$ & ( ) Insatisfeito & ( ) Indiferente & ( ) Satisfeito & $\begin{array}{l}\text { ( ) Plenamente } \\
\text { Satisfeito }\end{array}$ \\
\hline 10 & Em relação ao número de ônibus quebrado durante a viagem, o(a) sr(a) está & $\begin{array}{l}\text { ( ) Plenamente } \\
\text { Insatisfeito }\end{array}$ & ( ) Insatisfeito & () Indiferente & ( ) Satisfeito & $\begin{array}{l}\text { ( ) Plenamente } \\
\text { Satisfeito }\end{array}$ \\
\hline
\end{tabular}


Pág. 2

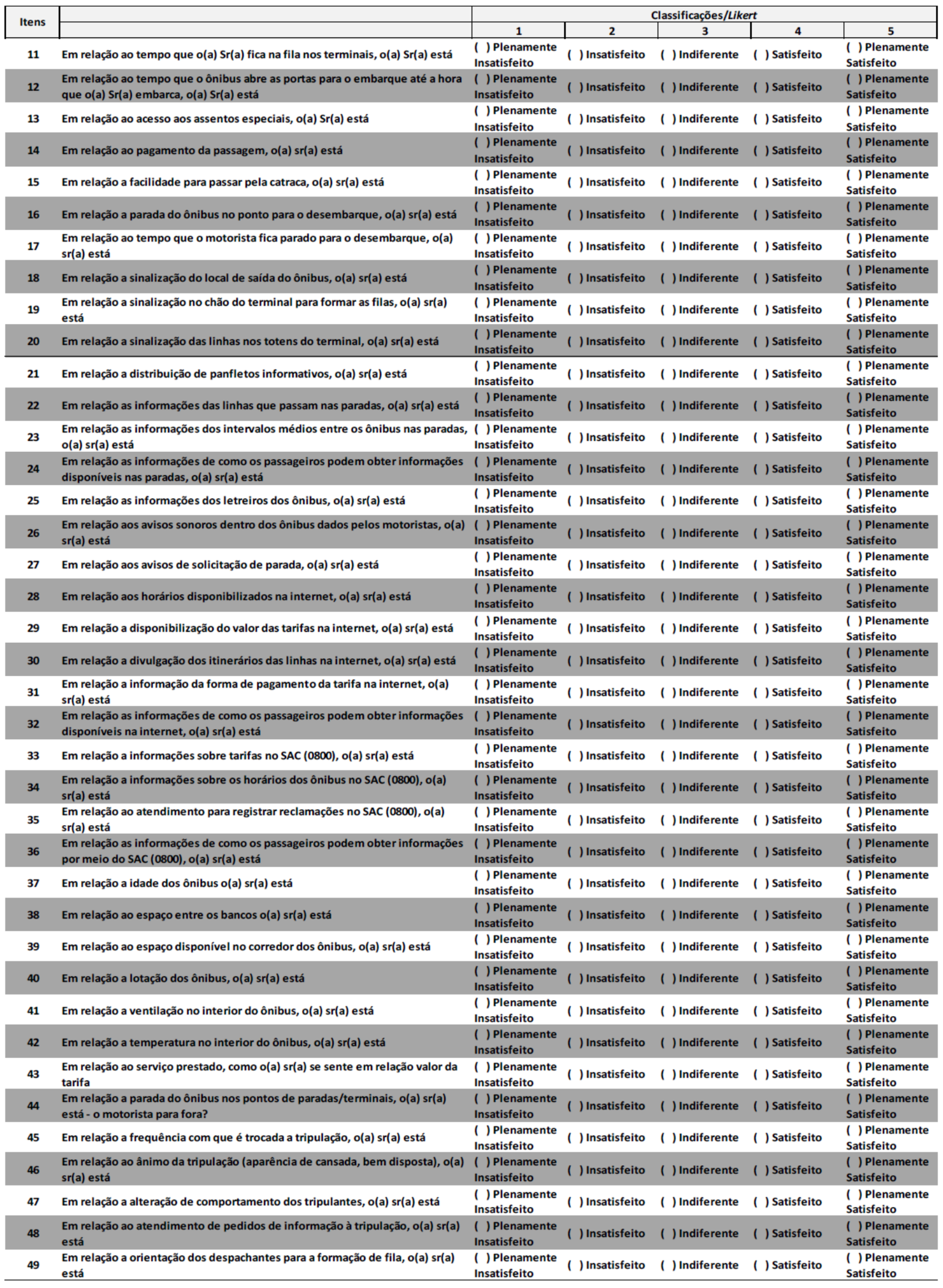

\section{Agradecemos!}


APÊNDICE D - Cálculo das pontuações dos PVF nas avaliações parciais

\section{AVALIAÇÃO PARCIAL DO PVF 1 - SEGURANÇA}

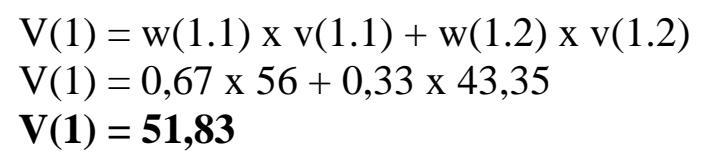

AVALIAÇÃO PARCIAL DO PVF 2 - CONFIABILIDADE

$\mathrm{V}(2)=\mathrm{w}(2.1) \times \mathrm{v}(2.1)+\mathrm{w}(2.2) \times \mathrm{v}(2.2)+\mathrm{w}(2.3) \times \mathrm{v}(2.3)+\mathrm{w}(2.4) \times \mathrm{v}(2.4)+\mathrm{w}(2.5) \times \mathrm{v}(2.5)$

$\mathrm{V}(2)=0,23 \times 50+0,22 \times 0,00+0,19 \times 100+0,19 \times 0,00+0,17 \times 0,00$

$\mathbf{V}(\mathbf{2})=\mathbf{3 0 , 5 0}$

AVALIAÇÃo PARCIAL DO PVF 3 - ACESSIBILIDADE

$\mathrm{V}(3)=\mathrm{w}(3.1) \times \mathrm{v}(3.1)+\mathrm{w}(3.2) \times \mathrm{v}(3.2)+\mathrm{w}(3.3) \times \mathrm{V}(3.3)$

$\mathrm{V}(3)=0,34 \times 0,00+0,33 \times 15,20+0,33 \times 44,40$

$\mathrm{V}(3)=\mathbf{1 9 , 6 7}$

AVALIAÇÃo PARCIAL DO PVF 4 - COMUNICAÇÃo

$\mathrm{V}(4)=\mathrm{w}(4.1) \times \mathrm{v}(4.1)+\mathrm{w}(4.2) \times \mathrm{v}(4.2)+\mathrm{w}(4.3) \mathrm{xv}(4.3)+\mathrm{w}(4.4) \times \mathrm{v}(4.4)+\mathrm{w}(4.5) \times \mathrm{v}(4.5)$

$\mathrm{V}(4)=0,19 \times 11,18+0,18 \times 0,00+0,24 \times 100+0,22 \times 46,32+0,17 \times 43,73$

$V(4)=43,75$

\section{AVALIAÇÃO PARCIAL DO PVF 5 - CONFORTO}

$\mathrm{V}(5)=\mathrm{w}(5.1) \times \mathrm{v}(5.1)+\mathrm{w}(5.2) \times \mathrm{v}(5.2)+\mathrm{w}(5.3) \times \mathrm{v}(5.3)+\mathrm{w}(5.4) \times \mathrm{v}(5.4)+\mathrm{w}(5.5) \times \mathrm{v}(5.5)$ $+\mathrm{w}(5.6) \mathrm{x} \mathrm{v}(5.6)$

$\mathrm{V}(5)=0,21 \times 0,00+0,19 \times 0,00+0,18 \times 0,00+0,17 \times 0,00+0,15 \times(-50)+0,10 \times 40$ $\mathbf{V}(\mathbf{5})=\mathbf{- 3 , 5 0}$

\section{AVALIAÇÃO PARCIAL DO PVF 7 - COMPORTAMENTO DOS OPERADORES}

$$
\begin{aligned}
& \mathrm{V}(7)=\mathrm{w}(7.1) \times \mathrm{v}(7.1)+\mathrm{w}(7.2) \times \mathrm{v}(7.2)+\mathrm{w}(7.3) \times \mathrm{v}(7.3) \\
& \mathrm{V}(7)=0,38 \times 20,50+0,35 \times 55,40+0,27 \times 41,50 \\
& \mathrm{~V}(\mathbf{7})=\mathbf{3 8 , 3 9}
\end{aligned}
$$




\section{APÊNDICE E - Decomposição dos PVF e PVE}

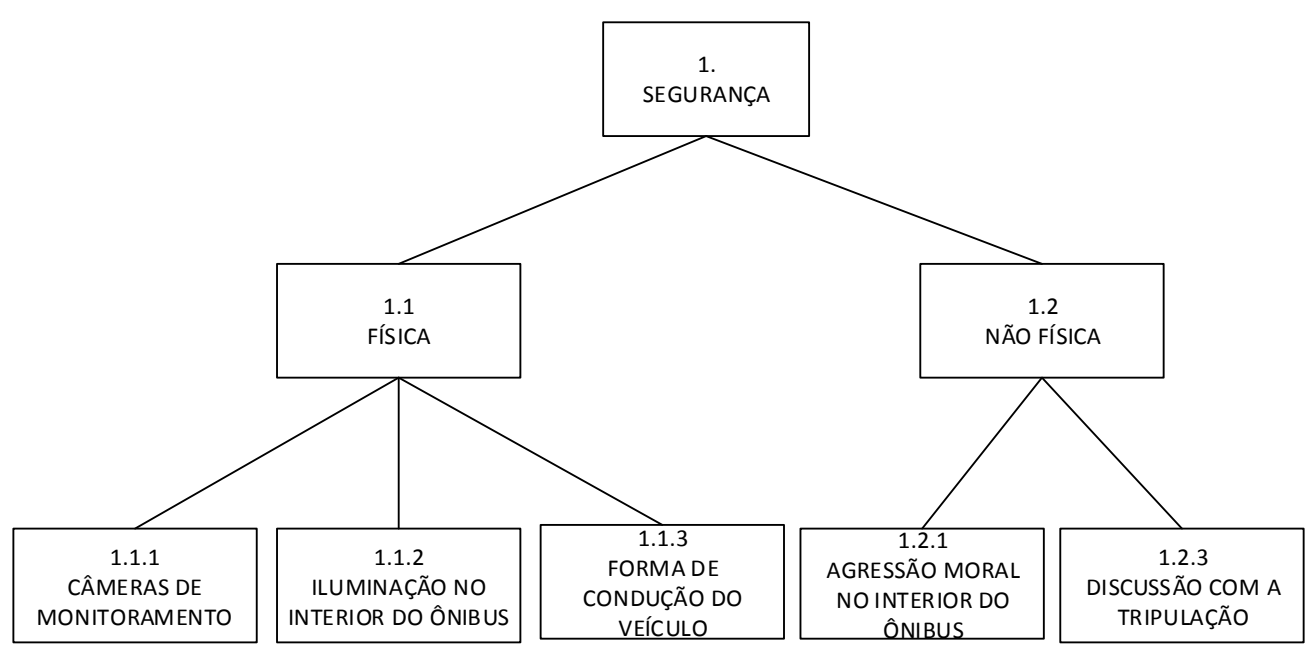

Decomposição do PVF segurança

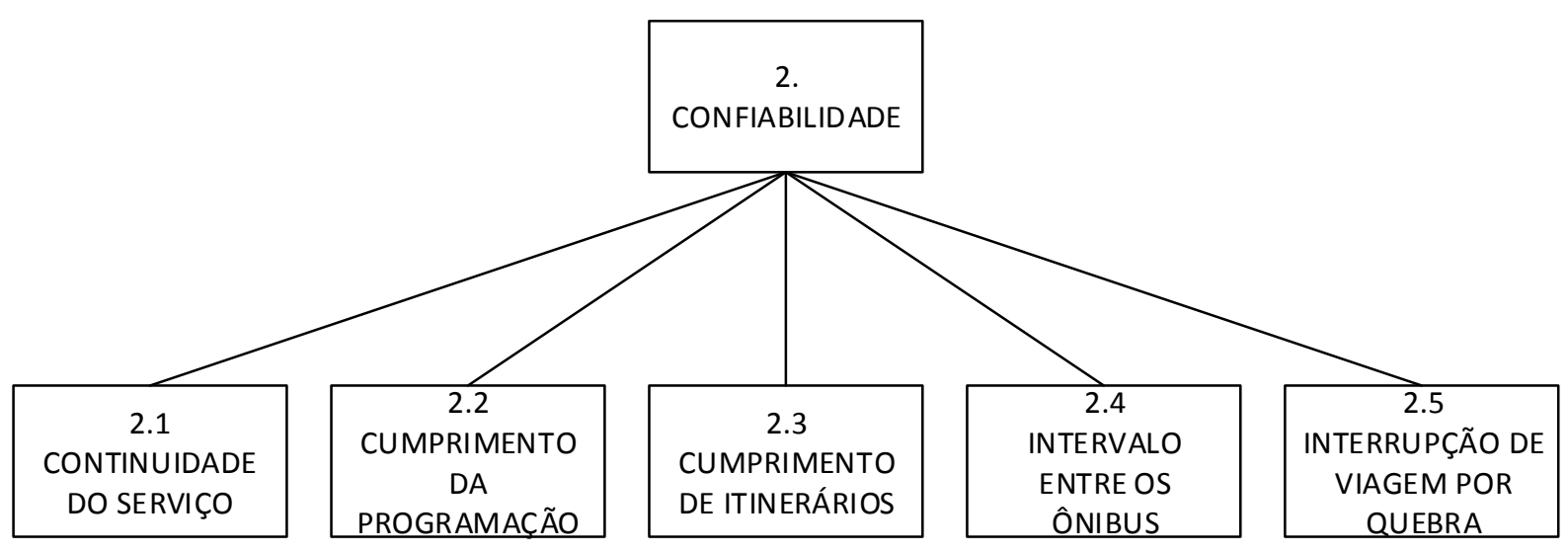

Decomposição do PVF confiabilidade

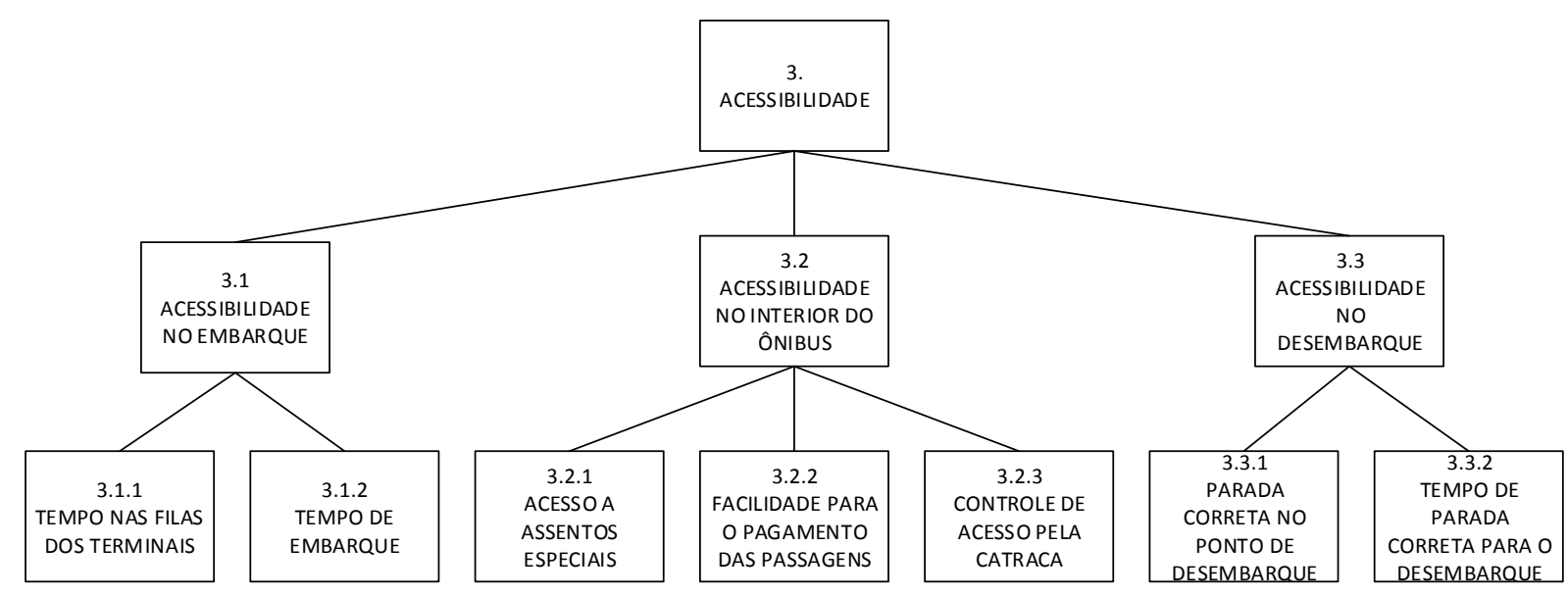

Decomposição do PVF acessibilidade 


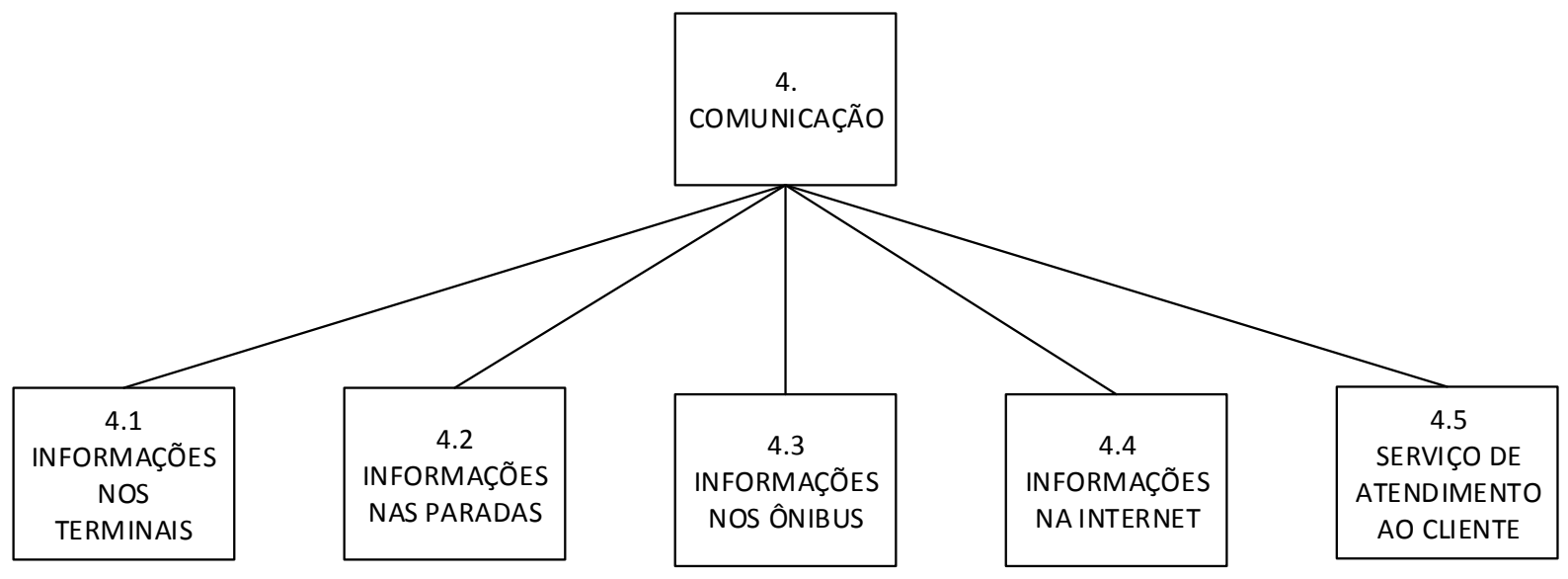

Decomposição do PVF comunicação em PVE

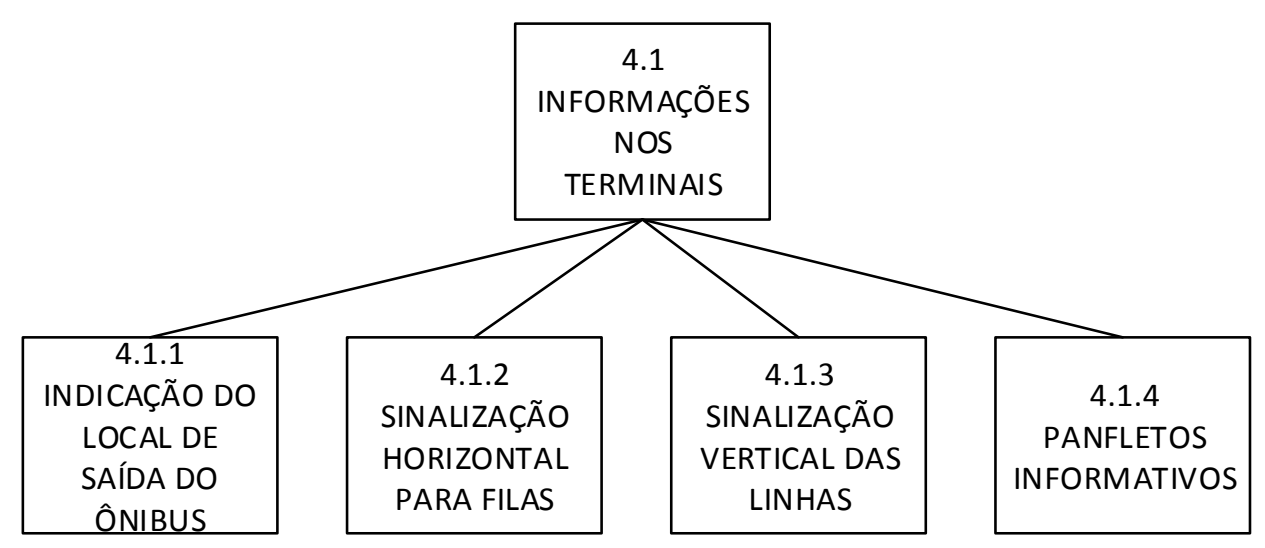

Decomposição do PVE informações nos terminais

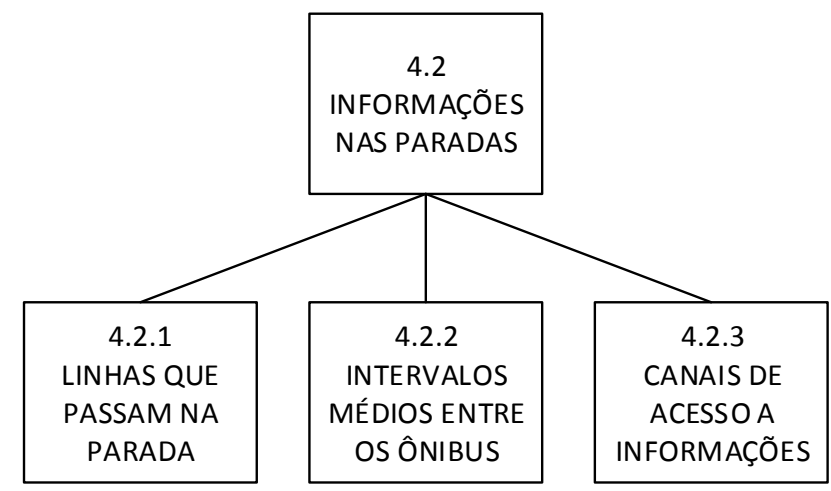

Decomposição do PVE informações nas paradas 


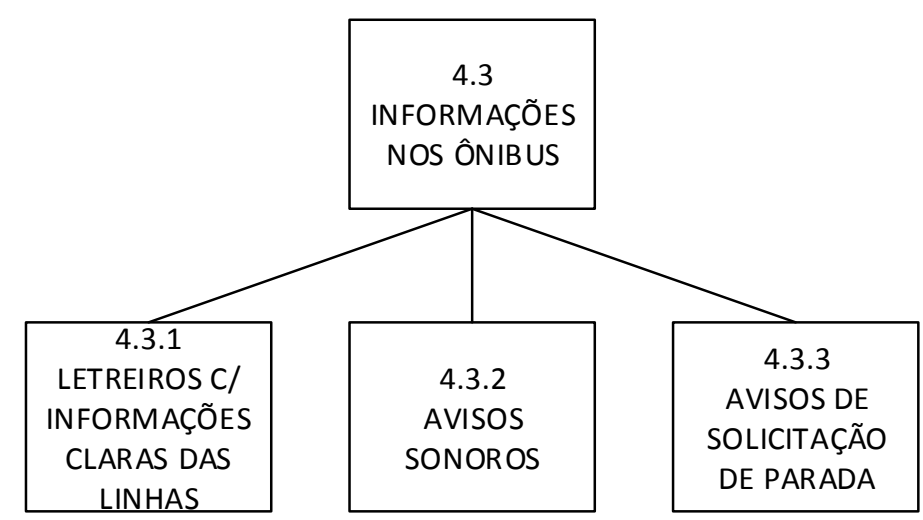

Decomposição do PVE informações nos ônibus

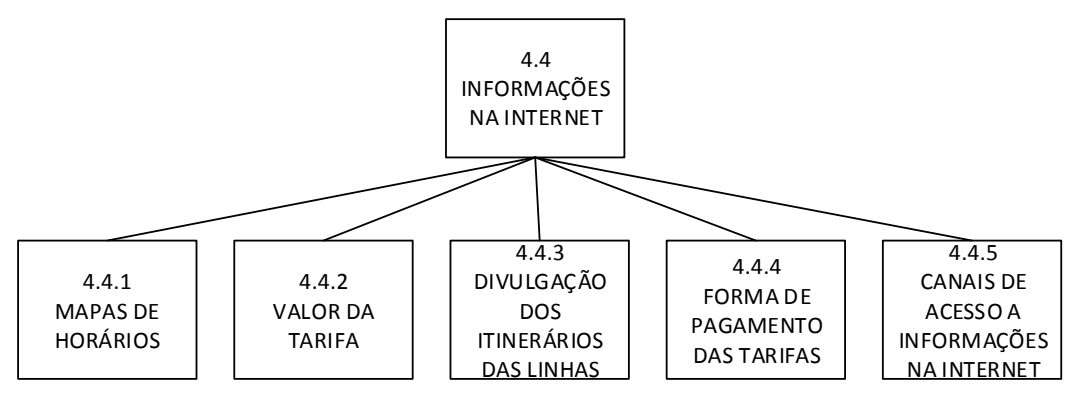

Decomposição do PVE informações na internet

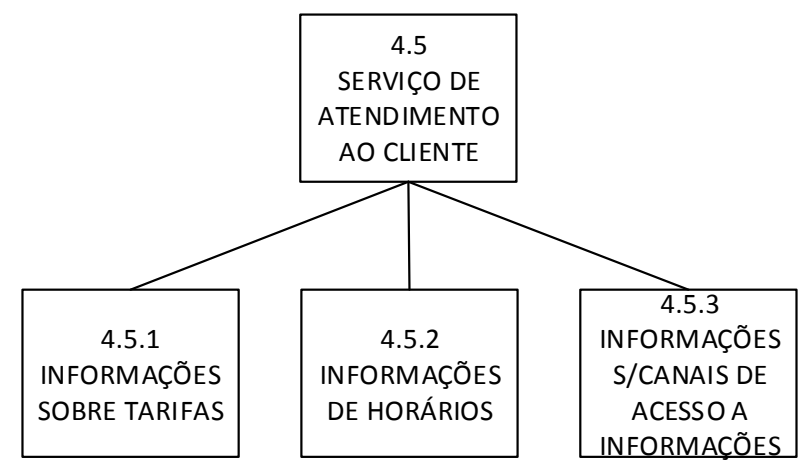

Decomposição do PVE serviço de atendimento ao cliente

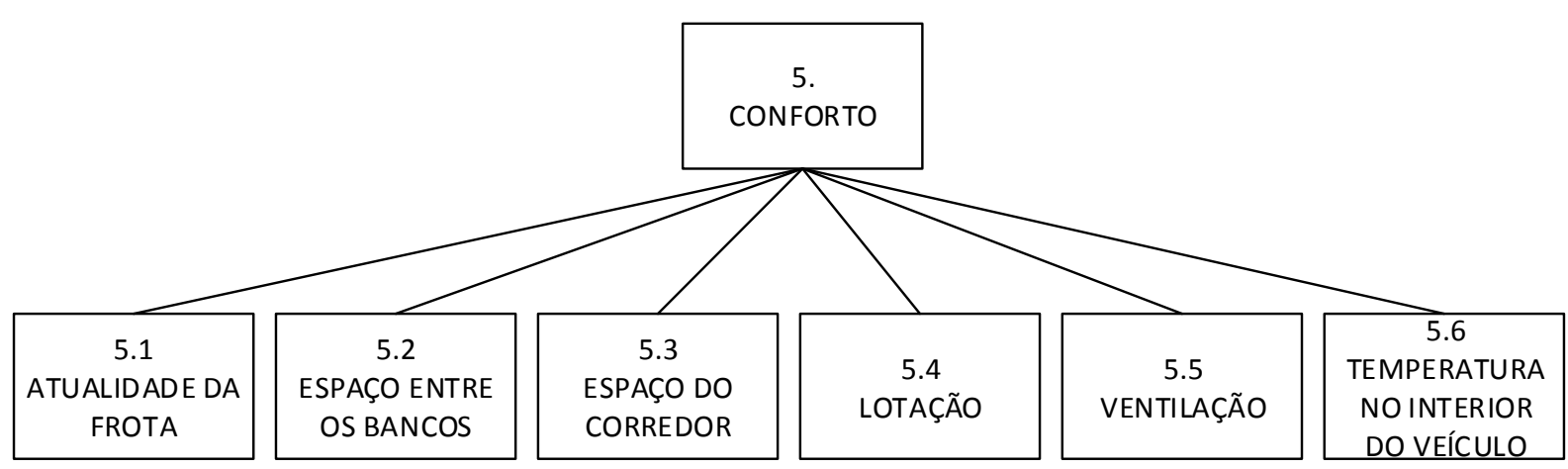

Decomposição do PVF conforto 


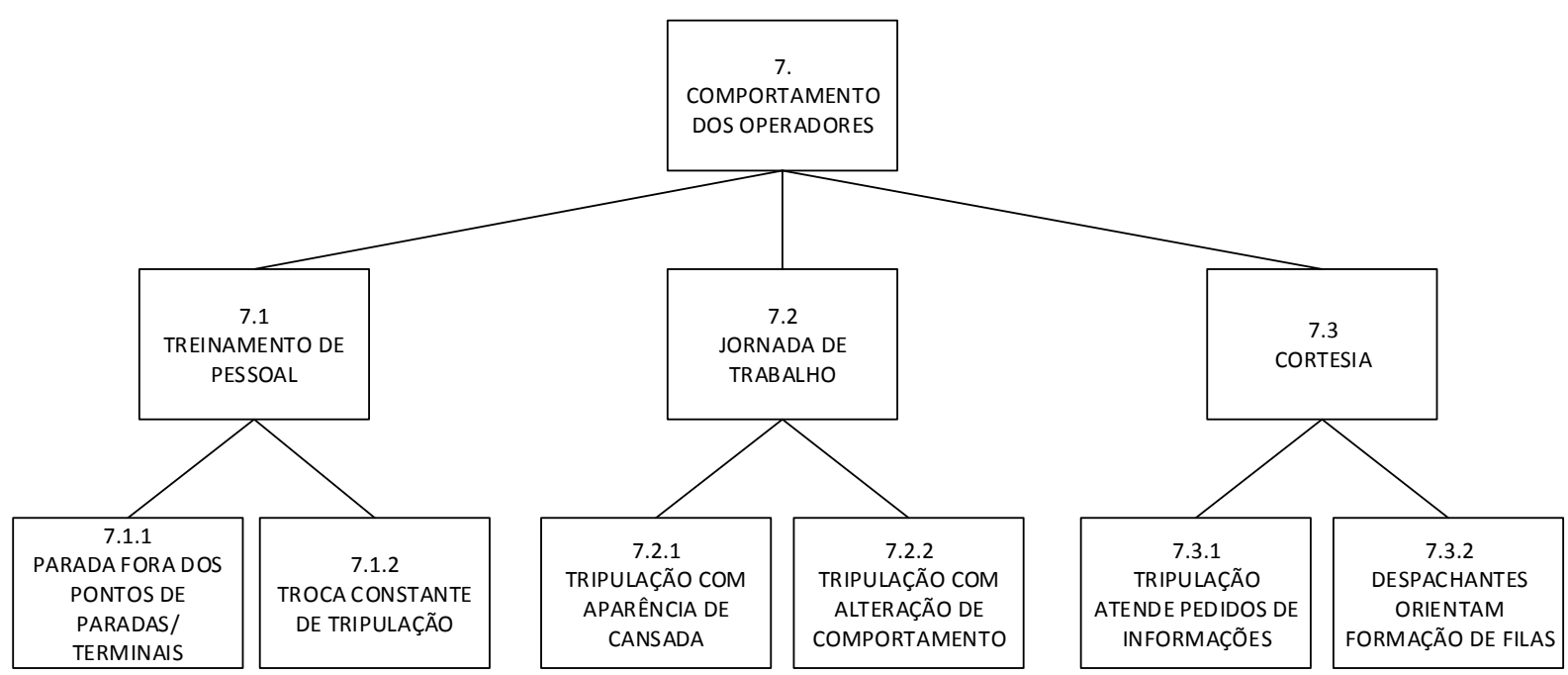

Decomposição do PVF comportamento dos operadores 